UNIVERSIDADE DE SÃO PAULO

FACULDADE DE ECONOMIA, ADMINISTRAÇÃO E CONTABILIDADE DEPARTAMENTO DE ADMINISTRAÇÃO PROGRAMA DE PÓS-GRADUAÇÃo EM ADMINISTRAÇÃo

BACKGROUND DO EMPREENDEDOR E A INOVAÇÃO DE PRODUTOS EM EMPRESAS INCUBADAS DE BASE TECNOLÓGICA

Natan de Souza Marques

Orientador: Prof. Dr. Roberto Sbragia

SÃO PAULO 
Prof. Dr. Marco Antônio Zago Reitor da Universidade de São Paulo

Prof. Dr. Adalberto Américo Fishmann Diretor da Faculdade de Economia, Administração e Contabilidade

Prof. Dr. Roberto Sbragia

Chefe do Departamento de Administração

Prof. Dr. Moacir de Miranda Oliveira Junior Coordenador do Programa de Pós-graduação em Administração 
NATAN DE SOUZA MARQUES

\section{BACKGROUND DO EMPREENDEDOR E A INOVAÇÃO DE PRODUTOS EM EMPRESAS INCUBADAS DE BASE TECNOLÓGICA}

Dissertação apresentada ao Programa de Pós-graduação em Administração do Departamento de Administração da Faculdade de Economia, Administração e Contabilidade da Universidade de São Paulo como requisito parcial para a obtenção do título de mestre em Ciências.

Orientador: Prof. Dr. Roberto Sbragia

\section{Versão Corrigida}

(Versão original disponível na Faculdade de Economia, Administração e Contabilidade)

\section{SÃO PAULO}


FICHA CATALOGRÁFICA

Elaborada pela Seção de Processamento Técnico do SBD/FEA/USP

Marques, Natan de Souza

Background do empreendedor e a inovação de produtos em empresas incubadas de base tecnológica / Natan de Souza Marques. - São Paulo, 2015

$115 \mathrm{p}$.

Dissertação (Mestrado) - Universidade de São Paulo, 2016.

Orientador: Roberto Sbragia.

1. Incubadora de empresas 2. Inovações tecnológicas 3. Background do empreendedor 4. Empresas incubadoras de base tecnológica I. Universidade de São Paulo. Faculdade de Economia, Administração e Contabilidade. II. Título.

CDD -658.11 
Aos meus pais, Milton Marques dos Santos e Neuracy Batista de Souza Marques, pelo incentivo, educação e apoio que sempre me concederam. 
Agradeço, primeiramente, a Deus pelas providências em minha vida. A Ele toda honra e toda glória.

Agradeço aos meus pais pelo carinho, amor e apoio que sempre me deram. São eles os responsáveis por toda a minha trajetória pessoal e profissional, uma vez que abraçaram esse meu projeto de vida, investindo muita energia e capital para que as várias etapas pudessem ser vencidas.

Ao meu orientador, Prof. Dr. Roberto Sbragia, pelas orientações e acompanhamento ao longo de todo o curso. Exemplo de profissional que busco sempre seguir.

Agradeço grandemente ao Prof. Dr. Moacir de Miranda Oliveira Junior, o qual, desde os primeiros dias dessa minha trajetória na Universidade de São Paulo, me apoiou e me colocou diante de oportunidades profissionais valiosas para a minha carreira. Não bastasse isso, viabilizou toda a pesquisa que originou essa dissertação, da qual me honra ter participado. Ao nobre professor e amigo, deixo aqui meus sinceros agradecimentos e respeito pela pessoa que é.

Ao Prof. Dr. Felipe Mendes Borini deixo aqui meu profundo agradecimento e respeito pelo profissional que é e pelas imensas contribuições para que essa pesquisa pudesse ser realizada, com o auxilio em todo o processo de análise dos dados e aplicação da técnica estatística utilizada.

À Coordenação de Aperfeiçoamento de Pessoal de Nível Superior (Capes) deixo aqui os meus agradecimentos pelo apoio financeiro para a realização do meu mestrado, sem o qual, tudo teria sido bem mais difícil.

À minha irmãzinha, a quem tenho tamanho apreço, Aline Mariane de Faria, pelo companheirismo e amizade concedidos a mim desde os primeiros dias do mestrado até hoje. Tantas vezes compartilhamos momentos de angústia e momentos de alegrias também, sempre unindo forças e sempre nos apoiando mutuamente. Obrigado ainda pelas portas que foram abertas em empresas de Santa Rita do Sapucaí para que as pesquisas pudessem ser feitas, os créditos pudessem ser cumpridos, e as publicações acontecessem, como consequência. Externalizo aqui a imensa admiração que tenho por você. Sou imensamente grato Nine, por tudo.

Aos meus irmãos, Hilton Marques, Rodrigo Marques e Diêgo Marques, pelo companheirismo e irmandade desde sempre.

Ao nobre presidente, meu grande amigo e irmão, Bassiro Só, a quem tenho profundo respeito e admiração pela pessoa e pelo profissional que é. Obrigado meu amigo pelas orientações, pelos conselhos, pelo companheirismo, pela amizade verdadeira, pela irmandade.

À minha amiga, Ângela Maria Benevides Gordillo, pelo companheirismo e amizade e pelas muitas horas de conversas e risadas durante nossas idas ao bandeijão e na sala de pesquisa.

Ao nobre professor Itiel Moraes agradeço pela amizade e companheirismo durante esse período de mestrado, às orientações acadêmicas, e, principalmente, ao conhecimento 
compartilhado, desde a minha graduação até hoje. Tenho aprendido muito com você professor, muito obrigado por tudo!

Aos meus professores da graduação na Universidade Federal da Bahia e hoje, na Universiadade Federal do Oeste da Bahia, apresento aqui os meus eternos agradecimentos, em especial ao meu orientador da graduação, Prof. Dr. Erick Samuel Rojas Cajavilca, com quem aprendir muito e até hoje firmo parcerias de pesquisa. Obrigado professor pela amizade!

A todos os meus familiares, em especial, meu avô Arcênio Martins de Souza e minha avó Niva Batista de Souza, deixo aqui o meu profundo agradecimento pelo apoio, ensinamentos e amor com que me tratam. Eu os admiro muito!

A todos os meus amigos que me acompanharam durante o período de mestrado, aos colegas de disciplinas, deixo aqui os meus agradecimentos pela amizade e, muitas vezes, pelas recomendações e insights no desenvolvimento dessa pesquisa.

Agradeço aqui a todos os funcionários da FEA/USP pela presteza e atenção dispensadas a mim durante esse período. Muito Obrigado a todos!

À Fundação Instituto de Administração, agradeço pelas oportunidades profissionais que tenho vivenciado e pela experiência que tenho adquirido.

Enfim, sou eternamente grato por tudo... 



\section{RESUMO}

Muitos estudos analisam as características do empreendedor relacionando-as com desempenho (Lumpkin \& Dess, 1996), com a descoberta de oportunidades empreendedoras (Shane, 2000), criação de novos empreendimentos (Gartner, 1985), entre outros. Em empresas baseadas em conhecimento a inovação é fundamental para a competitividade, refletido na capacidade de lançar novos produtos. Essa prerrogativa leva incubadoras a buscarem em seus processos de seleção empresas que apresentem potencial inovativo, analisando tanto o plano de negócios e a ideia, quanto as capacidades do time de gestão ou do empreendedor proponente da ideia (Aerts, Matthyssens \& Vandenbempt, 2007). Assim, o objetivo geral desse estudo foi analisar a contribuição do background do empreendedor para a inovação de produtos em empresas incubadas de base tecnológica do estado de São Paulo. Especificamente, o estudo busca (1) identificar o background dos empreendedores de empresas vinculadas a incubadoras de empresas de base tecnológica; (2) Identificar o nível de inovação de produtos dessas empresas; (3) identificar a relação entre o background do empreendedor e a inovação de produtos nessas empresas; e (4) identificar a interferência do tamanho da organização nessas relações. Para alcançar esses objetivos, o estudo foi conduzido junto a incubadoras de empresas de base tecnológica localizadas no Estado de São Paulo, envolvendo 461 organizações. Um modelo conceitual foi elaborado, incluindo variáveis de input (características do empreendedor - educação e experiência), output (número de produtos lançados no mercado) e moderadora (tamanho da empresa). Um questionário foi aplicado aos gestores das empresas incubadas, resultando em 95 respostas válidas. Uma análise quantitativa foi realizada, baseado principalmente no método estatístico Regressão Logística.

Como resultado, foi preliminarmente concluído que o background do empreendedor, particularmente, a formação técnica, tem uma importante associação com a inovação de produtos. Além disso, o tamanho da organização moderou significativamente essa relação, indicando que em empresas maiores parece indicar uma contribuição mais significativa da área de educação técnica - particularmente em disciplinas exatas, para a inovação em produtos. Já em empresas menores, além da associação significativa da educação técnica do empreendedor, a experiência também foi significativa para a inovação de produtos em empresas menores. Indicando que em empresas menores o conhecimento centra-se no empreendedor, enquanto que empresas maiores, o conhecimento é disseminado na equipe. Essas descobertas, a serem confirmadas em estudos futuros e considerando as limitações do presente estudo, complementam a literatura e abre novas perspectivas para instruir incubadoras a selecionarem melhor suas empresas incubadas.

Palavras-chaves: Incubadora de Empresas; Inovações Tecnológicas; Background do Empreendedor; Empresas Incubadas de Base Tecnológicas. 


\begin{abstract}
Many studies look entrepreneurial characteristics relating them with performance (Lumpkin \& Dess, 1996), discovering new entrepreneurial opportunities (Shane, 2000), creation of new enterprises (Gartner, 1985), among others. In knowledge-based enterprises innovation is fundamental to competitiveness, reflected in their capacity of launching new products. This prerogative leads incubators to seek in their selection processes companies that present innovative potential, analyzing both, the business plan and the idea, as well as, the entrepreneurial or management team capabilities (Aerts, Matthyssens \& Vandenbempt, 2007). The overall objective of this study was to analyze the contribution of the background of entrepreneurs to the innovative performance in technology-based Businesses Incubated Firms. More specifically, the study tries: (1) to identify the background of entrepreneurs of companies linked to technology based business incubators; (2) Identify the level of product innovation of these firms; (3) Identify the relationships between the background of the entrepreneur and the product innovation of the firms; and (4) Identify the interference of the size of the firms on these relationships. The study was conducted together incubators located in the State of São Paulo, evolving 461 organizations. A conceptual model was conceived, including input (entrepreneurial characteristics - education and experience), output (number of innovative products launched to the market) and moderating (firm size) variables. A questionnaire was applied to the general managers of the incubators, resulting in 95 valid answers. A quantitative analysis was made, based mostly on logistic regression statistical methods. As a result, it was preliminary concluded that entrepreneur background, particularly, the technical education, has an important influence on product innovation level. Also firm size moderated significantly those relationships, indicating that in larger firms it seems to appear a more significance contribution of technical education area - particularly in exact disciplines to firm innovative performance. In smaller enterprises, in addition to significant association of entrepreneur's technical education, the experience was significant to product innovation, that indicate in smaller firms the organizational knowledge focuses on entrepreneur, while in larger companies the organizational knowledge is disseminated among the team. These finds, to be confirmed in future studies and considering the limitations of the present investigation, complement the literature and open new perspectives on the most adequated firms and managers to be selected to take place in Incubators.
\end{abstract}

Key-words: Business Incubators; Technological Innovation; Entrepreneur's Background; Technological-based incubated firms. 


\section{SUMÁRIO}

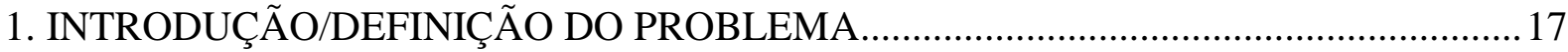

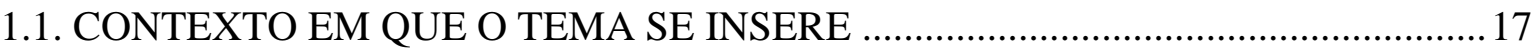

1.2. LÓGICA, ATUALIDADE E IMPORTÂNCIA DO TEMA DO ESTUDO ................. 20

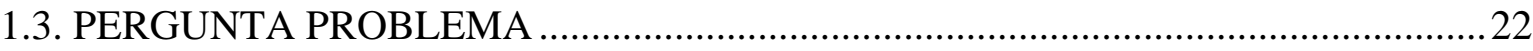

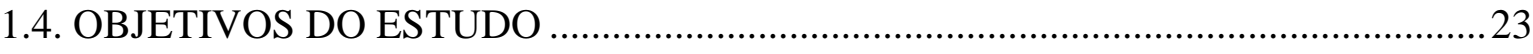

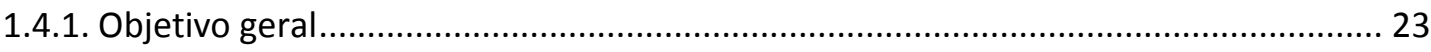

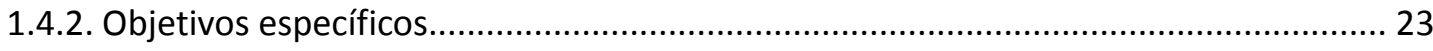

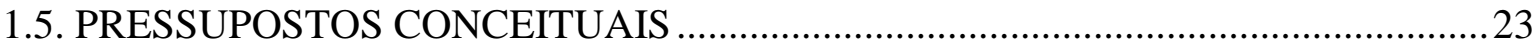

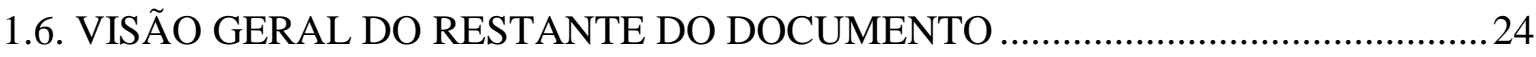

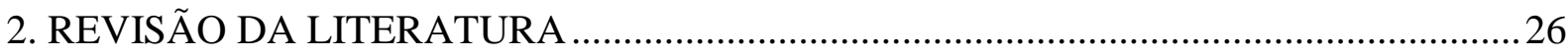

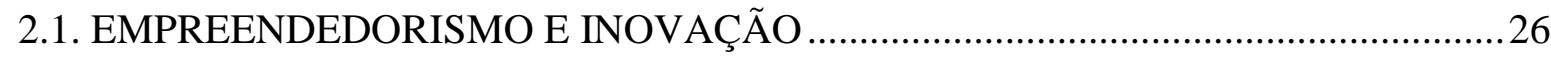

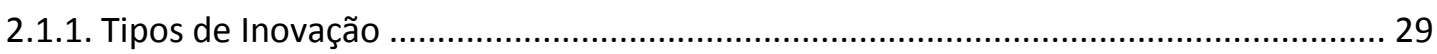

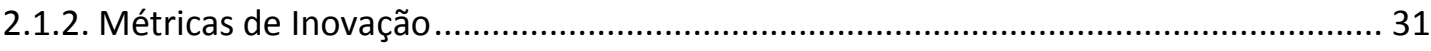

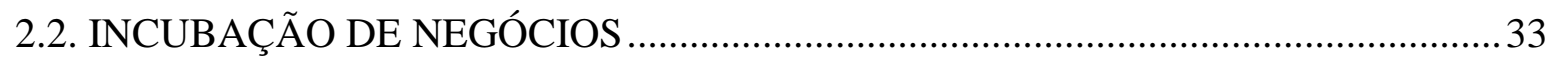

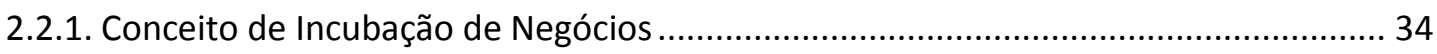

2.2.2. Processo de seleção de Empresas Incubadas .............................................................. 35

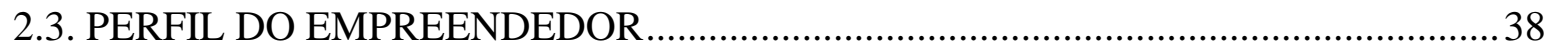

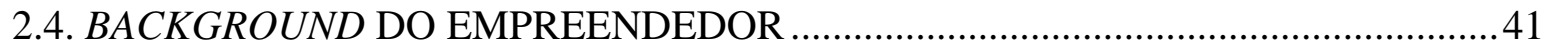

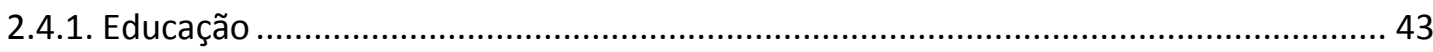

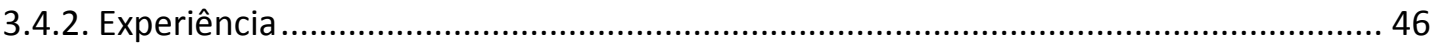

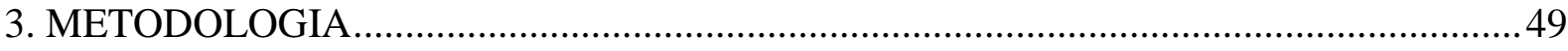

3.1. NATUREZA E MÉTODO DA PESQUISA ......................................................... 49

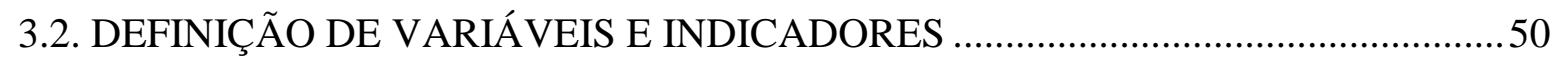

3.2.1.Constructos e Variáveis independentes ................................................................. 50

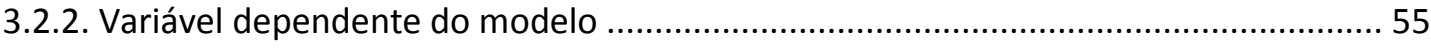

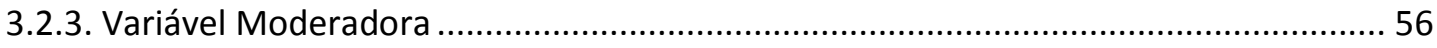

3.3. MODELO CONCEITUAL (DESIGN) E HIPÓTESES DA PESQUISA .....................56 


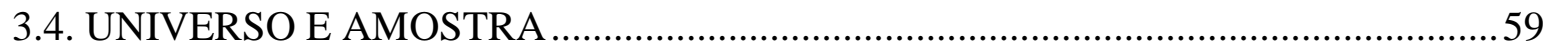

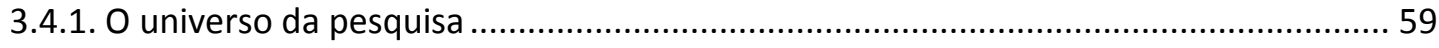

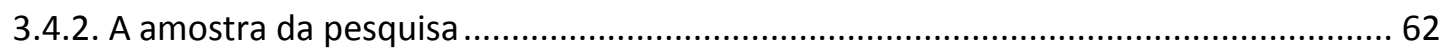

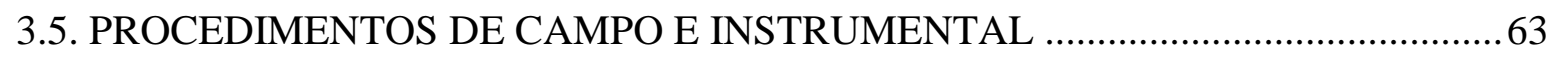

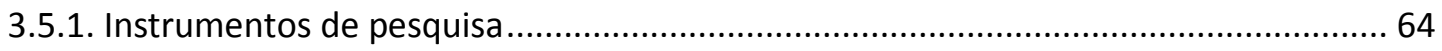

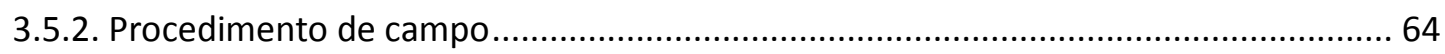

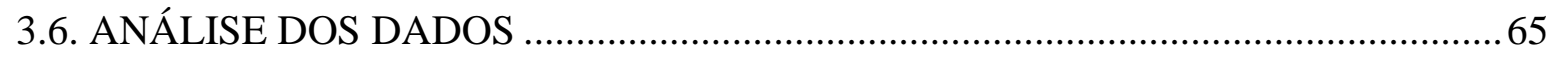

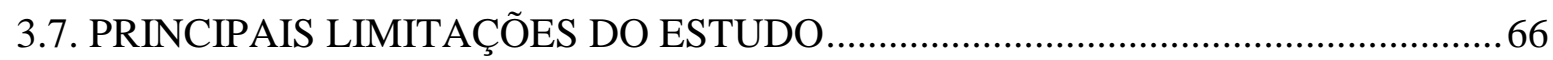

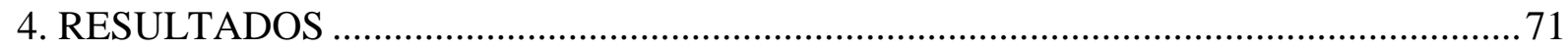

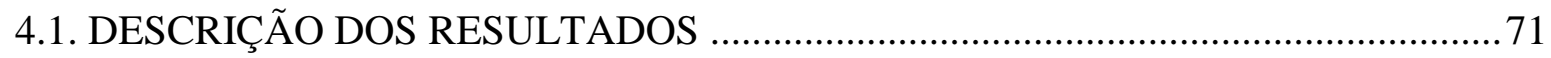

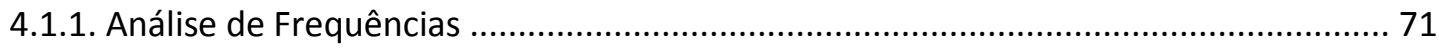

4.1.2. Análise das correlações e regressão logística ............................................................... 76

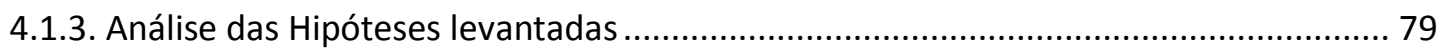

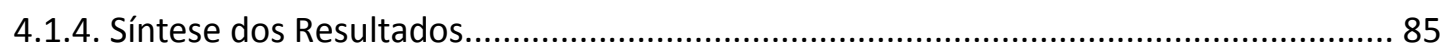

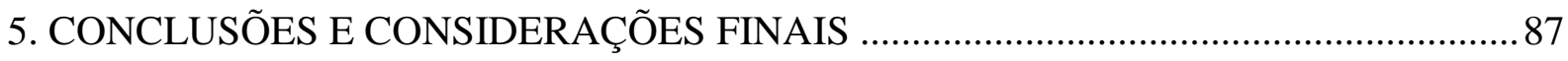

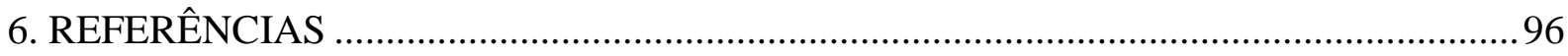

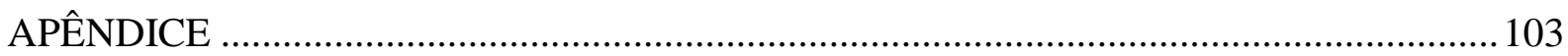




\section{LISTA DE ABREVIATURAS E SIGLAS}

IEBT - Empresas Incubadas de Base Tecnológica

IBT - Incubadora de Base Tecnológica

SDECTI - Secretaria de Desenvolvimento Econômico, Ciência, Tecnologia e Inovação SPAI - Sistema Paulista de Ambientes de Inovação 


\section{LISTA DE QUADROS}

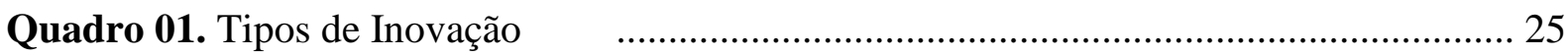

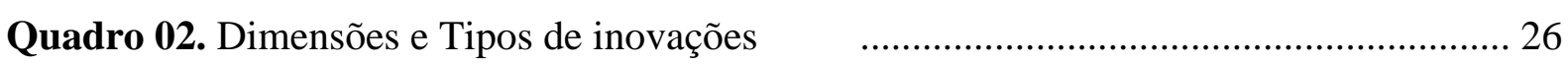

Quadro 03. Relações das ações e competências empreendedoras ...................................... 35

Quadro 04. Lista de Incubadoras no Estado de São Paulo ................................................ 56

Quadro 05. Número de Empresas Incubadas nas Incubadoras $\quad$.......................................56

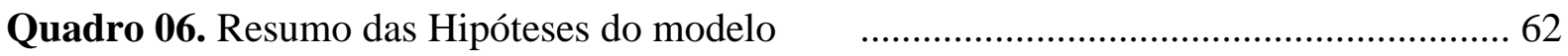

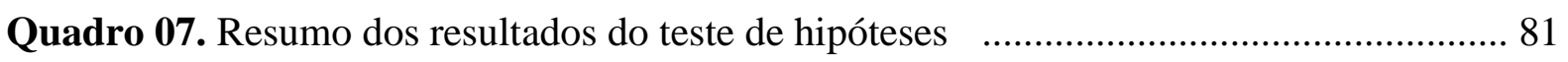




\section{LISTAS DE TABELAS}

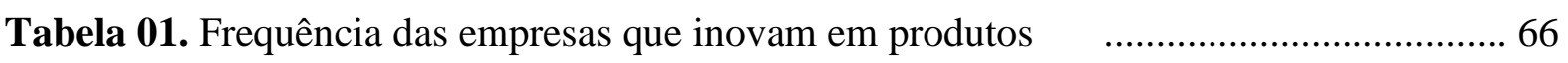

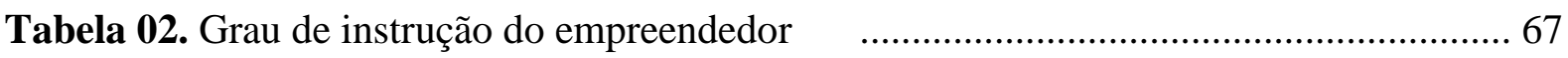

Tabela 03. Área de formação próximas às ciências exatas

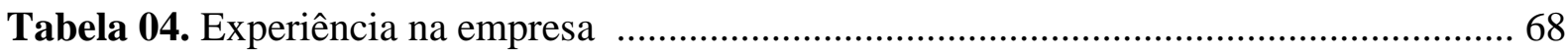

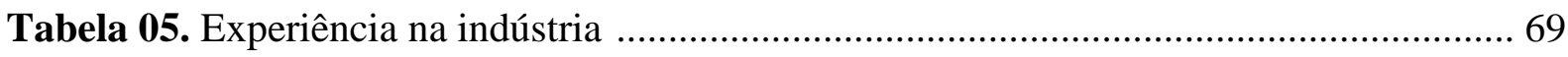

Tabela 06. Área de atuação próxima à P\&D e produção ……........................................... 70

Tabela 07. Matriz de correlação das variáveis independentes $\quad$...................................... 71

Tabela 08. Tabela de resultados da Regressão Logística (Modelo Completo) ................ 72

Tabela 09. Tabela de resultados da Regressão Logística (Grande Porte) ........................... 73

Tabela 10. Tabela de resultados da Regressão Logística (Pequeno Porte) ............................ 73 


\section{LISTA DE ILUSTRAÇÕES}

Figura 01. Modelo conceitual do estudo 


\section{INTRODUÇÃO/DEFINIÇÃO DO PROBLEMA}

Estudar empresas incubadas de base tecnológica da perspectiva da interface entre as características do empreendedor e a inovação de produtos mostrou-se uma lacuna passível de estudos. É nessa direção que essa pesquisa foi conduzida. Assim, a presente sessão busca dissertar sobre: (1) Contexto em que o tema se insere; (2) Lógica, atualidade e importância do tema do estudo; (3) Pergunta problema; (4) Objetivos do estudo; (5) Visão geral do restante do documento.

\subsection{CONTEXTO EM QUE O TEMA SE INSERE}

A gestão da inovação é uma importante atividade nas organizações contemporâneas. Ao longo da história, as organizações passaram por importantes mudanças de foco e de posicionamento estratégico, indo desde a busca por eficiência até a busca por inovatividade (Kumpe e Bolwijn, 1994). A busca por eficiência direcionou muitas organizações durante o final do século 19 e início do século XX. Nesse período, a competitividade das organizações estava atrelada à produtividade e comercialização dos produtos a preços baixos, competitivos, estratégia que exigia a redução de custos.

Em meados da década de 1960, as teorias e práticas em administração caminharam para a busca da qualidade como maneira de conferir competitividade às organizações, não sendo suficiente apenas a eficiência, mas agora, também a qualidade (Kumpe \& Bolwijn, 1994). Em um movimento natural na busca por serem competitivas, as organizações seguiram adiante, e passaram a considerar a diversificação da produção e a ampliação do mix de produtos, tornando-se agora flexíveis, porém, sem deixar de lado a eficiência e a qualidade (Kumpe \& Bolwijn, 1994).

Uma vez alcançados eficiência, qualidade e flexibilidade, as organizações começaram a perceber a necessidade de outras características que as diferenciassem das demais, e, portanto, as tornassem mais competitivas no mercado, passando assim à busca de unicidade por meio da inovatividade e da capacidade por inovar (Kumpe \& Bolwijn, 1994). Assim, as organizações modernas cumprem a difícil tarefa de unir a eficiência, qualidade, flexibilidade e serem inovativas. 
Essa trajetória relatada por Kumpe e Bolwijn (1994) permite um passeio pela evolução do foco das organizações, levando ao entendimento da postura atual que elas apresentam. Acrescenta-se ainda a esse passeio, atualmente, uma perspectiva que está emergindo nas organizações: A sustentabilidade. Porém, essa postura não elimina a necessidade de inovação. Essa necessidade de inovar conduziu as empresas a buscarem estruturas organizacionais mais compatíveis com a inovação; a construir uma cultura organizacional capaz de suportar a inovação; e a desenvolverem planos de inovação alinhados às estratégias do negócio.

Porém, as organizações dependem apenas de estruturas organizacionais direcionadas para a inovação para serem inovativas? Qual o papel do ambiente para a inovação nas empresas? O ambiente em que as organizações estão inseridas é um aspecto fundamental para que o processo de inovação ocorra. Esse tema vem ganhando importância nos estudos acadêmicos e, também, vem chamando os governos a participarem cada vez mais do fomento a esses ambientes. Os principais ambientes de inovação são clusters, Incubadoras de empresas e Parques tecnológicos.

Nesses ambientes, indicados acima, o fluxo de conhecimentos entre as empresas inseridas neles ganham forte destaque, favorecendo a inovação. Os clusters, ou aglomerados empresariais, é um conceito levantado por Porter (1990) e que, segundo ele, "é um aglomerado de indústrias conectadas por meio de links de vários tipos” (Porter, 1990, p. 131). Os estudos de Porter identificaram nos clusters mecanismos eficazes para a competitividade das organizações. Estudando a vantagem competitiva das nações, Porter visualizou nesses aglomerados industriais uma explicação para os seus estudos, identificando que empresas inseridas nesses aglomerados mostraram-se mais competitivas do que aquelas situadas fora deles.

Outro importante ambiente de inovação são os parques tecnológicos. Esses são organizações baseados na propriedade, com centros administrativos identificáveis focados na missão de acelerar negócios por meio da aglomeração de conhecimentos e compartilhamento de recursos (Phan, Siegel e Wright, 2005). O crescimento desse tipo de organização, assim como o crescimento das incubadoras de empresas, tem estimulado debates acadêmicos no sentido de identificar se essas organizações garantem o desempenho das empresas inseridas neles, universidades, e a economia das regiões nas quais se inserem. (Phan, Siegel e Wright, 2005). 
O ultimo dentre os ambientes de inovação citados anteriormente são as incubadoras de empresas. Elas são parte de um campo mais amplo de iniciativas que têm como objetivo estimular e apoiar o empreendedorismo (Grimaldi e Grandi, 2005; Cooper, 1985; Autio e Klofsten, 1998; Mian, 1996; Marrifield, 1987). Por definição, incubadoras são organizações que buscam um meio efetivo para ligar tecnologia, capital e know-how para alavancar talentos empreendedores, acelerar o desenvolvimento de novas empresas, e assim, acelerar a exploração da tecnologia (Grimaldi e Grandi, 2005). Outros autores apontam que a incubadora é uma denominação geral para organizações que constituem ou criam um ambiente de apoio que é propício à criação e desenvolvimento de novas empresas (Bergek e Norrman, 2008; Chan e Lau, 2005; Lindholm-Dahlstrand e Klofsten, 2002; Lyons e Li, 2003).

Nesses ambientes, essas novas empresas são denominadas empresas incubadas, e se favorecem do fluxo de conhecimento proveniente das interações com a incubadora e com as demais empresas incubadas para alavancar as ideias de negócios e transformá-las em negócios viáveis e lucrativos. Assim, as empresas incubadas podem se inserir em incubadoras de diferentes focos, a exemplo de incubadoras tradicionais, temáticas, sociais, de cooperativas e de base tecnológica.

Em incubadoras de empresas de base tecnológica, as empresas incubadas são fortemente direcionadas para a inovação, sendo possível identificar ações, desde a seleção até a graduação das empresas, no sentido de conceder a essas empresas a oportunidade e a capacidade de se tornarem cada vez mais inovadoras. Nesse estudo, o foco é direcionado para a análise de relações entre o background do empreendedor e a inovação de produtos.

Na literatura sobre empreendedorismo, os empreendedores são estudados, também, do ponto de vista das características e competências. Lenzi, Kiesel e Zucco (2010) apontam uma série de competências e, quando transformadas em ações, tornam-se possível identificar cinco tipos de ações: Ação de preparação; de organização; de avaliação; de ação corrente; e de ação constante. Todas essas ações são movidas por competências que qualificam os empreendedores a desenvolvê-las como tal.

Essas competências não compõem o background do empreendedor, podendo ser desenvolvidas ao longo do tempo e práticas. O background do empreendedor é considerado 
aqui como as características pessoais de formação e educação do empreendedor, e que, de certa forma, os habilitam a criar competências que os permitam desenvolver as ações descritas no parágrafo anterior.

Assim, o presente estudo se limita a analisar as relações entre o background do empreendedor e a inovação de produtos em empresas incubadas de base tecnológica. A escolha por estudar o background, delimitando, portanto, a pesquisa, é explicada pelo direcionamento das contribuições desse estudo, o qual busca identificar características de formação e experiência que estão associadas à inovação de produtos e, com isso, permitir uma melhor seleção de empresas incubadas por incubadoras quando considerado o empreendedor como um dos critérios de seleção de empresas incubadas por incubadoras.

\subsection{LÓGICA, ATUALIDADE E IMPORTÂNCIA DO TEMA DO ESTUDO}

Empreendedorismo e inovação apresentam abordagens teóricas próximas. Na literatura, a inovação é definida como a exploração de novas oportunidades (Neely e Hii, 1998), ou a geração de riquezas por meio da transformação de algo já existente (Drucker, 1987). Esses conceitos recebem um suporte teórico forte na teoria do desenvolvimento econômico (Schumpeter, 1934), com a definição de destruição criadora.

As definições apresentadas no parágrafo anterior presumem a existência de oportunidades empreendedoras (Shane e Venkataraman, 2000; Schumpeter, 1934) para que a inovação seja possível, de tal forma que, a inovação é considerada o instrumento específico do empreendedor (Drucker, 1987). Por assim ser, tornou-se comum na literatura estudos cujo objeto de análise é o empreendedor (Gartner, 1985; Gartner, 1989; Hornaday \& Aboud, 1971; Hornaday \& Bunker, 1970; McClelland, 1987).

Sendo o empreendedor o objeto alvo das pesquisas, muitas perguntas foram levantadas com o objetivo de identificar características que explicassem, por exemplo, diferenças entre empreendedores e não empreendedores, evidenciando-as por meio de traços que os diferenciam, a exemplo da idade (Cooper, 1973; Howell, 1972; Mayer \& Goldstein, 1961); valores (DeCarlo \& Lyons, 1979; Hornaday \& Aboud, 1971; Hull, Bosley \& Udell, 1980; Komives, 1972); tomada de riscos (Brockhaus, 1980b; Hull, Bosley \& Udell, 1982; Liles, 1974; Palmer, 1971); foco no controle (Brockhaus, 1980a; Brockhaus \& Nord, 1979; Hull, 
Bosley \& Udell, 1982; Liles, 1974; Lee \& Tsang, 2001); necessidade de realização (Komives, 1972; McClelland, 1961; McClelland \& Winter, 1969; Rauch \& Frese, 2007; Lee \& Tsang, 2001); e outras.

Muitos estudos analisam as características empreendedoras relacionando-as com desempenho (Lumpkin \& Dess, 1996), descoberta de oportunidades empreendedoras (Shane, 2000), criação de novos empreendimentos (Gartner, 1985), dentre outros. Nesse estudo, buscou-se analisar a relação entre background do empreendedor e a inovação de produtos, assumindo a inovação de produtos como resultante da descoberta de oportunidades empreendedoras.

Em empresas de base tecnológica a inovação é fundamental para a competitividade, havendo, portanto, uma busca por inovação refletida no lançamento de novos produtos, sendo essa uma atividade importante. Além disso, inovar é o que se espera da maioria dessas empresas quando inseridas em incubadoras de empresas. Essa prerrogativa leva as incubadoras a buscarem nos seus processos seletivos priorizarem empresas que apresentam potencial inovativo, analisando tanto o plano de negócios e a ideia, quanto o empreendedor ou equipe de gestão (Aerts, Matthyssens \& Vandenbempt, 2007).

As dificuldades de selecionar empresas inovativas analisando os critérios descritos no parágrafo anterior emergem da carência apresentada pela literatura no tocante a estudos que embasem, com mais detalhes, características importantes do empreendedor que estão associadas à inovação de produtos. Com essas informações as incubadoras poderão mais acertadamente selecionar suas empresas incubadas, de tal forma que, torna-se possível otimizar os recursos aplicados pelas incubadoras, promovendo empreendimentos mais inovadores. É nesse sentido que as contribuições desse estudo se direcionam: permitir a identificação prévia de características favorecedoras da inovação de produtos.

As revisões da literatura nessa direção permitiram a visualização dessa lacuna, uma vez que as características dos empreendedores já são amplamente estudadas, porém, há uma carência de trabalhos que relacionam essas características com a inovação de produtos ou qualquer outra medida de inovação: desempenho inovador, grau de inovatividade, dentre outros.

As contribuições desse estudo recebem desdobramentos teóricos e práticos. As contribuições teóricas caminham na direção da soma ao estado da arte em empreendedorismo e inovação 
com os resultados da pesquisa, os quais buscam cobrir uma importante lacuna na literatura, que é a ausência de estudos que relacionam diretamente o background do empreendedor e a inovação de produtos. Desse ponto, espera-se que a contribuição principal do estudo seja direcionada para lançar luz à literatura sobre a relação background do empreendedor e inovação de produtos, fornecendo com isso um suporte teórico para os esforços de capacitação dos sócio-empreendedores que tenham como objetivo tornar a empresa inovadora.

Do ponto de vista das contribuições práticas esperadas do estudo, podem-se mencionar duas principais. A primeira delas refere-se à possibilidade de utilização dos resultados como orientação aos empreendedores, como meio de direcionarem seus esforços de formação e experiência, ampliando o seu background de maneira eficiente, com esforços direcionados para aquelas variáveis que demonstraram maior influência na inovação de produtos das empresas incubadas. Isso permitirá uma postura mais inovativa por parte das empresas, e permitirá, além do mais, o crescimento em termos de faturamento, ampliação do mix de produtos, participação no mercado, todos resultantes e direcionados pela inovação. Essas são as contribuições práticas da pesquisa para o empreendedor.

A segunda contribuição principal do estudo é direcionada para a otimização dos esforços e aplicação dos recursos das Incubadoras de Empresas de Base Tecnológica. Essa eficientização de esforços e recursos por parte das incubadoras se explica pela eficiência da seleção das empresas com potencial de sucesso futuro. Assim, os resultados do estudo orientarão as incubadoras na seleção das empresas, considerando, para tanto, aspectos do empreendedor que possam influenciar na inovatividade da empresa candidata à incubação. Essa é uma importante questão abordada na literatura: a seleção de empresas incubadas. Os aspectos mais utilizados para a seleção de empresas incubadas por incubadoras é a análise do potencial de mercado da ideia apresentada e o perfil da equipe que gerenciará a empresa, ou seja, em grande parte, os sócios. Esse processo poderá se apoiar nos resultados desse estudo.

\subsection{PERGUNTA PROBLEMA}

Tendo em vista a lógica e contextualização apresentados anteriormente, o presente projeto busca levantar a seguinte pergunta de pesquisa: O background do empreendedor está 
associado com a inovação de produtos em empresas incubadas de base tecnológica no Estado de São Paulo? Essa pergunta dá margem aos objetivos apresentados adiante.

\subsection{OBJETIVOS DO ESTUDO}

A pesquisa tem os seguintes objetivos geral e específicos:

\subsubsection{Objetivo geral}

O objetivo geral da pesquisa é analisar relações entre o background dos empreendedores e a inovação de produtos em Empresas Incubadas de Base Tecnológica no Estado de São Paulo.

\subsubsection{Objetivos específicos}

(1) Identificar o Background dos empreendedores de empresas vinculadas a incubadoras de empresas de base tecnológica no estado de São Paulo;

(2) Identificar a inovação de produtos das empresas incubadas de base tecnológica do estado de São Paulo;

(3) Identificar relações entre o background do empreendedor e a inovação de produtos em empresas de base tecnológica no estado de São Paulo;

(4) Identificar a interferência do porte da organização nessas relações.

\subsection{PRESSUPOSTOS CONCEITUAIS}

Os pressupostos conceituais inerentes a esse estudo, os quais necessitam contemplar essa sessão para que as análises se alinhem, são: Background do empreendedor e Inovação de Produtos.

Por background do empreendedor, assumem-se as características de formação e a experiência do empreendedor, sendo, portanto, passível de ampliação mediante alterações nessas variáveis. Evidentemente, o background é o conjunto de características que estão contidas no perfil do empreendedor. O background considera apenas formação e experiência, enquanto o 
perfil do empreendedor considera um numero maior de características, a exemplo de idade, gênero, dentre outras.

Já por inovação de produtos, assume-se o conceito da OCDE (1992), o qual define a Inovação de Produto como aquela proveniente de novos produtos ou produtos significativamente melhorados.

\subsection{VISÃO GERAL DO RESTANTE DO DOCUMENTO}

Discutidas as questões iniciais do estudo nesta introdução, as demais seções estão organizadas da seguinte maneira: A seção 02 apresenta a revisão da literatura pertinente ao estudo. Nessa parte, analisamos a teoria do ponto de vista de quatro tópicos importantes: Empreendedorismo e inovação; Incubação de negócios; Perfil do Empreendedor; e Background do empreendedor. No tocante ao empreendedorismo e inovação, levantam-se os aspectos conceituais inerentes à essas duas áreas, assim como suas relações; apresentamos os tipos de inovação, as estratégicas de inovação e apontamos algumas métricas para a inovação.

No tópico Incubação de Negócios, apresentam-se os conceitos de incubação de negócios; os tipos de incubadoras de empresas, evidenciando algumas tipologias disponíveis na literatura sobre o tema; assim como, o processo de seleção de empresas incubadas e seus mecanismos. No tópico Perfil do Empreendedor apresenta-se a discussão teórica em torno das características, competências e ações inerentes ao empreendedor, e disponíveis na literatura. Por fim, fechando a seção 02, apresentam-se os conceitos referentes ao background do empreendedor. Contextualizam-se o background do empreendedor dentro da literatura sobre as características dos empreendedores, assim como, apresentam-se os estudos que abordam as características desse background (Formação e experiência).

Na seção 03, os aspectos metodológicos do estudo são apresentados. Assim, são abordadas a natureza e o método da pesquisa; as variáveis e indicadores utilizados; o modelo conceitual (Design da pesquisa); o universo e a amostra; os procedimentos de campo e o instrumental de pesquisa utilizado; as técnicas de análise de dados a serem utilizadas; e, por ultimo, as principais limitações do estudo. 
$\mathrm{Na}$ seção 04, os resultados encontrados são apresentados e discutidos. Primeiramente, apresentam-se a descrição dos dados, indicando as frequências das variáveis que compõe o modelo, e na sequência, são apresentados os resultados da aplicação da técnica estatística para os modelos (Modelo geral, modelo para empresas de pequeno porte e modelo para empresas de grande porte). Os resultados são acompanhados pelas discussões à luz da literatura consultada.

Na seção 5 são apresentadas as conclusões e as considerações finais do estudo, discutindo-se as respostas aos objetivos levantados e apresentados anteriormente, nesta introdução. Além do mais, é evidenciada as contribuições do estudo para a teoria e prática, e também, as limitações resultantes do método, da aplicação das técnicas e conceituais. As referências utilizadas no estudo são apresentadas no capítulo 6 . 


\section{REVISÃO DA LITERATURA}

A presente seção apresenta o desenvolvimento teórico que sustenta a pesquisa. Assim, a base conceitual se estrutura nos seguintes temas: Empreendedorismo e inovação; Incubação de negócios; e background do empreendedor. Cada tema traz em si as discussões necessárias para o desenvolvimento da pesquisa, estando as subseções dispostas na mesma ordem dos temas apresentados. Assim, a subseção 2.1 apresenta os conceitos referentes ao empreendedorismo e inovação; a subseção 2.2 apresenta as discussões teóricas sobre incubação de negócios; a subseção 2.3 aborda o perfil do empreendedor; e a subseção 2.4 discute a literatura sobre background do empreendedor.

\subsection{EMPREENDEDORISMO E INOVAÇÃO}

Empreendedorismo é um tema muito discutido na literatura, tendo sua importância reconhecida para o desenvolvimento das organizações e, consequentemente, para o desenvolvimento econômico. Os primeiros estudos nessa direção surgiram com os trabalhos de Schumpeter (1942), o qual, por meio do conceito de destruição criativa, colocou a inovação em evidência, abrindo um amplo caminho para que as organizações buscassem se tornar cada vez mais inovadoras.

Para Schumpeter (1942), destruição criativa é o processo de substituição de um produto por outro melhor desenvolvido em termos tecnológico e funcional. É essa destruição o que ele definiu como o motor da inovação, daí a proximidade da inovação com o empreendedorismo. Essa teoria apresentada por Schumpeter é vista como a abordagem econômica do empreendedorismo, resultante da Teoria do Desenvolvimento Econômico.

Outras abordagens seguiram aos trabalhos de Schumpeter, a exemplo dos estudos de McClelland (1961) e Drucker (1985). A visão de McClelland (1961) observa o lado comportamental do empreendedorismo. Assim, ele analisa o empreendedorismo do ponto de vista do comportamento do empreendedor, se aproximando bastante das linhas teóricas da psicologia para responder aos seus questionamentos. É nessa vertente que o empreendedor começou a ser percebido e os seus traços começaram a ser analisados. McClelland (1961) 
aponta a necessidade de realização por parte do empreendedor como um aspecto significativo no fomento ao empreendedorismo nas organizações.

Drucker (1985), por outro lado, analisa o empreendedorismo do ponto de vista da gestão. Assim, ele enfatiza as capacidades de gestão e a importância da postura empreendedora para o empreendedorismo nas organizações. Essas três abordagens fundamentaram teoricamente uma série de outros estudos nesse campo do conhecimento.

Conceitualmente, o empreendedorismo é visto como o estudo de como, por quem e com quais efeitos, oportunidades para criar bens e serviços são descobertas, avaliadas e exploradas (Venkataraman, 1997). Esse conceito, também assumido por Shane e Venkataraman (2000) corrige um equivoco cometido por muitos estudiosos em empreendedorismo quando assumem o estudo do empreendedorismo olhando unicamente o empreendedor e analisando apenas o que o empreendedor é e o que ele faz (Venkataraman, 1997; Shane e Venkataraman, 2000). Esse equívoco leva os pesquisadores a desconsiderarem em seus estudos um dentre dois importantes fatores para o empreendedorismo: a presença da oportunidade de lucro e a presença de indivíduos empreendedores (Venkataraman, 1997).

Assim, muito embora os indivíduos empreendedores sejam importantes, é necessário que haja oportunidades empreendedoras (Shane e Venkataraman, 2000), sem as quais não faria sentido o estudo do empreendedorismo. Oportunidades empreendedoras são situações que permitem a introdução de novos produtos, serviços, matérias primas e a venda a preços superiores aos seus respectivos custos de produção (Casson, 1982). Nesse sentido, oportunidades empreendedoras permitem a inovação, o que demonstra a proximidade das duas áreas, sendo a inovação assumida como algo inerente ao empreendedor (Drucker, 1985).

A inovação é vista como a “implementação de produtos ou serviços novos ou significativamente melhorados, ou um processo, ou um novo método de marketing, ou um novo método organizacional nas práticas de negócios, na organização do local de trabalho ou nas relações externas" (OECD, 1997). Ela envolve a exploração de novas ideias (Neely e Hii, 1998) e se difere da invenção devido ao seu caráter comercial, uma vez que uma invenção somente se caracteriza uma inovação a partir da primeira transação comercial (Freeman, 1982). 
$\mathrm{Na}$ literatura, os conceitos de inovação se aproximam bastante da definição apresentada pela OECD, sendo esse um conceito chave na área do conhecimento em inovação. Tidd e Bessant (2015) definem a inovação como o processo de transformar as oportunidades em novas ideias que tenham amplo uso prático. Essas novas ideias, na literatura, é vista não somente como algo revolucionário, que modifique radicalmente o mercado, mas também como modificações pontuais ou aprimoramentos nos processos e produtos.

Freeman (1982) define a inovação industrial como abrangedora de atividades técnicas, comerciais, de projetos, de manufatura e de gestão que estão envolvidas no marketing de um novo (ou aperfeiçoado) produto ou no primeiro uso comercial de um novo (ou aperfeiçoado) processo ou equipamento. Rothwell e Gardiner (1985) apontam também que a inovação não lida apenas com a comercialização de algo totalmente novo (uma inovação radical), mas também, a utilização de mudanças de pequena escala no know-how tecnológico (inovação adicional ou de aperfeiçoamento). Além desses, Porter (1990) também agrega ao estado da arte em inovação afirmando que as empresas abordam a inovação em um sentido mais amplo, o que inclui tanto novas tecnologias quanto novas maneiras de fazer as coisas.

Nessa direção, a inovação é classificada na literatura de duas importantes maneiras: do ponto de vista da natureza da inovação, é classificada em radical ou incremental; do ponto de vista do tipo da inovação, ela pode ser de processo, de produto, de marketing ou organizacional (OECD, 1997; Neely e Hii, 1998). Uma inovação radical é vista como aquela que modifica totalmente as características de inovações anteriormente implementadas. Já a inovação incremental é representada por mudanças significativas em inovações já existentes (OECD, 1997; Neely e Hii, 1998).

A inovação pode ser de produto, de processo, organizacional (Neely e Hii, 1998; OECD, 1997) e de mercado (OECD, 1997). Inovação de produto é aquela proveniente de novos produtos ou produtos significativamente melhorados; a inovação de processo envolve a adoção de processos de produção ou distribuição, novos ou melhorados, ou um novo método de serviço social; e a inovação organizacional leva a uma utilização mais efetiva de recursos humanos, o que é crucial para a exploração bem sucedida de novas ideias (Neely e Hii, 1998; OECD, 1997); e a inovação de mercado modifica totalmente ou significativamente a dinâmica do mercado (OECD, 1997). 
Todas essas inovações, em todos os tipos apresentados, podem ser classificadas como radicais ou incrementais, assim, as inovações podem ser radicais ou incrementais em produtos; processos; organizacional e de mercado (Tidd e Bessant, 2015; Rothwell e Gardiner, 1985). Adiante, os tipos de inovação serão definidos com mais detalhes:

\subsubsection{Tipos de Inovação}

Conforme mencionado, a inovação permite algumas classificações provenientes de tipologias identificadas na literatura. A base principal para a tipificação da inovação dentre os estudos disponíveis na literatura são as definições do Manual de Oslo (OECD, 1997). Esse manual apresenta importância para os estudos em inovação, haja vista que, se mostra como uma metodologia utilizada para avaliar o processo de inovação (Pereira, 2014).

O Manual de Oslo apresenta quatro tipos de inovação diferentes, sendo elas a inovação de produto; a inovação de processo; a inovação organizacional e a inovação de marketing. $\mathrm{O}$ quadro a seguir sintetiza os conceitos relacionados a cada tipo de inovação descrito.

\section{Quadro 01. Tipos de Inovação}

\begin{tabular}{ll}
\hline \multicolumn{1}{c}{ Tipo de Inovação } & \multicolumn{1}{c}{ Característica } \\
\hline Inovações de produto & $\begin{array}{l}\text { Envolvem mudanças significativas nas potencialidades de } \\
\text { produtos e serviços. Incluem-se bens e serviços totalmente } \\
\text { novos e aperfeiçoamentos importantes para produtos existentes. }\end{array}$ \\
Inovações de processo & $\begin{array}{l}\text { Representam mudanças significativas nos métodos de produção } \\
\text { e de distribuição. }\end{array}$ \\
Inovações organizacionais & $\begin{array}{l}\text { Implementação de novos métodos organizacionais, tais como } \\
\text { mudanças em práticas de negócios, na empresa do local de } \\
\text { trabalho ou nas relações externas da empresa. }\end{array}$ \\
Inovações de marketing & $\begin{array}{l}\text { Envolvem a implementação de novos métodos de marketing, } \\
\text { incluindo mudanças no desenho do produto e na embalagem, na } \\
\text { promoção do produto e sua colocação, e em métodos de } \\
\text { estabelecimento de preços de bens e serviços. }\end{array}$ \\
\hline
\end{tabular}

Fonte: Pereira (2014, p. 32).

Esse estudo tem como variável dependente a ser analisada a inovação de produto. Esse tipo de inovação, conforme definido por OECD (1997), é parte componente da Inovação Tecnológica de Produtos e Processos. De maneira específica, o autor propõe que a inovação de produto refere-se tanto a produtos tecnologicamente novos lançados no mercado quanto aos produtos tecnologicamente aprimorados e inseridos no mercado. 
Assim, um produto tecnologicamente novo, segundo OECD (1997, p. 32),

é aquele cujas características tecnológicas ou usos pretendidos se diferem daqueles produtos produzidos anteriormente. Tais inovações podem envolver tecnologias radicalmente novas, podem basear-se na combinação de tecnologias existentes em novos usos, ou podem ser derivadas do uso de novo conhecimento.

Por outro lado, um produto tecnologicamente aprimorado é definido como:

Um produto existente cujo desempenho tenha sido significativamente aprimorado ou elevado. Um produto simples pode ser aprimorado (em termos de melhor desempenho ou menor custo) através de componentes ou materiais de desempenho melhor, ou um produto complexo que consista em vários subsistemas técnicos integrados pode ser aprimorado através de modificações parciais em um dos subsistemas (OECD, 1997, p. 32).

Os demais tipos de inovação, cujos conceitos encontram-se no quadro apresentado anteriormente, juntamente com a inovação de produtos, também podem ser classificados segundo a sua natureza, em inovação radical e inovação incremental, conforme apresentado por Neely e Hii (1998). Assim, ao autores enquadram as inovações dentro do quadro que considera inovações de produto radical e incremental; inovação de processos radical e incremental; e inovação organizacional radical e incremental, exemplificando-os, conforme o quadro a seguir.

Quadro 02. Dimensões e Tipos de Inovações

\begin{tabular}{ccc}
\hline & Incremental & Radical \\
\hline Produto & $\begin{array}{c}\text { Chips de 16 bits em } \\
\text { substituição aos chips de 32 }\end{array}$ & $\begin{array}{c}\text { Lançamento do compact- } \\
\text { disc. }\end{array}$ \\
Processo & bits. & \\
& $\begin{array}{c}\text { Melhorias de qualidade em } \\
\text { sistemas de inspeção. }\end{array}$ & $\begin{array}{c}\text { Prototipagem de produtos em } \\
\text { computadores. }\end{array}$ \\
Organizacional & $\begin{array}{c}\text { Implementação de círculos } \\
\text { de qualidade. }\end{array}$ & $\begin{array}{c}\text { Reuniões por } \\
\text { teleconferência. }\end{array}$ \\
\hline
\end{tabular}

Fonte: Neely e Hii (1998)

Essas discussões dos tipos de inovação já foram levantadas inicialmente por Schumpeter (1982), o qual, em seu estudo seminal, apontou para a importância do processo de gestão da inovação nas organizações, identificando que a inovação nas organizações pode acontecer de diferentes maneiras, descritas adiante: (1) por meio da introdução de novos métodos de produção; (2) introdução de novos produtos; (3) abertura de novos mercados; (4) conquista da 
nova fonte de matérias primas e produtos semimanufaturados; e (5) introdução de nova forma de organização de um setor industrial. Esses diferentes tipos se adequam dentro do que a OECD (1997) descreveu como tipos de inovação, assim como Neely e Hii (1998).

Identificar os tipos de inovação é importante para o processo de inovação nas organizações, haja vista que, permite o direcionamento dos esforços considerando as características do tipo de inovação com o qual se está lidando. Adicionalmente, mensurar as inovações também é um ponto importante para o monitoramento desse processo nas organizações, por esse motivo, a literatura dá lugar a discussões sobre os aspectos de mensuração da inovação.

\subsubsection{Métricas de Inovação}

A mensuração da inovação nas empresas recebe espaço na literatura mediante a análise de dois importantes fatores: o grau de inovatividade e o desempenho inovador. Por grau de inovatividade entende-se o grau com que a empresa tem agilidade para adotar inovação por indivíduos ou unidade de adoção em relação a outros membros do sistema social (Rogers, 1962). Já por desempenho inovador é tido como o desempenho da empresa para a inovação. O desempenho, de maneira geral, pode ser mensurado por uma série de medidas, sendo as mais tradicionais, por exemplo, lucro, produtividade, quantidade e qualidade do trabalho (Pereira, 2014), e, quando se fala de desempenho inovador, alguns indicadores também são apontados, a introdução de novos produtos (Freeman e Soete, 2008), Índice de Novos Produtos (Sbragia et al., 1998), dentre outros.

Com relação à inovatividade, sua mensuração é apresentada na literatura de diversas formas. Deshpandé et al. (1993) apresenta uma escala que tem como foco a introdução de novos produtos e mercado. Essa forma de mensuração á a maneira mais simples de mensuração, permitindo a mensuração em termos de valores absolutos da inovatividade. Outro indicador mais sofisticado é o Índice de novos produtos, apresentados por Sbragia et al., (1998) e Tipping, Zeffren e Fusfeld (1995). Esse indicador considera o percentual da receita bruta com novos produtos introduzidos no mercado nos últimos 3 a 5 anos pelo faturamento bruto anual, melhor visualizado na formula seguinte:

$$
I N P=\frac{\text { Parcela do faturamento anual com produtos de até } 5 \text { anos de vida }}{\text { Faturamento anual da empresa }} \times 100 \%
$$

Fonte: Sbragia et al. (1998) 
Outros indicadores descritos na literatura se propõem a mensurar, por exemplo, a capacidade ou propensão da empresa para inovar ou desenvolver novos produtos (Garcia e Calantone, 2002). Hult et al. (2003) e Hult et al (2004) se propõe a mensurar o grau de inovatividade mediante análise do capital social do comportamento facilitador da inovação. Maravelakis et al. (2006) se propõe a mensurar a inovação e o perfil de inovação do produto. Além desses, também Tajeddine et al. (2006) e Ferraresi (2010) enfocam o comportamento das pessoas na empresa, e Rapp et al. (2008) mensuram a inovatividade no setor de e-business relacionando atividades de inovação nesse segmento com a orientação para o mercado e o resultado de vendas e desempenho organizacional (Pereira, 2014).

Do ponto de vista da inovação de produtos, Cooper e Edgett (2008) também contribuem para a literatura apresentando um indicador de produtividade no desenvolvimento de novos produtos, o qual relaciona as vendas ou lucros provindos do desenvolvimento de novos produtos com os gastos em Pesquisa e Desenvolvimento, conforme fórmula seguinte:

$$
N P D \text { productivity }=\frac{\text { Sales }(\text { or profits }) \text { from } N P D}{R \& D \text { Spending }}
$$

Fonte: Cooper e Edgett (2008)

Todos esses indicadores apresentam suas vantagens, mas também, apresentam suas desvantagens. Alguns deles são mais simples em termos teóricos, considerando uma quantidade única de variáveis, enquanto outros são mais sofisticados em termos de quantidade de variáveis utilizadas na mensuração. Quando considerado aqueles de simples mensuração, identifica-se a introdução de novos produtos. Esse indicador apresenta a vantagem de ser de fácil coleta, envolvendo a introdução de novos produtos em termos absolutos, havendo, portanto, que se coletar apenas o número de produtos lançados no mercado, sejam eles totalmente novos ou significativamente melhorados.

Além desse índice, outros mais sofisticados são apresentados. O índice de novos produtos, apresentado por Sbragia et al. (1998) e Tipping, Zeffren e Fusfeld (1995) é um exemplo de mensuração mais sofisticada, assim como o índice de Produtividade no desenvolvimento de novos produtos, apresentado por Cooper e Edgett (2008). Esses mensuradores são interessantes, pois, analisam de maneira integrada mais que uma variável, o que permite uma 
melhor visualização e resultados mais robustos de mensuração, porém, também exigem certo conhecimento por parte dos informantes desses dados para que a qualidade desses indicadores seja garantida.

No presente estudo, o indicador utilizado para mensurar a inovação em produtos é o lançamento de novos produtos. A escolha desse indicador em detrimento dos demais apresentados anteriormente se dá devido à facilidade de coletar dados mais confiáveis para o indicador índice de novos produtos nas empresas, podendo ser coletado o número absoluto de produtos lançados, analisando-os em termos métricos ou analisando se inovam ou não.

O indicador de Índice de Novos Produtos (INP), apresentado por Sbragia et al (1998), não foi escolhido para mensurar a inovação de novos produtos dadas as características das empresas estudadas. Por se tratar de empresas relativamente pequenas, as informações necessárias para o calculo desse índice podem não serem mensuradas nas empresas, a exemplo da parcela do faturamento anual com produtos de até 5 anos de vida, e o faturamento anual da empresa, cujas dificuldades de fornecimento desses dados por parte dos empreendedores existem.

Além do índice citado anteriormente, também o índice de Produtividade de Desenvolvimento de Novos Produtos, NPD Productivity, definido por Cooper e Edgett (2008), não será utilizado como indicador para mensurar a inovação de produtos, também, devido à necessidade de informações de difícil coleta nas empresas, a exemplo das vendas (ou lucros) de Novos Produtos Desenvolvidos e os gastos com P\&D.

Por essas razões, o presente estudo mensura a inovação em produtos mediante a utilização do indicador Lançamento de Novos Produtos.

\subsection{INCUBAÇÃO DE NEGÓCIOS}

Essa sessão aborda um importante conceito na literatura em Inovação, que é a incubação de negócios. Essa prática vem se mostrando válida para o desenvolvimento econômico e tecnológico em países desenvolvidos e emergentes. Cases de sucesso podem ser apresentados, a exemplos do Vale do Silício e da Rota 190, ambientes que permitiram o início e desenvolvimento de importantes corporações globais inovadoras, como a Hewlett-Packard, e abrigam outras como Google, Microsoft, dentre outras. Assim, serão apresentados os 
conceitos relacionados à incubação de negócios, tipos de incubadoras de empresas, e o processo de seleção de empresas incubadas.

\subsubsection{Conceito de Incubação de Negócios}

O conceito de incubação de negócios está entrelaçado à ideia de desenvolvimento de novos negócios. Esse conceito é materializado em organizações definidas como Incubadoras de Empresas. Na literatura, alguns autores definem essas organizações como criadoras de ambientes de apoio condutivos ao surgimento e desenvolvimento de novos negócios (Bergek e Norrman, 2008; Chan e Lau, 2005; Lindholm-Dahlstrand e Klofsten, 2002; Lyons e Li, 2003). Esse conceito apresenta o ponto focal da ideia de incubação de negócios, que é apoiar novos empreendimentos em seu período de criação e desenvolvimento, porém, ainda pode ser melhor desenvolvido com a contribuição de outras definições disponíveis.

Vistas como instrumento de promoção de inovação e redução da taxa de mortalidade de empresas start-ups, as incubadoras de empresas - em seu trabalho de apoio à criação e desenvolvimento de novos empreendimentos - fornecem às empresas incubadas suporte que vão desde apoio com instalações físicas - a exemplo de espaços de escritórios e capital -, até apoio aos empreendimentos em termos de conhecimento e gestão (Aerts et al, 2007). Esse conceito é interessante à medida que apresenta as formas de apoio das incubadoras às empresas incubadas. Com maior intensidade, as incubadoras de empresas fornecem às empresas incubadas apoio físico e de gestão, ficando para as aceleradoras o papel de buscar investidores para aportes de capital nos empreendimentos.

Aceleradoras de empresas são definidas como um tipo de programa de incubação que permitem às equipes de empreendedores e seus empreendimentos se conectarem com investidores e acessarem recursos, tanto dos investidores quanto dos stakeholders importantes (Malek et al, 2014). Essas aceleradoras se diferem das incubadoras tradicionais nesse aspecto, não havendo uma ênfase por parte das incubadoras no papel de conectar as empresas incubadas com investidores ou com os principais stakeholders.

A literatura aponta ainda para o papel fundamental de equilibrar os tipos de apoio concedidos pelas incubadoras de empresas, entre apoio físico e apoio à gestão. A ênfase relativa nesses tipos de empreendimentos tem variado ao longo do tempo, passando desde um foco inicial em 
instalações e serviços administrativos até uma ênfase mais recente na importância do apoio aos negócios (Peters et al, 2004). Essa ênfase mais recente é defendida na literatura com argumentos que apontam que esse apoio é fundamental para o desenvolvimento de novos empreendimentos, haja vista que, sem esse apoio, as incubadoras de empresas se configuram mais como hotéis de empresas do que como incubadoras em si (Bergek e Norrman, 2008).

\subsubsection{Processo de seleção de Empresas Incubadas}

O estudo dos processos de seleção de empresas incubadas figura-se na literatura no que concerne ao estudo dos componentes do sistema de incubação. Hackett e Dilts (2004) apresenta uma visão geral sistemática das pesquisas em incubação de empresas. Os autores apresentam cinco direcionamentos teóricos: (1) Estudos de desenvolvimento de incubadoras, que procuram apresentar definições, taxonomias e prescrição de políticas; (2) Estudos de configuração de incubadoras, os quais procuravam estudar os componentes de incubadoras, dentre eles, seleção de empresas incubadas; (3) Estudos de desenvolvimento de empresas incubadas, os quais se preocupam com o desenvolvimento de novos empreendimentos e impacto do planejamento no desenvolvimento; (4) Estudos dos impactos incubadoraincubação, os quais buscam verificar se o conceito de incubação influencia o sucesso das empresas incubadas e até mesmo da própria incubadora; e (5) Estudos teorizando sobre incubadora-incubação.

Os estudos relacionados à seleção de empresas incubadas encontram-se na segunda orientação de pesquisa, as quais versam sobre os componentes das incubadoras de empresas. A compreensão do processo de seleção de empresas incubadas é vista, na literatura, como uma importante questão de gestão da incubadora, uma vez que ela é a base para a alocação efetiva de recursos, tanto com relação à incubadora quanto com relação à economia em geral (Colombo e Delmastro, 2002; Lumpkin e Ireland, 1988; Hackett e Dilts, 2004). A dificuldade desse processo, no entanto, encontra-se na identificação de empresas promissoras, evitando aquelas que a incubadora não consegue apoiar, bem como aquelas que não precisam de incubadora (Bergek e Norrman, 2008). Esse desafio, segundo Hackett e Dilts (2004) requer "um sofisticado entendimento do mercado e do processo de formação de novos empreendimentos". 
Seguindo nessa direção, identifica-se um consenso com relação à importância do processo de seleção. O mesmo não acontece, por exemplo, quando se refere aos critérios utilizados para a seleção de empresas incubadas. Isso se dá, em grande parte, por reflexo das diferenças entre as incubadoras e seus objetivos. Estudos como o de Bergek e Norrman (2008) tentam traçar um modelo que agrupem incubadoras de empresas com relação às suas características gerais, buscando com isso, permitir a identificação de melhores práticas. Nesse sentido, os autores identificam alguns componentes dos modelos de incubadoras, e consideram os três principais para fundamentar seu modelo: Seleção; Apoio ao negócio; e Mediação.

Bergek e Norrman (2008) perceberam que, na literatura, não havia consenso com relação aos critérios utilizados nos processos de seleção, porém, analisando esses critérios, os autores os agruparam em duas abordagens gerais: seleção com foco na ideia e seleção com foco no empreendedor. Em termos gerais, os critérios de seleção caminhavam nessas duas direções. Os critérios citados pelos autores como facilmente identificáveis nas práticas de seleção são, dentre outros: experiência prévia do empreendedor; expertise técnica do empreendedor ou da equipe de gestão; propriedades do mercado; propriedades do produto ou serviço; potencial de lucro. Os dois primeiros critérios são focados na seleção de empreendedores, enquanto os outros focam a seleção de ideias.

Além da seleção com base nos critérios, Bergek e Norrman (2008) apontam outros fatores envolvidos na seleção. Segundo eles, a seleção também pode ser considerada com relação à flexibilidade ou rigidez do processo, podendo assumir uma abordagem "picking-the-winners" ou "survival-of-the-fittest". $\mathrm{Na}$ abordagem picking-the-winners, a incubadora procura selecionar aqueles empreendimentos que apresentam alto potencial de serem bem sucedidos. Isso implica em uma seleção mais criteriosa, implicando na seleção de um número menor de candidatos. Essa abordagem, segundo os autores, quando levadas ao extremo, faz com que a incubadora assuma um posicionamento semelhante às venture capital firms.

A segunda abordagem, survival-of-the-fittest, busca transferir ao mercado a tarefa de selecionar os empreendimentos vencedores dos perdedores. Nesse tipo de seleção, a incubadora é mais flexível, o que implica na seleção de uma grande quantidade de empresas a serem incubadas, não existindo aqui, um foco muito específico com relação ao nicho de mercado em que a incubadora atua. 
A grande contribuição dos autores nessa direção é a junção dessas formas de seleção, o que resulta em um modelo de seleção de empresas incubadas definido por quatro estratégias de seleção: (1) survival-of-the-fittest e seleção por ideia; (2) survival-of-the-fittest e seleção por empreendedor; (3) picking-the-winners e seleção por ideia; (4) picking-the-winners e seleção por empreendedor. $\mathrm{Na}$ primeira estratégia, a incubadora selecionará uma quantidade significativa de ideias e colocará essas ideias em prova para que o mercado as selecionem naturalmente; a segunda estratégica conduz a incubadora a selecionar uma quantidade significativa de empreendedores também colocando-os à prova no mercado para que sejam selecionados. A terceira estratégia leva a incubadora a selecionar apenas aquelas ideias com grande potencial de sucesso no mercado; da mesma forma, a quarta estratégia leva a incubadora a selecionar apenas aqueles empreendedores com perfil de potencial vencedor no mercado.

Além do estudo de Bergek e Norrman (2008), outro estudo que contribui para o entendimento das práticas de seleção em incubadoras é o trabalho de Aerts et al (2007). Nesse paper os autores buscam descrever praticas de seleção em incubadoras de empresas europeias no ano de 2003 e compará-las com as incubadoras americanas no ano de 1980. A partir dessa descrição de práticas, os autores procuram fazer um link com o desempenho das empresas incubadas em termos de falência de empresas incubadas. Dentro desse escopo, o que interessa à pesquisa que ora se propõe, são as práticas de seleção por eles mensuradas.

Os autores fundamentam-se na categorização feita por Lumpkin e Ireland (1988) para conduzir seus estudos. Lumpkin e Ireland (1988) identificaram três grupos de critérios de seleção: (1) experiência do time de gestão; (2) força/potencial financeiro; e (3) fatores pessoais e de mercado. Como critérios de identificação da experiência do time de gestão, os autores consideraram: idade; sexo; habilidades técnicas; habilidades de gestão; habilidades financeiras; habilidades de mercado; agressividade/persistência; referência de outros. Com relação à força/potencial financeiro, os autores consideraram: liquidez; lucratividade; utilização de ativos; price earning (indicador utilizado para analisar o valor de uma ação); e debt utilization. Por fim, com relação aos fatores pessoais e de mercado, os autores consideraram: tamanho atual do mercado; taxa de crescimento do mercado; singularidade do produto/serviço; negociabilidade do produto/serviço; escrita do plano de negócio. 
Após a aplicação de um survey nas incubadoras de empresas europeias no ano de 2003, os autores conseguiram levantar as principais ênfases dadas nos processos de seleção e concluíram que existe uma relação direta entre a taxa de sobrevivência das empresas incubadas e um perfil de seleção mais balanceado, ou seja, quanto mais balanceada for a ênfase dada aos critérios (experiência do time de gestão; força/potencial financeiro; fatores pessoais e de mercado) no processo de seleção, maiores serão também as chances de sobrevivência das empresas incubadas.

Pesquisas prévias, realizadas por Lumpkin e Ireland (1988), perceberam que 45,5\% das incubadoras americanas enfatizavam o critério "fatores pessoais e de mercado" no momento da seleção; 24,2\% enfatizavam a "força / potencial financeiros"; 15,2\% enfatizavam “experiência do time de gestão"; e percebeu-se também, que 15,2\% das incubadoras norteamericanas não apresentaram nenhum dos três critérios de seleção.

Nos estudos sobre o processo de seleção de empresas incubadas é possível identificar a análise de características dos empreendedores. Nesse sentido, torna-se necessário entender as características desses empreendedores a fim de conceder eficiência aos processos de seleção, mediante análise das características que mais impactam na inovatividade da empresa incubada.

\subsection{PERFIL DO EMPREENDEDOR}

O conceito de perfil, segundo Ferreira (1996), refere-se à "descrição de uma passoa em traços mais ou menos rápidos”. Essa definição é genérica encontrada em dicinário mas que permite direcionamento das discussões sobre o tema. Especificamente na literatura sobre empreendedorismo, o perfil do empreendedor começou a ser analisado com profundidade no âmbito da teoria comportamental, defendida por McClelland (1972). Motivado em estudar o lado psicológico e comportamental do empreendedor, McClelland estudou a motivação psicológica, fundamentando a sua teoria nesse pilar, e direcinoando-a para a identificação de três necessidades básicas, sendo elas: Necessidade de realização; Necessidade de afiliação; e necessidade de poder.

Essas necessidades motivam os empreendedores a assumirem ações e competencias que os permitam suprir essas necessidades. Lenzi, Kiesel e Lucco (2010) reunem ações e 
competências empreendedoras que direcionam e movem os empreendedores para algumas ações. O quadro 03 adiante lista essas ações e competências listadas por Lenzi, Kiesel e Lucco (2010, p. 7).

Quadro 03. Relação das ações e competências empreendedoras.

\begin{tabular}{|c|c|}
\hline Autor & Principais ações e competências \\
\hline Mill (1848) & Tolerância ao risco. \\
\hline Weber (1917) & Origem da autoridade formal. \\
\hline $\begin{array}{l}\text { Schumpeter }(1928,1934 \\
1942,1949,1967,1982)\end{array}$ & $\begin{array}{l}\text { Inovação, iniciativa, sonho criatividade, energia, realização pessoal, poder, } \\
\text { mudança. }\end{array}$ \\
\hline Sutton (1954) & Busca de responsabilidade. \\
\hline Hartman (1959) & Busca da autoridade formal. \\
\hline $\begin{array}{l}\text { McClelland (1961, 1971, } \\
\text { 1973) }\end{array}$ & Tomada de risco, necessidade de realização, necessidade de afiliação. \\
\hline Davids (1963) & Ambição, desejo de independência, responsabilidade e autoconfiança. \\
\hline Pickle (1964) & Relacionamento humano, habilidade de comunicação, conhecimento técnico. \\
\hline Palmer (1971) & Avaliação de riscos. \\
\hline Hornaday \& Aboud (1971) & $\begin{array}{l}\text { Necessidade de realização, autonomia, agressão, poder, reconhecimento, } \\
\text { inovação, independência. }\end{array}$ \\
\hline Winter (1973) & Necessidade de Poder. \\
\hline Borland (1974) & Controle Interno. \\
\hline Liles (1974) & Necessidade de realização. \\
\hline Bruce (1976) & Tomada de decisões e de riscos. \\
\hline Shapero $(1977,1980)$ & Inovação, tomada de riscos, iniciativa, independência. \\
\hline Gasse (1977) & Orientação por valores pessoais. \\
\hline Timmons (1978) & $\begin{array}{l}\text { Autoconfiança, orientação por metas, tomada de riscos moderados, centralização } \\
\text { de controle, criatividade, inovação. }\end{array}$ \\
\hline Cantillon (1978) & Inovação. \\
\hline Sexton (1980) & Energia, ambição, revés positivo. \\
\hline Welsh \& White (1981) & Necessidade de controle, responsabilidade, autoconfiança, riscos moderados. \\
\hline $\begin{array}{l}\begin{array}{l}\text { Dunkelberg \& } \quad \text { Cooper } \\
(1982)\end{array} \\
\end{array}$ & Orientação ao crescimento, profissionalização e independência. \\
\hline Pinchot $(1985,1989,2004)$ & Visão, execução, planejamento. \\
\hline Drucker $(1986,2002)$ & Inovação, iniciativa. \\
\hline $\begin{array}{l}\text { Filion }(1988,1991,1993, \\
\text { 1999) }\end{array}$ & Visão, imaginação, oportunidade, objetivos. \\
\hline Cooley (1990) & $\begin{array}{l}\text { Dedicação pessoal, planejamento e metas, persuasão, independência, } \\
\text { compromentimento, iniciativa. }\end{array}$ \\
\hline Zahra (1991) & Renovação estratégica, novos negócios. \\
\hline $\begin{array}{l}\text { Cunningham e Lischeron } \\
(1991)\end{array}$ & Liderança, ação, tomada de riscos, inovação. \\
\hline Farrel (1993) & Visão, valores pessoais. \\
\hline Spencer \& Spencer (1993) & $\begin{array}{l}\text { Realização, planejamento, persuasão, autoconfiança, persistência, } \\
\text { oportunidades, tomada de riscos, qualidade, comprometimento, informações, } \\
\text { metas. }\end{array}$ \\
\hline Cossete (1994) & Visão, formulação de estratégias. \\
\hline Miner (1998) & Realização, rede de relacionamento, novas ideias, administração. \\
\hline Sharma \& Chrisman (1999) & Criação, inovação. \\
\hline Dolabela (1999) & Inovação, criatividade, visão, planejamento, iniciativa, oportunidade. \\
\hline Fleury $(2000,2002)$ & $\begin{array}{l}\text { Ação, mobilização de recursos, entrega, engajamento, responsabilidade, visão } \\
\text { estratégica. }\end{array}$ \\
\hline Klerk \& Kruger (2003) & $\begin{array}{l}\text { Inovação, criatividade, visão de futuro, condição de assumir tomada de riscos, } \\
\text { determinação, valores, adaptabilidade, prontidão, firmeza, ambição, suficiência } \\
\text { de capital. }\end{array}$ \\
\hline Dornelas (2003) & Oportunidade, criação, iniciativa, inovação, gerenciamento de riscos, \\
\hline
\end{tabular}




\begin{tabular}{|l|l|}
\hline & planejamento, persistência, relacionamentos. \\
\hline Santos (2004) & Criatividade, inovação, novos negócios. \\
\hline Seifert (2004, 2005) & Criatividade, inovação, novos negócios, renovação estratégica. \\
\hline Dutra (2004) & $\begin{array}{l}\text { Capacidade de inovação, comunicação, liderança, resolução de problemas, } \\
\text { direcionamento estratégico, negociação, planejamento, relacionamentos, visão } \\
\text { sistêmica, orientação para a qualidade. }\end{array}$ \\
\hline
\end{tabular}

Fonte: Lenzi, Kiesel e Zucco (2010)

Lenzi, Kiesel e Zucco (2010), ao levantar esse conjunto de competências, afirmam que grande parte delas, inseridas no dia a dia do empreendedor, levam-os a cinco diferentes ações, sendo elas: Ação de prepararação; Ação de organização; Ação de avaliação; Ação de correção; e ação constante.

Outro autor que contribui para a literatura sobre características do empreendedor é Dornelas (2015). O autor também levantou as características dos empreendedores na literatura e analisa quais as características são as mais citadas pelos pesquisadores, em 25 artigos publicados em periódicos internacionais e livros de referência no período de 1972 a 2005, chegando às seguintes características: Correr riscos, independência/autonomia, inovador, realização, autocontrole, criativo, autoconfiança, responsabilidade, determinação, energia/entusiasmo, liderança, metas, tolera incertezas, ambição, dinheiro, iniciativa, oportunidades, rede de contato, busca de informação, comprometimento, persistência, poder, positividade

A literatura, por vezes, assumem nomenclaturas diferentes para se referir às mesmas características. Algumas vezes mencionam características, outras vezes, competência. No presente estudo, busca-se estudar as características do empreendedor. Porém, há que se destacar aqui, que as características abrangem um campo muito amplo, podendo ser diferenciadas em habilidades técnicas, habilidades gerenciais e características pessoais. Muitas das características citadas anteriormente encaixam-se como habilidades gerenciais, outras como habilidades técnicas, outras como características dos empreendedores.

Nesta pesquisa, busca-se estudar as características que compõe o background do empreendedor, isto é, as características de formação e experiência. Assim, não obstante a existência de uma série de características, quando intencionando identificar associações com a inovação de produtos, realça-se essas duas características, formação e experiência, que levam os empreendedores a desenvolverem competências que os permitem tomar ações no sentido de inovar em produtos. 
Assim, como essas duas características compõe o background do empreendedor, apresenta-se abaixo a definição conceitual nessa direção.

\subsection{BACKGROUND DO EMPREENDEDOR}

As características dos empreendedores começaram a ser tratadas na literatura a partir do trabalho de McClelland (1961). Essa abordagem busca identificar características psicológicas inerentes aos empreendedores e que os diferenciavam dos demais. Assim, essa abordagem considera que o empreendedor é uma função de características estáveis que os compunham e que outras pessoas, os não empreendedores ou gestores, não possuíam (Shane, 2000; McClelland, 1961). Desse ponto de vista, alguns traços como a necessidade de realização (McClelland, 1961), a propensão à assumir riscos (Brockhaus e Horowitz, 1986), alto eficácia (Chen et al, 1998), foco no controle interno e tolerância à ambiguidade (Begley e Boyd, 1987) foram levantados e apontados pela literatura que compunha a teoria psicológica do empreendedorismo como sendo características possuídas pelos empreendedores e que os diferenciavam dos demais.

Alguns estudos, no entanto, apontaram que algumas características apresentadas pela abordagem dos traços do empreendedor não se sustentavam como determinantes das diferenças entre empreendedores e não empreendedores. Estudos posteriores identificaram que características como foco no controle e tomada de riscos não apresentaram variações significativas entre empreendedores e não empreendedores (Begley e Boyd, 1987; Sexton e Bowman, 1984; Busenitz e Barney, 1997). Essas contraposições dos estudos evidenciam muitas limitações dessa abordagem.

Busenitz e Barney (1997) apontam que existem três distintas explicações para o fracasso na tentativa da teoria psicológica em descobrir sistematicamente diferenças psicológicas e pessoais/demográficas significativas entre empreendedores e não empreendedores em grandes organizações. O primeiro deles é explicado por alguns autores como sendo resultante do uso de metodologias inadequadas (Ginsberg e Buchholtz, 1989). Porém, ainda assim, com a utilização de métodos mais sofisticados de pesquisas, os resultados não tem se alterado muito daqueles apresentados anteriormente (Busenitz e Barney, 1997). 
A segunda explicação refere-se a que, alguns autores na literatura têm argumentado que pesquisas sobre diferenças individuais deveriam ser abandonadas em detrimento de pesquisas que focassem as causas externas do comportamento empreendedor (Acs e Audretsch, 1987; Aldrich e Zimmer, 1986; Gartner, 1989; Shapero, 1984). Porém, esses estudos orientados para o ambiente externo, por si só, não têm sido suficientes para se descartar completamente a abordagem das diferenças individuais (Busenitz e Barney, 1997).

A terceira explicação sugere que outro grupo de pesquisadores tem insistido na identificação de características individuais (Busenitz e Barney, 1997). Contudo, esse grupo afirma que as pesquisas desenvolvidas até então, abordando as diferenças de características individuais de empreendedores, têm focado diferenças individuais erradas (Robinson et al., 1991). Ainda assim, mais do que examinar diferenças demográficas/pessoais e psicológicas, esses estudiosos sugeriram a importância de examinar diferenças entre esses conjuntos de indivíduos (Gartner et al., 1992).

Além das características psicológicas apontadas como sendo pertencentes aos empreendedores, e uma vez que os estudos têm apontado para diferenças não significativas entre empreendedores e não empreendedores no tocante a essas características, há também as características pessoais/demográfica. Essas características também se mostraram limitadas (Busenitz e Barney, 1997), e no geral, as características, quando considerando grandes empresas, apresentam diferenças bastante pequenas ou raramente sistemáticas (Cooper e Dunkelberg, 1987). Apesar disso, algumas características pessoais/demográficas continuam a ganhar importância na literatura, algumas delas são idade, gênero e educação (Robinson e Sexton, 1994).

Muitas dessas características recebem certa importância por relacionarem-se com a descoberta de oportunidades empreendedoras, a exemplo do conhecimento prévio (Shane, 2000); educação e experiência (Lee e Tsang, 2001). Esses são os principais traços empreendedores que estão fundamentados na literatura como ligados à descoberta de oportunidades empreendedoras. A importância dessas características na descoberta de novas oportunidades empreendedoras - e aqui consideramos o lançamento de novos produtos como um indicativo de exploração de oportunidades empreendedoras - é explicado pelo conceito de assimetria da informação (Schumpeter, 1942; Shane e Venkataraman, 2000; Lumpkin e Dess, 1996; Shane, 2000). 


\subsubsection{Educação}

Assimetria da informação indica que os indivíduos têm acesso a diferentes tipos de informações, ou seja, as informações disponíveis não são iguais para todos os indivíduos (Schumpeter, 1942). E isso fornece à descoberta de oportunidades empreendedoras uma característica interessante abordada na literatura: os indivíduos apresentam uma propensão a descobrir oportunidades empreendedoras que se aproximam ao background que o mesmo apresenta, em termos de educação e conhecimentos previamente adquiridos (experiência) (Shane, 2000; Shane e Venkataraman, 2000).

A educação é vista na literatura como um aspecto fundamental para a descoberta de oportunidades empreendedoras (Shane e Venkataraman, 2000). O aumento da complexidade dos ambientes de negócios e a intensificação do fluxo de informações geradas pelas empresas e pelo ambiente no qual a empresa está inserida tem exigido do empreendedor e dos seus gestores formação cada vez mais específica e elevada, no sentido de conferir qualidade na lida com as decisões e interações no ambiente de negócios (Lee e Tsang, 2001).

Estudos nessa direção têm apontado, por exemplo, que empreendedores apresentam níveis de formação significativamente mais elevados do que a população em geral, isso considerando amostras do Canadá e Estados Unidos (Cooper e Dunkelberg, 1987; Thompson, 1986; Lee e Tsang, 2001). Além do mais, estudos também apontam que empreendedores apresentaram níveis de educação superiores do que trabalhadores assalariados e que, existe uma associação positiva entre o nível de educação e ganhos provenientes dos trabalhos e iniciativas autônomas, empreendedoras (Robinson e Sexton, 1994).

Estudo de Kangasharju e Pekkala (2002) têm apontado ainda para a variação da importância do fator educação para o sucesso em iniciativas empreendedoras quando considerado conjecturas econômicas de crise e crescimento econômico. Descobertas apontam que os sucessos em iniciativas empreendedoras variam quando considerados períodos de alta e baixa do cenário econômico independente do nível de educação. Isso significa que em períodos de recessão, a probabilidade de saída de iniciativas empreendedoras é menor para empreendedores altamente qualificados, e maior quando considerados períodos de crescimento econômico, isso considerando a conjectura econômica finlandesa em dois momentos diferentes de sua história econômica (Kangasharju e Pekkala, 2002). 
A educação é analisada na literatura sobre empreendedorismo também em função do tamanho da organização. Alguns estudos levantaram a inserção do tamanho da organização como um fator relevante para as discussões. Muitos deles apresentaram resultados contraditórios entre si. Por exemplo, um estudo desenvolvido no Pacífico Sul apontou que a educação e o treinamento dos empreendedores foram percebidos como fatores críticos de sucesso (Yusuf, 1995), da mesma forma, foram percebidas associações positivas entre o nível de educação e o desempenho do empreendimento (Robinson e Sexton, 1994). Por outro lado, estudos também apontaram que o nível de educação estava apenas positivamente relacionado com a lucratividade da empresa, isso para uma amostra de 48 empresas start-ups na Coréia (Jo e Lee, 1996). Dyke et al (1992) identificou tanto relações positivas quanto relações negativas entre o nível de educação do proprietário e o desempenho da empresas.

Outros estudos identificaram também relações negativas entre o nível de educação e indicadores de desempenho. Como exemplo, o estudo de Stuart e Abetti (1990) identificou uma relação negativa entre o nível de educação e desempenho de empresas de base tecnológicas e o estudo de Tan e Tay (1995) também identificou que o nível de educação do empresário é negativamente correlacionado com o crescimento das vendas.

Ao analisar as contradições entre os resultados dos trabalhos anteriores, Lee e Tsang (2001) perceberam que elas são resultantes da não consideração do fator tamanho das empresas nas pesquisas. Os autores levantaram a hipótese de que o nível de educação tem uma associação positiva com crescimento da organização e que essa relação é intensificada quando estratificada por tamanho das organizações, e os resultados do estudo desses autores apontou para uma associação positiva entre o nível de educação dos empreendedores e o crescimento da empresa e, além do mais, apontou também que essa associação é maior, positivamente, em empresas maiores do que em pequenas empresas. Isso se dá devido ao aumento de complexidade das grandes empresas frente às pequenas, e segundo os autores, a educação permite ao individuo o desenvolvimento de habilidades importantes para o gerenciamento de grandes empresas.

Seguindo nessa direção, percebe-se a existência de uma ampla literatura que apoia a educação e sua relação com diferentes indicadores, sejam eles desempenho, crescimento da empresa, crescimento das vendas, dentre outros. Esses resultados permitem identificar também a 
possibilidade de relação positiva entre o nível de educação do empreendedor e a inovação de produtos em empresas incubadas de base tecnológica. Tendo em vista a natureza complexa e técnica que caracterizam essas organizações, acredita-se que o nível de educação concede ao empreendedor habilidades importantes para o gerenciamento da organização e o seu desempenho bem sucedido em uma das atividades mais importantes nessas organizações que é a inovação de produto, uma vez que isso exige um nível de conhecimento mais elevado para que o processo de desenvolvimento de novos produtos e seu lançamento ocorra.

Ainda no tocante à formação do empreendedor e suas relações com a inovação de produtos em empresas Incubadas de Base Tecnológica é preciso abordar as características da formação em si, ou seja, analisar não apenas o nível de formação, mas também, as áreas específicas de formação do empreendedor.

Essa análise torna-se importante devido à sua estreita relação com o conceito de assimetria da informação, o qual aponta que as pessoas possuem diferenças de informações ou informações incompletas, o que tornam a relação entre os agentes desiguais (Spence, 1973; Akerlof, 1976; Stiglitz e Weiss, 1981), e, portanto, devido a essa assimetria de informações, as pessoas não descobrem oportunidades empreendedoras de forma igual (Shane, 2000; Shane e Venkataraman, 2000; Venkataraman, 1997). Assim, pessoas que adquirem novos conhecimentos antes das outras tem uma maior propensão a descobrir oportunidades empreendedoras utilizando esses conhecimentos (Shane, 2000).

A assimetria da informação é uma discussão importante no âmbito do empreendedorismo, uma vez que as diferenças de informações que os indivíduos possuem é que dá margem para a realocação e recombinação de recursos não realizados antes, o que caracteriza a oportunidade empreendedora (Casson, 1982; Shane, 2000). É nessa lógica que consiste o processo empreendedor. Tendo em vista que as pessoas possuem diferentes informações (Kirzner, 1997), ou informações incompletas, as transações nos mercados são conduzidas com base no que as pessoas envolvidas sabem, ou acham, em torno do que está sendo negociado. Isso conduz a erros que distribuem inadequadamente os recursos (Shane, 2000), possibilitando outras alocações ou combinações, mais eficientes, e que gera ao empreendedor lucros superior ao preço de custo, configurando uma oportunidade empreendedora (Casson, 1982). 
Essa lógica permite identificar o porquê que algumas pessoas descobrem oportunidades empreendedoras enquanto outras não. Essa assimetria de informação, em grande parte, decorre das diferenças de formação entre as pessoas, refletindo assim, diferenças na área de conhecimento em que as pessoas se formam. Com diferentes conhecimentos, as pessoas podem descobrir oportunidades empreendedoras que mais se aproximam daqueles conhecimentos que possuem (Shane \& Venkataraman, 2000).

Dessa revisão, resultaram as duas hipóteses apresentadas adiante:

Hipótese 01: O nível de formação do empreendedor é positivamente relacionado com a inovação de produtos.

Hipótese 02: Empreendedores com formações mais próximas das ciências exatas inovam mais em produtos do que aqueles cujas formações são mais próximas das ciências humanas.

\subsubsection{Experiência}

A experiência do empreendedor, assim como o conhecimento, compõe o seu background, que o acompanha e o auxilia na descoberta de oportunidades empreendedoras. Lee e Tsang (2001) afirmam que a experiência do empreendedor consiste em três componentes principais: experiência empreendedora, industrial e gerencial. A experiência empreendedora consiste no envolvimento do empreendedor na formação de novos empreendimentos anteriormente e o nível de funções gerenciais assumidos pelo empreendedor em tais empreendimentos (Stuart e Abetti, 1990; Lee e Tsang, 2001); a experiência industrial diz respeito à experiência do empreendedor na indústria na qual o negócio está inserido; e a experiência gerencial é a experiência total do empreendedor com gestão naquele setor industrial (Lee e Tsang, 2001).

Quando se analisa a experiência é preciso considerar alguns estudos que foram desenvolvidos nessa direção. Muitos deles analisaram a relação entre a experiência e o desempenho (Lee e Tsang, 2001; Gasse, 1982; Stuart e Abetti, 1990; Van de Ven et al, 1984; Vesper, 1980; Dyke et al, 1992; Duchesneau e Gartner, 1990). O estudo de Lee e Tsang (2001), abrangendo 168 empreendedores chineses em pequenas e médias empresas em Singapura identificou uma relação positiva entre a experiência dos empreendedores e o crescimento do negócio. 
O estudo de Gasse (1982) identificou influências positivas e negativas da experiência do empreendedor no desempenho. Lee e Tsang (2001) exemplifica que experiências prévias podem agir como uma barreira, ou no mínimo, dificultar mudanças estratégicas significativas quando elas se mostram necessárias. Isso porque, apoiado em suas experiências passadas, muitas vezes o empreendedor mostra-se inábil a enxergar outras maneiras que não as que ele já utiliza e aprendeu ao longo de sua experiência.

Conforme apontado inicialmente, alguns estudos buscaram identificar impactos de experiências específicas, dentre as apresentadas anteriormente, no desempenho. Assim, analisando apenas as experiências de gestão e industrial, Jo e Lee (1996) analisaram a influência desses tipos de experiência no desempenho do negócio. Porém, a análise dos autores mostra-se interessante por que ele analisa conjuntamente a experiência e a educação e seu impacto no desempenho, e paralelamente, analisa também a influência da experiência, isoladamente, e seu impacto no desempenho do negócio.

Percebeu-se com os resultados do estudo que, quando analisado a experiência em conjunto com a educação, há uma relação positiva com o desempenho do negócio, porém, quando analisado somente a experiência, foi identificado que há uma relação negativa com o desempenho do negócio. Com isso, Jo e Lee (1996) apontam que iniciar um novo negócio confiado apenas na experiência pode se mostrar, no mínimo, perigoso, uma vez que existe a experiência, porém, ela não recebe o suporte sólido apresentado pela educação.

Do outro lado, alguns estudos apontaram relações positivas entre a experiência e outras variáveis. Stuart e Abetti (1990), por exemplo, relataram efeitos positivos da experiência em gestão; Van de Ven et al. (1984) e Vesper (1980) identificaram efeitos positivos da experiência industrial; e Dyke et al. (1992) identificaram efeitos positivos tanto na experiência gerencial quanto na industrial. Duchesneau e Gartner (1990), analisando conjuntamente a experiência de gestão e industrial identificaram que, combinadas, essas experiências impactam positivamente o sucesso dos negócios.

Da revisão sobre a experiência do empreendedor foram levantadas as seguintes hipóteses: 
Hipótese 03: Empreendedores que atuam em áreas mais próximas da produção e desenvolvimento de novos produtos inovam mais em produtos que empreendedores que atuam em áreas mais distantes das citadas.

Hipótese 04: A experiência do empreendedor em termos totais está positivamente relacionada com a inovação em produtos.

Hipótese 05: A experiência de atuação do empreendedor na empresa está positivamente relacionada com a inovação em produtos.

Acredita-se que as cinco hipóteses anteriores são moderadas por outra variável, definida aqui como o "Porte da Empresa". Algumas pesquisas, assim como mencionado no desenvolvimento teórico, evidenciaram a importância da variável tamanho da organização para entender a influencia do conhecimento e experiência do empreendedor no desempenho da empresa.

Estudos apontam para a influência da variável porte analisando-a do ponto de vista da complexidade envolvida em empresas com maiores portes quando comparadas às empresas de menores portes. A lógica dessa relação de moderação se explica pela existência de um maior número de variáveis inseridas no processo de gestão das empresas de grande porte frente as empresas de pequeno porte, o que, teoricamente, exige um background maior por parte dos empreendedores, tornando-os capacitados para o gerenciamento dessas organizações. Por esse motivo, acredita-se que essa variável interfere na relação entre o background e a inovação de produtos.

Assim, nesse estudo, consideramos a seguinte hipótese genérica:

Hipótese 06: A relações entre o background do empreendedor e a inovação de produtos são mais significativas em empresas de maior porte do que naquelas de menor porte. 


\section{METODOLOGIA}

A presente sessão apresenta os aspectos metodológicos da pesquisa. Assim, a sessão está estruturada da seguinte forma: Na subseção 3.1 é apresentado a natureza e o método utilizado na pesquisa; na subseção 3.2 as variáveis e indicadores são definidos; na subseção 3.3 o modelo conceitual da pesquisa é apresentado; na subseção 3.4 são discutidos o universo e a amostra; na subseção 3.5 são apresentados os procedimentos de campo e instrumental; na subseção 3.6 são apresentadas as técnicas utilizadas para a análise dos dados; e, por fim, a subseção 3.7 apresenta as limitações metodológicas do estudo.

\subsection{NATUREZA E MÉTODO DA PESQUISA}

As posições metodológicas de uma pesquisa têm como ponto de partida o objetivo que ela apresenta. Observar o objetivo da pesquisa permite definir de maneira coerente o método a ser utilizado. Essa pesquisa, conforme apresentado na primeira seção, tem como objetivo analisar relações entre o background dos empreendedores e a inovação de produtos em Empresas Incubadas de Base Tecnológica no Estado de São Paulo, sendo a pergunta-problema definida da seguinte forma: O background do empreendedor influencia a inovação de produtos em empresas incubadas de base tecnológica no estado de São Paulo?

Tendo em vista as características da pergunta-problema e do objetivo geral da pesquisa, o presente estudo propõe-se de natureza quantitativa, uma vez que as relações entre as variáveis são testadas por meio da medição numérica, contagem e uso de estatísticas com vistas a identificar e entender padrões. A literatura aponta para dois diferentes enfoques de pesquisas: qualitativas e quantitativas. As pesquisas qualitativas, segundo Sampieri et al (2006, p. 5), "utiliza coleta de dados sem medição numérica para descobrir ou aperfeiçoar questões de pesquisa e pode ou não provar hipóteses em seu processo de interpretação". Já o enfoque quantitativo é definido por Sampieri et al (2006, p. 5) como aquele que "usa coleta de dados para testar hipóteses com base na medição numérica e na análise estatística para estabelecer padrões de comportamento".

A pesquisa apresenta o enfoque quantitativo devido às razões já citadas. Além do mais, a pesquisa é definida como correlacional, segundo o conceito de Sampieri et al (2006). Segundo 
esse autor, as pesquisas podem ser definidas como exploratórias, correlacionais, descritivas e explicativas. Os estudos do tipo exploratório "são realizados quando o objetivo consiste em examinar um tema pouco estudado" (Sampieri et al, 2006, p. 100). No caso do tema dessa pesquisa, existe uma quantidade satisfatória de estudos na literatura que podem fundamentar as hipóteses de pesquisa, portanto, não se trata de um estudo exploratório. Estudos do tipo correlacional "têm como objetivo avaliar a relação entre duas ou mais variáveis ou conceitos" (Sampieri et al, 2006, p. 104). Essa é a característica da presente pesquisa, haja vista que apresenta relações entre duas ou mais variáveis.

Estudos do tipo descritivo buscam "especificar propriedades e características importantes de qualquer fenômeno que se analise" (Sampieri et al, 2006, p. 102). A presente pesquisa não se encaixa nesse tipo de estudo, uma vez que, não busca meramente descrever um fenômeno, mas sim, analisar relações entre as variáveis que compõe o fenômeno. Por último, estudos do tipo explicativo "pretendem estabelecer as causas dos acontecimentos, fatos ou fenômenos estudados" (Sampieri et al, 2006, p. 105). Desse ponto de vista e seguindo os conceitos apresentados, a pesquisa também não se enquadra como explicativa. Em resumo, a pesquisa apresenta enfoque quantitativo, sendo definida como correlacional.

\subsection{DEFINIÇÃO DE VARIÁVEIS E INDICADORES}

O modelo de pesquisa que será apresentado na subseção 3.3 permite a identificação de cinco variáveis independentes, inderidas em dois constructos, uma variável independente e uma variável moderadora. Os constructos compostos pelas variáveis independentes são definidos como: (1) Educação do empreendedor e (2) Experiência do empreendedor. A variável dependente é a inovação de produtos, e a variável moderadora é o tamanho da organização.

\subsubsection{Constructos e Variáveis independentes}

Os constructos do modelo, já citados acima, são componentes do background do empreendedor, seja pela vertente da educação do empreendedor, seja pela experiência adquirida. Essas variáveis são descritas com maior detalhe a seguir. 


\subsubsection{Educação do empreendedor}

A educação do empreendedor é um constructo que compõe o background. É adquirida mediante a inserção do empreendedor em cursos universitários ou técnicos, assim como, em sua formação básica e cumprimento das séries do sistema educacional. Representa as informações que os empreendedores trazem consigo e permitem identificar o direcionamento da descoberta de oportunidades empreendedoras quando consideradas as informações que o empreendedor traz consigo. Esse constructo é mensurado mediante a utilização de duas variáveis, sendo elas: (1) Nível de formação dos empreendedores; e (2) Área de conhecimento do empreendedor; os quais são descritos adiante, nessa mesma ordem.

\section{Nível de Formação do empreendedor}

O nível de formação do empreendedor, conforme discutido na revisão da literatura, mostra-se uma importante variável no estudo do constructo educação e sua relação com a inovação de produtos. Sendo a inovação de produtos um reflexo de oportunidades empreendedoras e considerando as características inerentes ao processo de descoberta e exploração de oportunidades empreendedoras, a formação do empreendedor permite a obtenção de informações diferentes daquelas obtidas por outros. Assim, quanto mais informações, maior a probabilidade de o empreendedor identificar oportunidades empreendedoras, e, portanto, inovar em produtos.

Conforme discutido, essa afirmação se sustenta no conceito de assimetria da informação, considerada como o centro do processo empreendedor e aspecto que explica o porquê algumas pessoas descobrem e exploram oportunidades empreendedoras enquanto outras não. Nessa pesquisa, o nível de formação do empreendedor é uma das variáveis para mensuração da educação do empreendedor.

Para mensurar o nível de formação utiliza-se a escala de mensuração que considera a escolaridade (grau de instrução) como sendo, em ordem crescente: Ensino Fundamental; Ensino Médio; Ensino Profissionalizante; Ensino Superior; MBA/especialização lato sensu; Mestrado; Doutorado; e Pós-doutorado. 


\section{Área de conhecimento do Empreendedor}

A área de conhecimento do empreendedor é outra variável considerada no modelo. Essa variável permite a identificação da natureza das informações que os empreendedores possuem. Assim os empreendedores tendem a inovar em produtos de acordo com as informações que eles possuem, as quais são moldadas pela área de conhecimento escolhida.

Para mensurar essas áreas de conhecimento, nessa pesquisa, utiliza-se a classificação de áreas do conhecimento definida pela Capes (Coordenação de Aperfeiçoamento de Pessoal de Nível Superior). Segundo essa classificação, as seguintes áreas de conhecimento podem ser consideradas: (1) Ciências Exatas e da Terra; (2) Ciências Biológicas; (3) Engenharias; (4) Ciências da Saúde; (5) Ciências Agrárias; (6) Ciências Sociais Aplicadas; (7) Ciências Humanas; (8) Linguística, Letras e Artes; e (9) Interdisciplinar.

Essas nove áreas se desdobram em diversas outras subáreas, representadas pelos cursos de formação. Optou-se aqui por utilizar as áreas, uma vez que, elas já agrupam as subáreas, facilitando assim a sua mensuração e análise. Para clarificar mais o que foi exposto, pode-se citar, por exemplo, a área Ciências Exatas e da Terra, a qual abrange as seguintes subáreas: Matemática, probabilidade e estatística, ciências da computação, astronomia, física, química, geociências. As demais áreas também contêm suas respectivas subáreas.

No tratamento dos dados dessa pesquisa, os dados sobre a área de conhecimento do empreendedor foram considerados de maneira binária, sendo eles reunidos em torno de duas categorias: (1) Aquelas áreas mais próximas das ciências exatas (o que abrange as ciências exatas e da terra e as engenharias); e (2) Aquelas áreas mais distantes das ciências exatas (englobando aqui todas as outras áreas descritas anteriormente).

\subsubsection{Experiência do Empreendedor}

A experiência do empreendedor é a segunda variável que compõe o background do empreendedor. Essa variável é analisada na literatura do ponto de vista da experiência empreendedora, experiência industrial e experiência gerencial. A experiência empreendedora refere-se às experiências na criação de novos negócios e o nível de funções gerenciais assumidos; a experiência industrial refere-se à experiência do empreendedor na indústria na 
qual o negócio está inserido; e a experiência gerencial é a experiência total do empreendedor com gestão naquele setor industrial. Esses conceitos foram definidos por Lee e Tsang (2001) e apresentados no desenvolvimento teórico desse estudo.

Como variáveis para esse constructo, utilizam-se aqui a (1) área de atuação do empreendedor; (2) o tempo de atuação profissional do empreendedor na empresa; e (3) a experiência profissional do empreendedor em termos totais. Essas variáveis são detalhadas adiante.

\section{Área de atuação do empreendedor}

Analisando o lado da experiência dos empreendedores, a qual compõe o background juntamente com a formação, pode-se observar a variável área de atuação do empreendedor. Analisar a área de atuação do empreendedor permite observar o aspecto qualitativo da experiência. A experiência pode ser mensurada do ponto de vista quantitativo, em número de anos, o que não identifica a qualidade, a qual, somente pode ser mensurada analisando outros aspectos, dentre eles a área de atuação.

Conforme mencionado no desenvolvimento teórico desse estudo, a área de atuação pode refletir e direcionar a inovação por parte dos empreendedores. Isso por que a área de atuação concede ao empreendedor informações práticas, o que faz com que ele obtenha informações que poderão levá-lo a descobrir e explorar oportunidades empreendedoras ligadas àquela área de atuação.

Assim, como indicador da área de atuação, utiliza-se a seguinte classificação: (1) Contribuição com o capital, mas sem participação direta nas atividades da empresa; (2) Administrativo; (3) Assistência técnica; (4) Compras; (5) Contabilidade; (6) Financeiro; (7) Gestão de Pessoas; (8) Gestão Operacional; (9) Implantação; (10) Marketing; (11) Operações logísticas; (12) Pesquisa, desenvolvimento e inovação; (13) Planejamento; (14) Pós-venda comercial; (15) Produção; (16) Vendas e estudos de mercado; (17) outros.

No tratamento dos dados dessa pesquisa os dados foram reunidos em duas categorias com o objetivo de responder às hipóteses levantadas: (1) Áreas mais próximas da Pesquisa e Desenvolvimento (o que englobou Pesquisa e Desenvolvimento e Produção); e (2) Áreas mais 
distantes da Pesquisa e Desenvolvimento e Produção (o que engloba as demais áreas de atuação citadas anteriormente).

\section{Tempo de atuação profissional}

Essa variável, tempo de atuação profissional, reflete o lado quantitativo da mensuração da experiência. Especificamente, ela busca mensurar o tempo de atuação do empreendedor na empresa. Essa análise é importante por que coloca o empreendedor diante de dois tipos importantes de experiências apontadas na literatura e abordadas no desenvolvimento teórico desse estudo, sendo elas, a experiência de gestão e a experiência na indústria que a empresa está inserida.

A literatura aponta que a experiência em gestão e a experiência na indústria permitem ao empreendedor inovar em várias direções, sejam elas inovação de produtos, inovações organizacionais, inovação de modelo de negócios, dentre outras. Isso é possível devido às informações e conhecimentos que o empreendedor adquire no período em que está atuando na empresa. O conhecimento do mercado e das necessidades dos clientes, assim como, das contingências da indústria, permite ao empreendedor descobrir e explorar oportunidades empreendedoras ligadas àquele setor ou internas à própria empresa.

\section{Experiência profissional do empreendedor}

A experiência profissional do empreendedor, em termos totais, também é um importante indicador a ser considerado. Essa variável reflete a experiência do empreendedor não somente na empresa e naquela indústria específica, mas também, em outras empresas, muitas vezes pertencentes a outras indústrias. Isso agrega ao empreendedor conhecimentos que podem o tornar distinto dos demais, refletindo assim na identificação e exploração de oportunidades empreendedoras e, consequentemente, fomenta a inovação.

O cruzamento de informações de diferentes setores, diferentes métodos de organização e atuação, podem conceber aos empreendedores importantes insights para inovações nas organizações. Esse indicador é mensurado mediante o tempo de experiência do empreendedor, sendo considerado aqui o tempo total de experiência, independente de qual empresa ele tenha atuado antes. 


\subsubsection{Variável dependente do modelo}

A variável dependente do modelo, conforme demonstrado na sessão 3.2, é a inovação de produto. Acredita-se que a inovação sofra influência do background do empreendedor. Inovação de produto, conforme descrito no desenvolvimento teórico, é parte componente da Inovação Tecnológica em Produtos e Processos (OECD, 1997). Especificamente, a inovação de produto pode se referir a produtos tecnologicamente novos lançados no mercado, ou produtos tecnologicamente aprimorados e inseridos no mercado.

Assim, um produto tecnologicamente novo, segundo $\operatorname{OECD}(1997$, p. 32),

\footnotetext{
"é aquele cujas características tecnológicas ou usos pretendidos se diferem daqueles produtos produzidos anteriormente. Tais inovações podem envolver tecnologias radicalmente novas, podem basear-se na combinação de tecnologias existentes em novos usos, ou podem ser derivadas do uso de novo conhecimento".
}

Por outro lado, um produto tecnologicamente aprimorado é definido como:

\footnotetext{
“Um produto existente cujo desempenho tenha sido significativamente aprimorado ou elevado. Um produto simples pode ser aprimorado (em termos de melhor desempenho ou menor custo) através de componentes ou materiais de desempenho melhor, ou um produto complexo que consista em vários subsistemas técnicos integrados pode ser aprimorado através de modificações parciais em um dos subsistemas" (OECD, 1997, p. 32).
}

Nessa pesquisa, busca-se mensurar a inovação de produtos mediante análise dos produtos tecnologicamente novos. Assim, o indicador utilizado para a mensuração dessa variável é o número de lançamento de novos produtos. Esse indicador é apresentado na literatura e foi escolhido por se configurar uma medida absoluta e de maior praticidade na coleta.

No tratamento dos dados dessa pesquisa considerou-se, para efeitos de aplicação da técnica estatística escolhida, a existência ou não de inovação nas empresas, analisando se a empresa tem inovações em produtos ou se essas empresas não têm. 


\subsubsection{Variável Moderadora}

A variável "tamanho da organização" é vista como uma variável moderadora da variável dependente "Inovação de Produtos" e das variáveis independentes do dispostas no modelo. É assim considerada por que, conforme apresentado no desenvolvimento teórico, essa variável pode impactar a relação entre as variáveis, moderando o resultado apresentado nessa relação.

Variável moderadora é definida como:

"Uma variável, qualitativa ou quantitativa, que afeta a direção e/ou a força da relação entre uma variável independente ou uma variável preditora e uma variável dependente. Especificamente em um framework de análise correlacional, uma variável moderadora é uma terceira variável que afeta a correlação de ordem zero entre duas outras variáveis" (Baron e Kenny, 1986, p. 1174).

Como indicador da variável "Tamanho da Organização" será utilizado o número de funcionários da organização. Assim, para efeitos de testes da hipótese 06, a análise foi realizada mediante a divisão entre empresas maiores e menores, de acordo com a média de funcionários daquela empresa, sendo que, aquelas empresas com número de funcionários maior que a média foram consideradas empresas maiores, enquanto que, empresas com número de funcionários abaixo da média foram consideradas empresas menores.

\subsection{MODELO CONCEITUAL (DESIGN) E HIPÓTESES DA PESQUISA}

O modelo desenhado abaixo permite a visualização das relações entre as variáveis explicativas e a variável dependente, que é a inovação de produtos, que representa também a descoberta de oportunidades empreendedoras. Essas variáveis são fundamentadas e construídas com base na revisão da literatura sobre traços do empreendedor, características do empreendedor e seus impactos na descoberta de oportunidades empreendedoras. O modelo ilustrado na figura 03 representa as hipóteses levantadas na sequência. 


\section{Figura 03. Modelo Conceitual do Estudo}

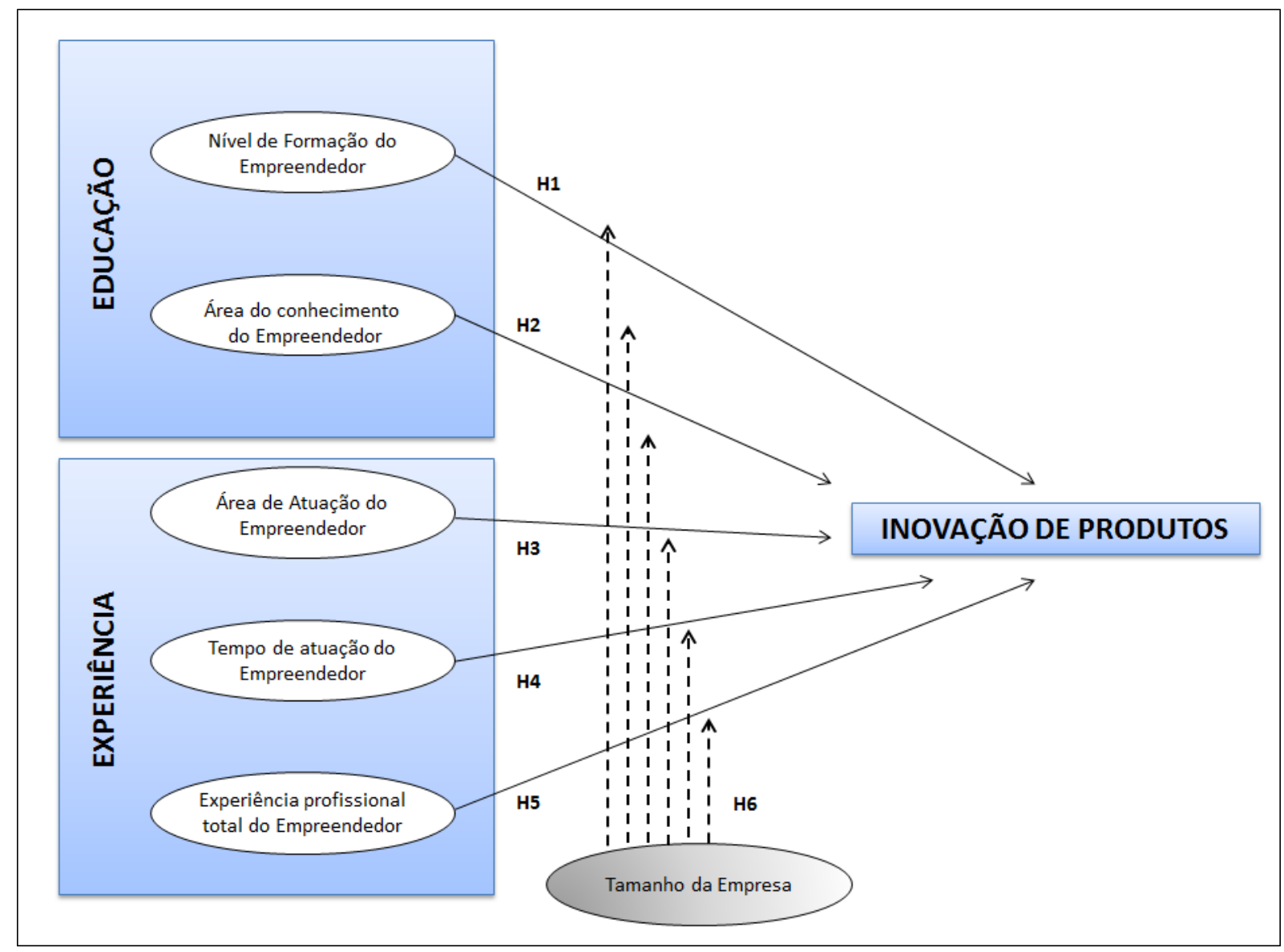

Fonte: Elaborado pelo autor

\subsubsection{Hipóteses da pesquisa}

De acordo com as discussões teóricas deste estudo, algumas hipóteses foram levantadas. A primeira delas diz respeito ao nível de formação do empreendedor e sua relação com a inovação de produtos, sendo ela:

Hipótese 01: O nível de formação do empreendedor é positivamente relacionado com a inovação de produtos.

Como lidamos aqui com empresas incubadas de base tecnológica e considerando que a literatura aponta para a assimetria da informação como algo fundamental na descoberta de oportunidades empreendedoras, as seguintes hipóteses também foram levantadas: 
Hipótese 02: Empreendedores com formações mais próximas das ciências exatas inovam mais em produtos do que aqueles cujas formações são mais próximas das ciências humanas.

Assim como a formação, a área de atuação do empreendedor também se mostra uma variável importante que compõe o background do empreendedor. Acredita-se, dessa forma, que quanto mais próximos das áreas de produção e desenvolvimento de novos produtos, maior a inovação em produtos. Portanto, a seguinte hipótese também é considerada no modelo:

Hipótese 03: Empreendedores que atuam em áreas mais próximas da produção e desenvolvimento de novos produtos inovam mais em produtos que empreendedores que atuam em áreas mais distantes das citadas.

Considerando a natureza técnica que envolve as atividades das empresas incubadas de base tecnológica, e fundamentando nas evidências empíricas e estudos anteriormente apresentados, acredita-se que a experiência do empreendedor na indústria em que está inserido e em gestão pode influenciar positivamente nas descobertas de oportunidades empreendedoras que permitam a inovação em produtos. Isso devido ao conhecimento e habilidades adquiridas ao longo das experiências nos negócios em que atuou anteriormente, ou até mesmo, as experiências adquiridas ao longo da atuação na própria empresa. Assim, as seguintes hipóteses foram levantadas:

Hipótese 04: A experiência do empreendedor em termos totais está positivamente relacionada com a inovação em produtos.

Hipótese 05: A experiência de atuação do empreendedor na empresa está positivamente relacionada com a inovação em produtos.

Além do mais, acredita-se que as hipóteses anteriores são moderadas por outra variável, definida aqui como o "Porte da Empresa". Algumas pesquisas, assim como mencionado no desenvolvimento teórico, evidenciaram a importância da variável tamanho da organização para entender a influencia do conhecimento e experiência do empreendedor no desempenho da empresa. 
Estudos apontam para a influência da variável porte analisando-a do ponto de vista da complexidade envolvida em empresas com maiores portes quando comparadas às empresas de menores portes. A lógica dessa relação de moderação se explica pela existência de um maior número de variáveis inseridas no processo de gestão das empresas de grande porte frente as empresas de pequeno porte, o que, teoricamente, exige um background maior por parte dos empreendedores, tornando-os capacitados para o gerenciamento dessas organizações. Por esse motivo, acredita-se que essa variável interfere na relação entre o background e a inovação de produtos.

Assim, nesse estudo, consideramos a seguinte hipótese genérica:

Hipótese 06: A relações entre o background do empreendedor e a inovação de produtos são mais significativas em empresas de maior porte do que naquelas de menor porte.

\subsection{UNIVERSO E AMOSTRA}

O universo e a amostra da pesquisa são apresentados adiante.

\subsubsection{O universo da pesquisa}

O Estado de São Paulo, dentre os estados Brasileiros, é o que apresenta maior número de incubadoras de empresas. A prática de incubação no estado encontra apoio em programas institucionais da Secretaria de Desenvolvimento Econômico, Ciência, Tecnologia e Inovação (SEDECTI), a exemplo do Sistema Paulista de Ambientes de Inovação (SPAI), instituído pelo decreto $\mathrm{n}^{\circ} 60.286$ de 25.03.2014.

Um relatório desenvolvido pela SEDECTI (2013) levantou a quantidade de incubadoras de empresas de base tecnológica no estado de São Paulo. Esse relatório aponta para um universo de 34 incubadoras de empresas. Essas incubadoras foram encontradas mediante prospecção nos sites da SEDECTI, do Serviço Brasileiro de Apoio às Micro e Pequenas Empresas (SEBRAE), além de sites das universidades paulistas, a saber: Universidade de São Paulo (USP); Universidade Estadual de Campinas (UNICAMP); e Universidade Estadual Paulista "Júlio de Mesquita Filho" (UNESP). 
As incubadoras levantadas pela SEDECTI estão apresentadas no quadro a seguir:

\section{Quadro 04: Lista de Incubadoras no Estado de São Paulo}

\section{Nome da Incubadora}

Incubadora de Empresas de Araraquara

Incubadora Empresarial de Bebedouro - ADEBE

Incubadora de Base Tecnológica de Botucatu - PROSPECTA

Núcleo Softex Campinas - Incubadora e Funding

Companhia de Desenvolvimento do Polo de Alta Tecnologia de Campinas -

CIATEC

Incubadora de Empresas de Base Tecnológica da Unicamp - INCAMP

Incubadora de Empresas de Garça

Incubadora Agende Guarulhos

Incubadora de Empresas de Jacareí

Incubadora de Empresas de Jundiaí

Incubadora de Empresas de Lins

Centro Incubador de Empresas Miguel Silva

Centro de Inovação, Empreendedorismo e Tecnologia - CIETEC ${ }^{1}$

Incubadora de Empresas de Osasco

EsalqTec - Incubadora Tecnológica

Incubadora de Empresas de Piracicaba

Incubadora Tecnológica de Presidente Prudente - INTEPP

Incubadora de Empresas de Base Tecnológica - SUPERA

Incubadora de Empresas de Santo André

Incubadora de Empresas de Santos

Centro de Desenvolvimento das Indústrias Nascentes - CEDIN

Centro Incubador de Empresas de Software - Softnet

Centro Incubador de Empresas Tecnológicas - CINET

Incubadora de Design

Incubadora de Empresas de São José do Rio Preto - CIE Rio Preto

Incubadora Tecnológica UNIVAP

CECOMPI - Empreendedorismo e Inovação Sustentável

Incubadora Tecnológica UNIVAP REVAP

Incubaero - Incubadora Aeronáutica

Incubadora de Empresas Mackenzie

Centro de Inovação, Empreendedorismo e Tecnologia - CIETEC

Incubadora Tecnológica de Empresas de Sorocaba - INTES

Fonte: SDECTI, 2013.

\section{Município}

Araraquara

Bebedouro

Botucatu

Campinas

Campinas

Campinas

Garça

Guarulhos

Jacareí

Jundiaí

Lins

Marília

Mogi das Cruzes

Osasco

Piracicaba

Piracicaba

Presidente Prudente Ribeirão Preto

Santo André

Santos

São Carlos

São Carlos

São Carlos

São Carlos

São José do Rio Preto

São José dos Campos

São José dos Campos

São José dos Campos

São José dos Campos

São Paulo

São Paulo

Sorocaba

Como o objeto da pesquisa são as Empresas Incubadas de Base Tecnológica, o universo dessa pesquisa é representado pelo montante dessas empresas. O quadro adiante apresenta esse quantitativo, definindo assim, o universo dessa pesquisa:

\footnotetext{
${ }^{1}$ O Centro de Inovação, Empreendedorismo e Tecnologia - Mogi das Cruzes é uma unidade do CIETEC.
} 
Quadro 05: Número de Empresas Incubadas nas Incubadoras

\begin{tabular}{|c|c|c|c|}
\hline Nome da Incubadora & Município & $\begin{array}{l}\text { Qtde. de } \\
\text { Empresas }\end{array}$ & Fonte \\
\hline Incubadora de Empresas de Araraquara & Araraquara & 14 & Site \\
\hline Incubadora Empresarial de Bebedouro - ADEBE & Bebedouro & 13 & Site \\
\hline $\begin{array}{l}\text { Incubadora de Base Tecnológica de Botucatu - } \\
\text { PROSPECTA }\end{array}$ & Botucatu & 17 & Site \\
\hline Núcleo Softex Campinas - Incubadora e Funding & Campinas & 08 & INCAMP \\
\hline $\begin{array}{l}\text { Companhia de Desenvolvimento do Polo de Alta } \\
\text { Tecnologia de Campinas - CIATEC }\end{array}$ & Campinas & 20 & CIATEC \\
\hline $\begin{array}{l}\text { Incubadora de Empresas de Base Tecnológica da } \\
\text { Unicamp - INCAMP }\end{array}$ & Campinas & 03 & Softex \\
\hline Incubadora de Empresas de Garça & Garça & 17 & Site \\
\hline Incubadora Agende Guarulhos & Guarulhos & 20 & Site \\
\hline Incubadora de Empresas de Jacareí & Jacareí & 10 & Site \\
\hline Incubadora de Empresas de Jundiaí & Jundiaí & 12 & Site \\
\hline Incubadora de Empresas de Lins & Lins & 23 & Lins \\
\hline Centro Incubador de Empresas Miguel Silva & Marília & 10 & CIEM \\
\hline $\begin{array}{l}\text { Centro de Inovação, Empreendedorismo e Tecnologia } \\
\text { - CIETEC }^{2}\end{array}$ & Mogi das Cruzes & - & - \\
\hline Incubadora de Empresas de Osasco & Osasco & 09 & Site \\
\hline EsalqTec - Incubadora Tecnológica & Piracicaba & 07 & EsalqTec \\
\hline Incubadora de Empresas de Piracicaba & Piracicaba & 11 & Site \\
\hline $\begin{array}{l}\text { Incubadora Tecnológica de Presidente Prudente - } \\
\text { INTEPP }\end{array}$ & Presidente Prudente & 06 & INTEPP \\
\hline $\begin{array}{l}\text { Incubadora de Empresas de Base Tecnológica - } \\
\text { SUPERA }\end{array}$ & Ribeirão Preto & 13 & Supera \\
\hline Incubadora de Empresas de Santo André & Santo André & 13 & Site \\
\hline Incubadora de Empresas de Santos & Santos & 0 & Santos \\
\hline $\begin{array}{l}\text { Centro de Desenvolvimento das Indústrias Nascentes } \\
\text { - CEDIN }\end{array}$ & São Carlos & 13 & CEDIN \\
\hline Centro Incubador de Empresas de Software - Softnet & São Carlos & 05 & Site \\
\hline Centro Incubador de Empresas Tecnológicas - CINET & São Carlos & 20 & Site \\
\hline Incubadora de Design & São Carlos & 05 & Site \\
\hline $\begin{array}{l}\text { Incubadora de Empresas de São José do Rio Preto - } \\
\text { CIE Rio Preto }\end{array}$ & $\begin{array}{l}\text { São José do Rio } \\
\text { Preto }\end{array}$ & 14 & Site \\
\hline Incubadora Tecnológica UNIVAP & $\begin{array}{l}\text { São José dos } \\
\text { Campos }\end{array}$ & 06 & Site \\
\hline $\begin{array}{l}\text { CECOMPI - Empreendedorismo e Inovação } \\
\text { Sustentável }\end{array}$ & $\begin{array}{l}\text { São José dos } \\
\text { Campos }\end{array}$ & 13 & CECOMPI \\
\hline Incubadora Tecnológica UNIVAP REVAP & $\begin{array}{l}\text { São José dos } \\
\text { Campos }\end{array}$ & 06 & REVAP \\
\hline Incubaero - Incubadora Aeronáutica & $\begin{array}{l}\text { São José dos } \\
\text { Campos }\end{array}$ & 08 & Site \\
\hline Incubadora de Empresas Mackenzie & São Paulo & 07 & Site \\
\hline $\begin{array}{l}\text { Centro de Inovação, Empreendedorismo e Tecnologia } \\
\text { - CIETEC }\end{array}$ & São Paulo & 125 & CIETEC \\
\hline $\begin{array}{l}\text { Incubadora Tecnológica de Empresas de Sorocaba - } \\
\text { INTES }\end{array}$ & Sorocaba & 13 & INTES \\
\hline \multicolumn{2}{|l|}{ ( } & 461 & \\
\hline
\end{tabular}

Fonte: SDECTI, 2013

\footnotetext{
${ }^{2}$ O Centro de Inovação, Empreendedorismo e Tecnologia - Mogi das Cruzes é uma unidade do CIETEC.
} 
Conforme aponta o quadro dois, o universo de Empresas Incubadas com o qual se está lidando é de 461 empresas. Como a unidade de análise são os Empreendedores dessas empresas incubadas, tem-se que a população é desconhecida, uma vez que as empresas podem ter mais que um sócio.

\subsubsection{A amostra da pesquisa}

A população da pesquisa, conforme apresentado na sessão anterior, é composta pelos Empreendedores das Empresas Incubadas de Base Tecnológica, sendo, portanto, desconhecida. Conceitualmente, uma amostra representa um subgrupo da população, sendo, assim, um subconjunto de elementos que pertencem a esse conjunto (Sampieri et al, 2006) e que representam as características da população.

A característica principal que define a população da pesquisa é que a unidade de análise aqui definida está relacionada diretamente com empresas Incubadas de Base Tecnológica. Assim, somente serão considerados para motivos de pesquisa aqueles empreendedores cuja empresa que está vinculado desenvolva alguma atividade de base tecnológica, e, além disso, que esteja vinculado a alguma Incubadora de Empresas. Isso já define um direcionamento para a seleção da amostra.

Assim, formalizando a definição da amostra nessa pesquisa: A amostra é composta por empreendedores de empresas cujas atividades desenvolvidas sejam de base tecnológica e que estejam vinculadas a alguma Incubadora de Empresas de Base Tecnológica (IEBT).

Do ponto de vista da seleção da amostra, a literatura aponta para dois tipos: Probabilísticas e não probabilísticas. A amostra probabilística, segundo Sampieri et al (2006, p. 254), reflete o "subgrupo da população no qual todos os elementos possuem a mesma probabilidade de serem escolhidos". Esse tipo de amostra se divide em: seleção sistemática; aleatória; por conglomerados; e estratificada. Por outro lado, as amostras não probabilísticas são definidas como o "subgrupo da população no qual a escolha dos elementos não depende da probabilidade, e sim das características da pesquisa" (Sampieri et al, 2006, 255). Essas amostras não probabilísticas dividem-se em: qualitativa; por cotas; de indivíduos-tipo; de especialistas; de indivíduos voluntários (Sampieri et al, 2006). Outros autores, como Sweeney, Williams e Anderson (2013) apontam ainda a amostra por conveniência e a amostra por julgamento. 
Tendo em vista que, o que define a característica probabilística ou não probabilista da amostra de uma pesquisa é o objetivo que a mesma possui, o tipo de pesquisa e a contribuição que se pensa fazer com ela (Sampieri et al, 2006), tem-se que essa pesquisa, pelas características que a define, é uma pesquisa cuja amostra é não probabilística. Essa escolha justifica-se aqui pela praticidade garantida à pesquisa pela amostragem não probabilística por conveniência. Haja vista a quantidade de Empresas Incubadas de Base Tecnológicas distribuídas em todo o território do estado de São Paulo, a amostra por conveniência mostrou-se mais adequada e coerente com as limitações de recursos na execução da pesquisa.

Conceitualmente, Sweeney, Williams e Anderson (2013) apontam que na amostragem por conveniência os elementos são incluídos na amostra sem probabilidades preespecificadas de seleção ou que sejam conhecidas. Esse tipo de amostragem, segundo os autores, facilita a seleção da amostra e a coleta de dados. Porém, como ônus, torna-se impossível avaliar a qualidade da mostra quando se refere à representatividade da população.

Uma vez apresentadas as definições necessárias, descreve-se aqui a quantidade da amostra obtida nessa pesquisa. Após a aplicação dos questionários ao universo de empresas incubadas foi alcançado o número de 112 respondentes. Destes, oito questionários foram eliminados por se tratar de empresas não vinculadas a alguma incubadora do estado de São Paulo, e 09 foram eliminados por terem sido respondidos por colaboradores das empresas, o que fugia do objeto da pesquisa. Portanto, a presente pesquisa foi desenvolvida em cima de uma amostra de 95 empreendedores de empresas incubadas de base tecnológica do estado de São Paulo, o que representa 20,60\% das empresas incubadas identificadas no estado de São Paulo.

\subsection{PROCEDIMENTOS DE CAMPO E INSTRUMENTAL}

A condução da coleta de dados de uma pesquisa perpassa por alguns passos importantes, sendo eles: seleção do instrumento; aplicação; codificação; e preparação para a análise (Sampieri et al, 2006). Esses passos, no entanto, dependem ainda do enfoque da pesquisa, podendo se diferenciar quando considerando os enfoques quantitativo e qualitativo. A definição do enfoque é importante para que o instrumental de pesquisa escolhido seja coerente e cumpra a coleta dos dados necessários para a pesquisa. 
Em um enfoque qualitativo, a coleta de dados ocorre por meio de entrevistas, observações, sessões em profundidade. Esses instrumentos permitem a coleta dos dados e devem ser confiáveis e validos. Já o enfoque quantitativo implica na medição, utilizando, para tanto, análises de conteúdo, observação ou testes padronizados, questionários, dentre outros. Esses instrumentos também requerem confiabilidade e validade (de constructo, critério e conteúdo) (Sampieri et al, 2006).

Tendo em vista a natureza quantitativa da pesquisa, o instrumento de coleta e o procedimento de campo são descritos adiante.

\subsubsection{Instrumentos de pesquisa}

O instrumento utilizado na pesquisa foi o questionário, o qual foi respondido pelos empreendedores das empresas incubadas, durante o ano de 2013. O questionário é composto por 48 questões, divididas em seis blocos, sendo eles: (1) Qualificação; (2) Caracterização do colaborador; (3) Caracterização do sócio empreendedor; (4) Caracterização da empresa; (5) Percepção da incubadora pela empresa incubada; (6) Pesquisa, desenvolvimento e inovação; e, por último, (7) Identificação.

Sampieri et al (2006) aponta que o questionário é, talvez, o instrumento mais utilizado em coletas de dados. Os autores conceituam o questionário como "um conjunto de questões com relação a uma ou mais variáveis a serem medidas" (Sampieri et al, 2006, p. 325). O questionário é constituído, em sua maioria, por questões fechadas, com poucas questões abertas, sendo elas, objetivas de tal forma que se torna possível de serem codificadas.

\subsubsection{Procedimento de campo}

O campo foi realizado em um processo que envolveu a aplicação do questionário via web SurveyGizmo para as Empresas Incubadas de Base Tecnológica (IEBTs). O questionário foi inserido na plataforma web SurveyGizmo na internet, estruturado dinamicamente para facilitar as respostas, e então, enviado para o mailing list das Empresas Incubadas de Base Tecnológica ligadas às Incubadoras de Empresas no Estado de São Paulo. 
Assim, o campo configurou-se em duas fases. A primeira delas foi o pré-teste, etapa que permitiu testar o instrumento de pesquisa e aprimorá-lo conforme os resultados obtidos. $\mathrm{O}$ pré-teste foi aplicado a algumas empresas incubadas ligadas a três incubadoras de empresas: A Incubadora do CIETEC; a incubadora da Mackenzie; e a Incubadora Tecnológica de Empresas de Sorocaba. Essa etapa também foi aplicada via web SurveyGizmo e acompanhada a distância mediante ligações telefônicas.

Após pré testar os questionários, e uma vez realizado os ajustes necessários, eles foram enviados para as Empresas Incubadas de Base Tecnológica das Incubadoras em todo o Estado. Com o objetivo de se alcançar a amostra, os questionários foram enviados para todas as IEBTs ligadas a Incubadoras de Empresas no Estado de São Paulo. O link do questionário foi enviado via e-mail para as IEBTs e as respostas foram acompanhadas na plataforma web SurveyGizmo. Aqueles que não responderam foram contatados via telefone. As ligações foram realizadas via Skype para que os custos da pesquisa fossem viáveis.

Lembretes foram realizados via Skype semanalmente, por meio de ligação pessoal, durante toda a fase de campo da pesquisa, com vistas a aumentar o máximo possível o número de respostas, alcançando assim, a amostra necessária.

Ao final da fase de campo, os questionários respondidos foram tratados, e as respostas codificadas quando necessárias, para que pudessem ser inseridas no IBM SPSS Statistics para que as técnicas multivariadas necessárias pudessem ser aplicadas. As técnicas de análise dos dados utilizadas nessa fase estão descritas com mais detalhes na sessão adiante.

\subsection{ANÁLISE DOS DADOS}

As variáveis "formação do empreendedor"; “área do conhecimento do empreendedor”; "área de atuação do empreendedor"; e "tamanho da empresa" foram estruturados no questionário como sendo não métricos, enquanto que as variáveis "tempo de atuação do empreendedor na empresa" e "experiência profissional total do empreendedor" foram estruturados como métricos.

Essa definição dos indicadores e sua distinção entre métricos e não métricos é crítica, pois, permite a seleção das melhores técnicas de análise de dados aplicáveis ao modelo. Tendo em 
vista a dinâmica do modelo e as características de dependência das variáveis, a técnica de dependência Regressão Logística foi usada para testar as hipóteses, conforme apresentadas no quadro 05.

\section{Quadro 06. Resumo das hipóteses do modelo}

\begin{tabular}{|c|c|}
\hline Hipóteses & Técnicas \\
\hline Hipótese 01 & Regressão Logística \\
\hline Hipótese 02 & Regressão Logística \\
\hline Hipótese 03 & Regressão Logística \\
\hline Hipótese 04 & Regressão Logística \\
\hline Hipótese 05 & Regressão Logística \\
\hline Hipótese 06 & Regressão Logística considerando a variável moderadora "porte" da organização. \\
\hline
\end{tabular}

Fonte: Elaborado pelo autor

As hipóteses H1, H2, H3, H4, H5 e H6 foram testadas mediante a aplicação da técnica de dependência "regressão logística". A técnica de regressão logística mostrou-se a mais adequada para se testar as hipóteses levantadas, pois, as hipóteses envolvem variáveis independentes (explicativas) métricas ou dicotômicas, para a previsão de uma variável dependente binária. A variável dependente do modelo, inovação de produtos, é uma variável métrica. Portanto, para que a técnica estatística pudesse ser aplicada, a variável foi transformada em binária, considerando dois fatores: empresas que inovam em produtos (1) e empresas que não inovam em produtos (0).

Os dados foram analisados em dois momentos. No primeiro consideraram-se todas as variáveis, rodando os dados considerando todos os casos. Em um segundo momento, os dados foram rodados considerando o efeito moderador da variável "Porte da Organização", logo, para esse momento, os casos foram agrupados entre aqueles que representam empresas de maior porte e aqueles representantes de empresas com menor porte, sendo o porte mensurado aqui mediante o número de empregados. As técnicas utilizadas para o teste das variáveis foram as mesmas descritas anteriormente, havendo apenas a distinção dos casos.

\subsection{PRINCIPAIS LIMITAÇÕES DO ESTUDO}

Mapear Empresas Incubadas de Base Tecnológica em um estado com as dimensões de São Paulo implica a lida com algumas limitações importantes de serem listadas aqui. A primeira delas é materializada na distância e distribuição dessas incubadoras de empresas dentro do estado de São Paulo. Apesar do desenvolvimento da pesquisa ter sido realizado via 
ferramentas digitais e com o uso da internet, essa distância implicou em custos maiores para o desenvolvimento da pesquisa, diante da necessidade de deslocamento até algumas dessas incubadoras para que a pesquisa fosse viabilizada e as respostas aos questionários fossem realmente efetivadas.

Além dessas limitações práticas, existem também as limitações originadas da própria delimitação da pesquisa. Isto é, como a pesquisa foi delimitada para o estado de São Paulo, provavelmente, os resultados encontrados não correspondem à realidade de outras incubadoras localizadas em outras regiões que não dentro do estado de São Paulo. Portanto, a generalização dos resultados não é possível, especialmente quando considerado as diferenças regionais resultantes das dimensões do território brasileiro, cujas disparidades econômicas implicam em prováveis diferenças significativas também entre as Incubadoras de Empresas de Base Tecnológicas e, consequentemente, entre as Empresas Incubadas de Base Tecnológica (IEBTs).

Uma vez que o problema de pesquisa, além de ser delimitado em termos da definição do estado de São Paulo como alvo da pesquisa, é delimitado também para o background do empreendedor, surge aqui outra limitação, de natureza conceitual. A inovação de produtos nas organizações, segundo evidências da literatura, depende de uma série de outros fatores, a exemplo da cultura da organização, do ambiente onde a empresa está inserida, dos incentivos que essa empresa encontra para inovar, linhas de financiamentos destinadas à inovação, dentre outros fatores, o que concede ao fenômeno da inovação, seja ela de produto, de processo, organizacional ou de marketing, uma complexidade bastante elevada.

Dado essa complexidade, seria bastante pretencioso querer entender a inovação de produtos analisando apenas as características pessoais que compõe o background dos empreendedores. Assim, o objetivo desse trabalho vai ao encontro do entendimento de apenas um fator dentre os vários que compõe e explicam a inovação de produtos, que é o background do empreendedor. Diante disso, outros estudos são bem vindos no sentido de compreender os demais fatores, para assim, obter-se uma visão mais integrada do fenômeno, à altura da complexidade que ele exige. Como um estudo mais integrado referente ao fenômeno da inovação de produtos em empresas incubadas de base tecnológica no estado de São Paulo exige um tempo que transcende aos limites disponíveis para o desenvolvimento da pesquisa, 
optou-se pela delimitação apenas ao background do empreendedor, assumindo essa limitação conceitual.

Outra delimitação resultante do estudo é que o questionário somente captou a área de atuação do empreendedor na empresa, desconsiderando as áreas de atuação do empreendedor ao longo da sua experiência total. Isso implica que o estudo considera o background do empreendedor, no que toca à experiência em áreas de atuação, no período em que o empreendedor atua na empresa, sendo, portanto, necessários novos estudos que captem a área de atuação do empreendedor ao longo da sua experiência total.

Além disso, outra importante limitação assumida nesse estudo, é que a inovação de produtos foi considerada apenas pelo indicador "lançamento de novos produtos", desconsiderando o lançamento de serviços, que também compõe o conceito de inovação de produtos de acordo com OCDE (1997). Portanto, esse estudo indica a associação entre o background do empreendedor e a inovação de produtos, e não inovação de serviços.

O procedimento de campo também apresenta algumas limitações além daquelas apontadas no início dessa seção. A principal limitação desse método é o acesso às empresas incubadas. Naturalmente, esse acesso precisa ser consenso e permitido pelas empresas incubadas de base tecnológica, o que pode, eventualmente, resultar em questionários não respondidos por razão do não consentimento quanto à participação por parte dos empreendedores de algumas dessas empresas. Tentar-se-á minimizar essa limitação mediante a argumentação e convencimento dos respondentes quanto à importância das suas participações nas respostas aos questionários da pesquisa.

Além disso, outra limitação proveniente do procedimento de campo é que o questionário é enviado ao respondente, o qual, à distância, o responderá. Isso não permite um controle efetivo de quem realmente responderá ao questionário. O questionário é direcionado ao gestor da organização, tendo essa premissa espaço nas indicações iniciais do questionário, e, portanto, nesse ponto, espera-se um bom senso por parte dos respondentes para que ele seja respondido pelo publico alvo para o qual é destinado.

Diante disso, e ainda considerando limitações do procedimento de campo, a aplicação do questionário, por experiências prévias de pesquisa, poderá resultar em data missing que 
precisam ser identificados, trabalhados, e, caso seja necessário para uma melhor aplicação da técnica, o questionário será descartado, descartando assim aqueles casos cujo data missing tenha inviabilizado a aplicação da técnica de análise estatística. 


\section{RESULTADOS}

Uma vez fundamentado teoricamente a pesquisa e apresentados os aspectos metodológicos que a moldou apresenta-se agora os resultados alcançados e as discussões. Para tanto, esta seção está dividida entre (1) a descrição dos resultados, com a apresentação das tabelas de resultados estatísticos e (2) Análise e discussão dos resultados, com a inter-relação entre os resultados alcançados e a teoria que os fundamentam.

\subsection{DESCRIÇÃO DOS RESULTADOS}

Os dados obtidos com a aplicação dos questionários foram tabulados e analisados utilizandose, para isso, a técnica de Regressão Logística. A regressão logística, segundo Fávero et al (2009), “é uma técnica utilizada para descrever comportamento entre uma variável dependente binária e variáveis independentes métricas ou não métricas”. Os resultados são apresentados nessa seção, iniciando-se pela apresentação das frequências de cada variável, conforme apontado adiante.

\subsubsection{Análise de Frequências}

As análises de frequências serão apresentadas, iniciando-se pela variável dependente e seguindo pelas variáveis independentes do modelo. A variável dependente do modelo, inovação de produtos, é uma variável binária, centrada em duas ações possíveis: inova ou não inova em produtos. $\mathrm{O}$ resultado da frequência é apontado na tabela 1 adiante:

\section{Tabela 01}

Frequência das empresas que inovam em produtos

\begin{tabular}{|c|c|c|c|c|c|}
\hline \multicolumn{2}{|c|}{} & Frequência & Porcentual & $\begin{array}{c}\text { Porcentagem } \\
\text { válida }\end{array}$ & $\begin{array}{c}\text { Porcentagem } \\
\text { acumulativa }\end{array}$ \\
\hline \multirow{3}{*}{ Válido } & Não & 45 & 47,4 & 47,4 & 47,4 \\
\cline { 2 - 6 } & Sim & 50 & 52,6 & 52,6 & 100,0 \\
\cline { 2 - 6 } & Total & 95 & 100,0 & 100,0 & \\
\hline
\end{tabular}

Fonte: Elaborada pelo autor com base nos dados analisados

Conforme aponta a tabela acima, 47,4\% das empresas incubadas de base tecnológica analisadas não inovaram em produtos, enquanto que 52,6\% inovaram. Isso aponta para a 
existência de variância entre as empresas que inovam e aquelas que não inovam, indicando a ausência de heterocedasticidade para essa variável, cumprindo assim uma das premissas assumidas pela regressão logística.

Uma vez analisado a frequência da variável dependente do modelo serão apresentadas adiante as análises de frequências das variáveis independentes do modelo. Iniciando-se pela apresentação da frequência da variável grau de instrução, demonstrada na tabela 02, adiante:

\section{Tabela 02}

Grau de Instrução do Empreendedor

\begin{tabular}{|l|c|c|c|c|}
\hline & Frequência & Porcentual & $\begin{array}{c}\text { Porcentagem } \\
\text { válida }\end{array}$ & $\begin{array}{c}\text { Porcentagem } \\
\text { acumulativa }\end{array}$ \\
\hline Ensino Médio & 6 & 6,3 & 6,3 & 6,3 \\
Ensino & 5 & 5,3 & 5,3 & 11,6 \\
Profissionalizante & 29 & 30,5 & 30,5 & 42,1 \\
Ensino Superior & 22 & 23,2 & 23,2 & 65,3 \\
MBA/Especialização & 12 & 12,6 & 12,6 & 77,9 \\
Lálido Sensu & 8 & 8,4 & 8,4 & 86,3 \\
Mestrado & 13 & 13,7 & 13,7 & 100,0 \\
Doutorado & 95 & 100,0 & 100,0 & \\
Pós-doutorado & & & \\
Total & &
\end{tabular}

Fonte: Elaborado pelo autor com base nos dados coletados.

A tabela 02 aponta para as frequências da variável independente Grau de Instrução do Empreendedor. Apenas 11,6\% dos empreendedores não apresentaram níveis de instrução compatíveis com nível superior ou outros níveis maiores. Os demais, 30\% possuem nível superior e 57,9\% possuem níveis acima de especialização até pós-doutorado. Pelos resultados das frequências é possível visualizar também variações nas respostas dos empreendedores, o que indica, também, ausência de heterocedasticidade para essa variável.

Com relação à variável Área do Conhecimento, e considerando a hipótese levantada nessa direção, considerou-se aqueles com áreas de conhecimentos próximas das ciências exatas, diferenciando-as daqueles empreendedores com formação em áreas de conhecimentos mais próximas das ciências humanas, assim, as frequências apontaram para os resultados apresentados na tabela 03, adiante: 
Tabela 03

Áreas de formação próximas das ciências exatas

\begin{tabular}{|cc|c|c|c|c|}
\hline & Frequência & Porcentual & $\begin{array}{c}\text { Porcentagem } \\
\text { válida }\end{array}$ & $\begin{array}{c}\text { Porcentagem } \\
\text { acumulativa }\end{array}$ \\
\hline \multirow{2}{*}{ Válido } & Sĩo & 40 & 42,1 & 42,1 & 42,1 \\
& 55 & 57,9 & 57,9 & 100,0 \\
& Total & 95 & 100,0 & 100,0 & \\
\hline
\end{tabular}

Fonte: Elaborado pelo autor com base nos dados coletados.

Conforme aponta a tabela 03 acima, $40 \%$ dos empreendedores possuem formações mais próximas das ciências humanas, enquanto 55\% possuem formações próximas das ciências exatas. Como áreas próximas das ciências exatas consideraram-se engenharia e ciências exatas. Os resultados apontaram para a ausência de heterocedasticidade também para essa variável, permitindo a aplicação da regressão logística.

A variável Experiência na Empresa foi mensurada em anos de experiência, em termos absolutos. Conforme mencionado na revisão da literatura, a experiência pode ser classificada em três tipos, sendo eles: experiência na empresa; experiência na indústria; e experiência com a criação de novos empreendimentos. Essa variável considera a experiência do empreendedor na empresa, mensurando o número de anos que o empreendedor atua nela. Os resultados são apresentados na tabela 04 adiante:

\section{Tabela 04}

Experiência na empresa

\begin{tabular}{|c|c|c|c|c|c|}
\hline & & Frequência & Porcentual & $\begin{array}{c}\text { Porcentagem } \\
\text { válida }\end{array}$ & $\begin{array}{l}\text { Porcentagem } \\
\text { acumulativa }\end{array}$ \\
\hline \multirow{10}{*}{ Válido } & 2 & 10 & 10,5 & 10,5 & 10,5 \\
\hline & 3 & 16 & 16,8 & 16,8 & 27,4 \\
\hline & 4 & 16 & 16,8 & 16,8 & 44,2 \\
\hline & 5 & 8 & 8,4 & 8,4 & 52,6 \\
\hline & 6 & 13 & 13,7 & 13,7 & 66,3 \\
\hline & 7 & 13 & 13,7 & 13,7 & 80,0 \\
\hline & 8 & 6 & 6,3 & 6,3 & 86,3 \\
\hline & 9 & 5 & 5,3 & 5,3 & 91,6 \\
\hline & 10 & 1 & 1,1 & 1,1 & 92,6 \\
\hline & 12 & 1 & 1,1 & 1,1 & 93,7 \\
\hline
\end{tabular}




\begin{tabular}{|c|c|c|c|c|}
\hline 13 & 1 & 1,1 & 1,1 & 94,7 \\
15 & 1 & 1,1 & 1,1 & 95,8 \\
16 & 1 & 1,1 & 1,1 & 96,8 \\
18 & 1 & 1,1 & 1,1 & 97,9 \\
22 & 1 & 1,1 & 1,1 & 98,9 \\
24 & 1 & 1,1 & 1,1 & 100,0 \\
Total & 95 & 100,0 & 100,0 & \\
\hline
\end{tabular}

Fonte: Elaborado pelo autor com base nos dados coletados.

Além da experiência na empresa, a pesquisa mensurou também a experiência total dos empreendedores, sendo distribuídas a frequência conforme a tabela 05 adiante:

Tabela 05

Experiência na Indústria

\begin{tabular}{|c|c|c|c|c|c|}
\hline & & Frequência & Porcentual & $\begin{array}{c}\text { Porcentagem } \\
\text { válida }\end{array}$ & $\begin{array}{l}\text { Porcentagem } \\
\text { acumulativa }\end{array}$ \\
\hline & 1 & 1 & 1,1 & 1,1 & 1,1 \\
\hline & 2 & 1 & 1,1 & 1,1 & 2,1 \\
\hline & 3 & 1 & 1,1 & 1,1 & 3,2 \\
\hline & 4 & 2 & 2,1 & 2,1 & 5,3 \\
\hline & 5 & 3 & 3,2 & 3,2 & 8,4 \\
\hline & 6 & 4 & 4,2 & 4,2 & 12,6 \\
\hline & 7 & 4 & 4,2 & 4,2 & 16,8 \\
\hline & 8 & 7 & 7,4 & 7,4 & 24,2 \\
\hline & 9 & 3 & 3,2 & 3,2 & 27,4 \\
\hline & 10 & 5 & 5,3 & 5,3 & 32,6 \\
\hline Válido & 11 & 1 & 1,1 & 1,1 & 33,7 \\
\hline & 12 & 3 & 3,2 & 3,2 & 36,8 \\
\hline & 13 & 4 & 4,2 & 4,2 & 41,1 \\
\hline & 14 & 1 & 1,1 & 1,1 & 42,1 \\
\hline & 15 & 8 & 8,4 & 8,4 & 50,5 \\
\hline & 16 & 2 & 2,1 & 2,1 & 52,6 \\
\hline & 17 & 2 & 2,1 & 2,1 & 54,7 \\
\hline & 18 & 2 & 2,1 & 2,1 & 56,8 \\
\hline & 19 & 1 & 1,1 & 1,1 & 57,9 \\
\hline & 20 & 3 & 3,2 & 3,2 & 61,1 \\
\hline & 21 & 1 & 1,1 & 1,1 & 62,1 \\
\hline
\end{tabular}




\begin{tabular}{|c|r|r|r|r|}
\hline 22 & 1 & 1,1 & 1,1 & 63,2 \\
23 & 3 & 3,2 & 3,2 & 66,3 \\
24 & 1 & 1,1 & 1,1 & 67,4 \\
25 & 6 & 6,3 & 6,3 & 73,7 \\
27 & 4 & 4,2 & 4,2 & 77,9 \\
29 & 2 & 2,1 & 2,1 & 80,0 \\
30 & 4 & 4,2 & 4,2 & 84,2 \\
34 & 2 & 2,1 & 2,1 & 86,3 \\
35 & 2 & 2,1 & 2,1 & 88,4 \\
38 & 3 & 3,2 & 3,2 & 91,6 \\
40 & 3 & 3,2 & 3,2 & 94,7 \\
41 & 2 & 2,1 & 2,1 & 96,8 \\
42 & 1 & 1,1 & 1,1 & 97,9 \\
45 & 1 & 1,1 & 1,1 & 98,9 \\
47 & 1 & 1,1 & 1,1 & 100,0 \\
Total & 95 & 100,0 & 100,0 & \\
\hline
\end{tabular}

Fonte: Elaborado pelo autor com base nos dados coletados.

Além de mensurar o lado quantitativo da experiência do empreendedor, também foi mensurado qualitativamente, considerando a área de atuação do empreendedor. A mensuração dessa variável se deu considerando aqueles empreendedores com área de atuação mais próximo da Pesquisa e Desenvolvimento e da Produção, contra aqueles com áreas de atuação distintas. A frequência da área de atuação do empreendedor é apresentada adiante, na tabela 06:

Tabela 06

Área de atuação próxima à $\mathrm{P} \& \mathrm{D}$ e Produção

\begin{tabular}{|c|c|c|c|c|c|}
\hline & & Frequência & Porcentual & $\begin{array}{c}\text { Porcentagem } \\
\text { válida }\end{array}$ & $\begin{array}{l}\text { Porcentagem } \\
\text { acumulativa }\end{array}$ \\
\hline \multirow{3}{*}{ Válido } & Não & 9 & 9,5 & 9,5 & 9,5 \\
\hline & Sim & 86 & 90,5 & 90,5 & 100,0 \\
\hline & Total & 95 & 100,0 & 100,0 & \\
\hline
\end{tabular}

Fonte: Elaborado pelo autor com base nos dados coletados

Conforme apontam as frequências, todas as variáveis obtiveram variações nas respostas, o que indica a não homogeneidade das respostas, caracterizando assim a ausência de heterocedasticidade, que é uma das premissas para a aplicação da regressão logística. A 
variável que apresentou menos diferenciação nas respostas foi a variável área de atuação do empreendedor. Porém, ainda assim, houve variação e foi possível rodar os dados.

Uma vez apresentado as frequências das variáveis, torna-se importante analisar a correlação dessas variáveis, para assegurar a inexistência de multicolinearidade, e analisar os resultados da regressão logística para o modelo conceitual proposto.

\subsubsection{Análise das correlações e regressão logística}

Analisar as correlações entre as variáveis independentes do modelo é necessário para que se assegure a ausência de multicolinearidade, premissa exigida para que a técnica de regressão logística possa ser aplicada. A matriz de correlação das variáveis independentes inseridas no modelo é apresentada adiante, na tabela 07:

\section{Tabela 07}

Matriz de correlação das variáveis independentes

\begin{tabular}{|c|c|c|c|c|c|c|}
\hline \multicolumn{7}{|c|}{ Correlações } \\
\hline & & $\begin{array}{l}\text { Grau de } \\
\text { instrução }\end{array}$ & $\begin{array}{c}\text { Área do } \\
\text { conhecimento }\end{array}$ & $\begin{array}{c}\text { Experiência } \\
\text { na empresa }\end{array}$ & $\begin{array}{c}\text { Experiência } \\
\text { Total }\end{array}$ & $\begin{array}{l}\text { Área de } \\
\text { atuação }\end{array}$ \\
\hline Grau de instrução & $\begin{array}{l}\text { Correlação de Pearson } \\
\text { Sig. ( } 2 \text { extremidades) } \\
\text { N }\end{array}$ & $\begin{array}{c}1 \\
95\end{array}$ & & & & \\
\hline $\begin{array}{l}\text { Área do } \\
\text { conhecimento }\end{array}$ & $\begin{array}{l}\text { Correlação de Pearson } \\
\text { Sig. ( } 2 \text { extremidades }) \\
\text { N }\end{array}$ & $\begin{array}{c}, 195 \\
, 058 \\
95\end{array}$ & $\begin{array}{c}1 \\
95\end{array}$ & & & \\
\hline $\begin{array}{l}\text { Experiência na } \\
\text { empresa }\end{array}$ & $\begin{array}{l}\text { Correlação de Pearson } \\
\text { Sig. ( } 2 \text { extremidades) } \\
\text { N }\end{array}$ & $\begin{array}{l}-, 044 \\
, 671 \\
95\end{array}$ & $\begin{array}{c}, 008 \\
, 939 \\
95\end{array}$ & $\begin{array}{c}1 \\
95\end{array}$ & & \\
\hline Experiência Total & $\begin{array}{l}\text { Correlação de Pearson } \\
\text { Sig. ( } 2 \text { extremidades) } \\
\text { N }\end{array}$ & $\begin{array}{c}-, 154 \\
, 137 \\
95\end{array}$ & $\begin{array}{l}-, 008 \\
, 941 \\
95\end{array}$ & $\begin{array}{c}154 \\
, 136 \\
95\end{array}$ & $\begin{array}{c}1 \\
95\end{array}$ & \\
\hline Área de atuação & $\begin{array}{l}\text { Correlação de Pearson } \\
\text { Sig. ( } 2 \text { extremidades) } \\
\text { N }\end{array}$ & $\begin{array}{c}-, 044 \\
, 670 \\
95\end{array}$ & $\begin{array}{c}015 \\
, 883 \\
95\end{array}$ & $\begin{array}{c}-, 115 \\
, 267 \\
95\end{array}$ & $\begin{array}{c}113 \\
, 277 \\
95\end{array}$ & $\begin{array}{c}1 \\
95\end{array}$ \\
\hline
\end{tabular}

Fonte: Elaborado pelo autor com base nos dados coletados.

A matriz de correlação das variáveis independentes permite identificar a ausência de multicolinearidade entre elas. Nenhuma dentre as correlações encontradas foram superiores a 0,70, o que indica que não há interferência de uma variável na outra quando inseridas no modelo, permitindo a aplicação da técnica de Regressão Logística para o teste das hipóteses. 
Respeitando as premissas necessárias para a aplicação da técnica, os dados foram inseridos no SPSS, e os resultados são apresentados na tabela 08 adiante:

\section{Tabela 08}

Tabela de resultados da regressão logística (Modelo Completo)

\begin{tabular}{lccc} 
& Modelo 01 & Modelo 02 & Modelo 03 \\
\hline Constante & 0,525 & $-0,244$ & 0,206 \\
Grau de Instrução & $-0,250$ & & $-0,245$ \\
Área de Conhecimento & $1,476^{* *}$ & & $1,550^{* *}$ \\
Experiência na Empresa & & 0,105 & 0,113 \\
Experiência na Indústria & & 0,016 & 0,015 \\
Área de Atuação & & $-0,606$ & $-0,756$ \\
\hline $\mathrm{R}^{2} \mathrm{R}$ Nagelkerke & 0,160 & 0,070 & 0,223 \\
$\mathrm{~N}$ & 95 & 95 & 95 \\
Qui-Quadrado & 2,991 & 9,678 & 4,865 \\
\hline \hline
\end{tabular}

Nota. $* \mathrm{p}<0,05 ; * * \mathrm{p}<0,01$. Fonte: Elaborado pelo autor com base nos dados coletados.

Considerando o efeito moderador do porte da organização indicado no modelo, os dados foram tratados de maneira diferente. Primeiro considerou-se a aplicação das técnicas para toda a amostra disponível, sem discriminação do porte. Na sequência, os dados foram considerados mediante a separação da amostra em grande porte e pequeno porte. A divisão se deu tomando como base a mediana da quantidade de funcionários, o que resultou em uma amostra de 48 empresas de porte maior e 47 de porte menor. A técnica de Regressão Logística foi aplicada para todas as amostras.

A tabela 08 acima indica os resultados da regressão logística para o modelo completo. Segundo indica os resultados da tabela, considerando o modelo com as amostras completas, verifica-se que houve significância apenas da variável Área do Conhecimento, com um nível de significância $\mathrm{p}<0,01$. O modelo apresentou um $\mathrm{R}^{2}$ ( $\mathrm{R}$ de Nagelkerke) de 0,223, o que indica que esse modelo explica em 22,3\% o fenômeno analisado. Além disso, apresentou um Qui-quadrado de 4,865.

Esses resultados indicam a aceitação da hipótese H2 indicada no modelo, apontando para a associação positiva entre a área de conhecimento e a inovação de produtos, sendo que, quanto mais próximo as áreas de formação do empreendedor está das ciências exatas, mais elas inovam em produtos. As demais hipóteses levantadas para o modelo geral não foram suportadas. 
Quando considerado as empresas de maior porte, temos os resultados indicados na tabela 09 adiante:

\section{Tabela 09}

Tabela de resultados da Regressão Logística (Grande Porte)

\begin{tabular}{lccc} 
& Modelo 01 & Modelo 02 & Modelo 03 \\
\hline Constante & 0,208 & $-0,338$ & $-0,974$ \\
Grau de Instrução & $-0,213$ & & $-0,124$ \\
Área de Conhecimento & $2,112^{* *}$ & & $2,246^{* *}$ \\
Experiência na Empresa & & 0,039 & 0,009 \\
Experiência na Indústria & & 0,039 & 0,053 \\
Área de Atuação & & $-0,645$ & $-0,553$ \\
\hline $\mathrm{R}^{2} \mathrm{R}$ Nargerkerke & 0,288 & 0,087 & 0,350 \\
$\mathrm{~N}$ & 48 & 48 & 48 \\
Qui-Quadrado & 0,973 & 5,582 & 4,928 \\
\hline \hline
\end{tabular}

Nota. $* \mathrm{p}<0,05 ; * * \mathrm{p}<0,01$. Fonte: Elaborado pelo autor com base nos dados coletados.

Os resultados da tabela indicam significância apenas para a variável Área do Conhecimento, com um nível de significância $\mathrm{p}<0,01$. O que corrobora com a aceitação da hipótese $\mathrm{H} 2$ indicada no modelo, apontando para a ausência de interferência da variável porte na relação. Quando considerado a amostra dessa maneira, o modelo apresenta um $\mathrm{R}^{2}$ ( $\mathrm{R}$ de Nagelkerke) igual a 0,350 e um Qui-quadrado de 4,928, para uma amostra de 48 empresas.

Quando considerando as empresas de menor porte, chega-se aos seguintes resultados apresentados na tabela 10 adiante:

\section{Tabela 10}

Tabela de resultados da Regressão Logística (Pequeno Porte)

\begin{tabular}{lccc}
\cline { 2 - 4 } & Modelo 01 & Modelo 02 & Modelo 03 \\
\hline Constante & 0,856 & 18,166 & 18,843 \\
Grau de Instrução & $-0,289$ & & $-0,503$ \\
Área de Conhecimento & 0,969 & & $1,934^{*}$ \\
Experiência na Empresa & & $0,377^{*}$ & $0,541^{* *}$ \\
Experiência na Indústria & & 0,001 & 0,003 \\
Área de Atuação & & $-19,919$ & $-20,188$ \\
\hline $\mathrm{R}^{2} \mathrm{R}$ Nargerkerke & 0,085 & 0,200 & 0,355 \\
$\mathrm{~N}$ & 47 & 47 & 47 \\
Qui-Quadrado & 7,812 & 8,831 & 5,736 \\
\hline \hline
\end{tabular}

Nota. $* \mathrm{p}<0,05 ; * * \mathrm{p}<0,01$. Fonte: Elaborado pelo autor com base nos dados coletados. 
Os resultados indicam a aceitação da hipótese H2, com um nível de significância $\mathrm{p}<0,05$, e a aceitação da hipótese H3, com um nível de significância $\mathrm{p}<0,01$. O modelo considerando a amostra de 47 empresas de menor porte apresentou um $R^{2}$ ( $R$ de Nagelkerke) igual a 0,355 e um Qui-Quadrado igual a 5,736.

Para empresas de menor porte, a variável experiência da empresa entrou como sendo muito significativa, indicando interferência da variável porte nos resultados da relação. Assim, para empresas de menor porte, a experiência do empreendedor apresenta-se como uma variável de forte associação positiva com a inovação de produtos, seguido pela área de conhecimento com associação positiva, porém, menor que a variável área do conhecimento.

\subsubsection{Análise das Hipóteses levantadas}

Os resultados encontrados com as regressões logísticas apresentadas na subseção anterior permite a análise das hipóteses levantadas no modelo. As hipóteses de 01 a 05 são analisadas com base nos resultados da tabela 08 apresentada anteriormente. Essa tabela considera o modelo para a amostra total analisada, sem a divisão por tamanho da organização. Os resultados são apresentados por hipótese adiante:

Hipótese 01: O nível de formação do empreendedor é positivamente relacionado com a inovação de produtos.

A hipótese 01 do modelo considera o nível de formação do empreendedor e sua associação com a inovação de produtos em empresas incubadas. A lógica por trás dessa hipótese reside na revisão da literatura sobre a descoberta de oportunidades empreendedoras. Autores como Shane \& Venkataraman (2000) e Shane (2000) analisam a descoberta de oportunidades empreendedoras como algo relacionado ao conceito de assimetria da informação (Schumpeter, 1942), o qual define que pessoas apresentam conhecimentos diferentes, o que os fazem identificar oportunidades que os demais, aqueles que não apresentam conhecimentos similares, conseguem identificar.

A assimetria da informação é analisada neste trabalho como resultante da formação do empreendedor. Porém, é preciso considerar que o nível de formação do empreendedor, assim como a área do conhecimento, não são por si só, bastantes para a definição das informações 
adquiridas pelos empreendedores. Muitas das informações adquiridas pelos empreendedores advêm, também, do contexto ao qual esses empreendedores estão inseridos.

Os resultados da regressão logística apontaram para a rejeição da hipótese levantada. Para essa hipótese o nível de significância foi maior do que 0,05 ( $\mathrm{P}>0,05)$, rejeitando a hipótese. Assim, pelo que indica os resultados, o nível de formação do empreendedor não está associado à inovação de produtos em empresas incubadas de base tecnológica.

Para a amostra considerada, 62\% das empresas apresentam alguma relação com universidades. Isso indica que, boa parte dos empreendedores venha a serem alunos de cursos de graduação de universidades que, com alguma ideia em vista, montam a empresa de base tecnológica e a insere na incubadora. Empreendedores em fase de graduação, com nível superior incompleto, são considerados como níveis de ensino médio ou ensino profissionalizante, o que pode explicar a não associação entre o nível de formação e a inovação de produtos em empresas incubadas de base tecnológica no estado de São Paulo.

Além disso, o mesmo raciocínio da aquisição de assimetria de informação por outros meios que não a educação formal do empreendedor vem a corroborar para a ausência de associação entre essa variável e a inovação de produtos em empresas incubadas de base tecnológica. Além do mais, o nível de instrução é analisado aqui como uma variável que reflete a quantidade de conhecimentos adquiridos pelos empreendedores, sendo preciso analisar também a variável área de formação, captada na hipótese seguinte.

Hipótese 02: Empreendedores com formações mais próximas das ciências exatas inovam mais em produtos do que aqueles cujas formações são mais próximas das ciências humanas.

A área de formação do empreendedor é um importante fator a ser considerado quando se trata da assimetria de informação. A descoberta de oportunidades empreendedoras, assim como citado na análise da hipótese anterior, está estreitamente relacionada com o conceito de assimetria da informação (Shane, 2000; Shane \& Venkataraman, 2000; Venkataraman 1997), o qual aponta que as pessoas possuem diferenças de informações ou informações incompletas, o que torna as relações entre os agentes desiguais (Spence, 1973; Akerlof, 1976; Stiglitz \& Weiss, 1981), e essa desigualdade nas relações implica na descoberta de oportunidades empreendedoras de maneira desigual, uma vez que uns descobrem enquanto que outros não. 
A teoria aponta ainda que pessoas que adquirem novos conhecimentos antes das outras tem uma maior propensão a descobrir oportunidades empreendedoras utilizando os conhecimentos adquiridos (Shane, 2000). Assim, os conhecimentos adquiridos pelos empreendedores e mensurados em termos de área de formação são fundamentais na análise da descoberta de oportunidades empreendedoras, considerando aqui a inovação de produtos como uma oportunidade empreendedora.

Os resultados da regressão logística para essa variável apontou uma associação positiva forte com a inovação de produtos, com um nível de significância $\mathrm{p}<0,01$, aceitando assim a hipótese. Dessa forma, há uma associação positiva entre a formação do empreendedor e a inovação de produtos, com um beta igual a 1,550. Isso indica que empreendedores com formação mais próximas das ciências exatas inovam mais em produtos do que aqueles empreendedores cujas formações são mais próximas das ciências humanas, isso para a amostra de empresas incubadas de base tecnológica do estado de São Paulo.

Esse resultado indica que a experiência do empreendedor é algo que deve ser levado em consideração na seleção de empresas incubadas de base tecnológica, principalmente se o objetivo da incubadora é fomentar a inovação direcionada para a inovação de produtos. Como os produtos desenvolvidos em empresas de base tecnológica são caracterizados por intensa quantidade de conhecimentos técnicos especializados envolvidos, as áreas próximas das ciências exatas são aquelas que municiam os empreendedores com maior quantidade de informações que os permitirão inovarem em produtos.

Hipótese 03: Empreendedores que atuam em áreas mais próximas da produção e desenvolvimento de novos produtos inovam mais em produtos que empreendedores que atuam em áreas mais distantes das citadas.

As hipóteses anteriores analisaram o background do empreendedor do lado da formação. As hipóteses 03, 04 e 05 analisam a experiência do empreendedor e sua relação com a inovação de produtos. A hipótese três considera a área de atuação e promove relações com a inovação de produtos. 
A experiência é analisada aqui mediante a análise da área de atuação do empreendedor. A literatura sobre a experiência do empreendedor aponta para associações positivas entre esse constructo e o crescimento do negócio (Lee \& Tsang, 2001). Outros estudos apontam para relações positivas e negativas entre a experiência do empreendedor e o desempenho (Gasse, 1982).

Os resultados estatísticos apontaram para a rejeição da hipótese, uma vez que a variável obteve um nível de significância $p>0,05$, condição que rejeita a hipótese levantada. Portanto, não foi identificada associação entre a área de atuação e a inovação de produtos em empresas incubadas de base tecnológica. Assim, não necessariamente, empreendedores com áreas de atuação mais próximas da pesquisa e desenvolvimento e produção são aqueles que mais inovam em produtos.

Hipótese 04: A experiência do empreendedor em termos totais está positivamente relacionada com a inovação em produtos.

A experiência do empreendedor em termos totais foi mensurada nessa pesquisa como o total de anos que os empreendedores trabalham, independente do número de empresas que ele tenha passado. Essa variável capta a experiência do empreendedor na indústria, conforme o conceito apontado por Lee e Tsang (2001). A lógica que fundamenta a hipótese levantada é que os conhecimentos adquiridos pelos empreendedores na indústria os permitirão identificar oportunidades de inovar em produtos.

Essa hipótese não foi suportada, uma vez que obteve um nível de significância $p>0,05$, o que indica a rejeição da hipótese levantada. Assim, em empresas incubadas de base tecnológica não há associação entre a experiência total do empreendedor e a inovação de produtos. Outra hipótese levantada foi direcionada para a análise da experiência do empreendedor na empresa, o que indica, segundo o conceito apontado por Lee e Tsang (2001), a experiência do empreendedor na gestão, que é representada pela experiência de gestão do empreendedor na empresa em que atua, variável que compõe a hipótese seguinte.

Hipótese 05: A experiência de atuação do empreendedor na empresa está positivamente relacionada com a inovação em produtos. 
A atuação do empreendedor na empresa é vista como a experiência em gestão do empreendedor dentro daquela indústria (Lee \& Tsang, 2001), sendo, portanto, captada por meio da mensuração do total de anos trabalhados na empresa em que atuam.

Essa hipótese não foi suportada, uma vez que obteve um nível de significância $p>0,05$, o que aponta a rejeição da hipótese levantada. Dessa forma, a experiência do empreendedor na empresa não apresentou associação com a inovação de produtos em empresas incubadas de base tecnológica no estado de São Paulo.

Considerando o modelo completo analisado mediante a aplicação da regressão logística, é possível afirmar que, em empresas incubadas de base tecnológica do estado de São Paulo, a associação entre variáveis que mensuram o background do empreendedor e a inovação de produtos somente mostrou associação positiva na área de conhecimento, sendo que aqueles empreendedores com áreas de conhecimentos mais próximas das ciências exatas inovam mais em produtos. As variáveis que mensuram a experiência não foram suportadas nesse modelo.

Estudos apontam controvérsias entre alguns achados que apontaram a experiência e suas associações com o desempenho em organizações (Lee \& Tsang, 2001; Gasse (1982); Stuart \& Abetti (1990); Van de Vem et al. (1984); Vesper (1980); Dyke et al. (1992); Duchesneau \& Gartner (1990). Lee e Tsang (2001) apontaram associações positivas entre a experiência do empreendedor e o desempenho da empresa; Gasse (1982) identificou tanto associações positivas quanto negativas entre a experiência e o desempenho em negócios. Algumas explicações, a exemplo de Lee \& Tsang (2001), apontam que as experiências prévias do empreendedor podem agir como uma barreira aos novos desafios.

Stuart e Abetti (1990) identificaram associações positivas da experiência em gestão com o desempenho nos negócios; Van de Ven et al. (1984) e Vesper (1980) identificaram associações positivas entre a experiência industrial e a inovação em produtos; Dyker et al. (1992) identificaram associações positivas entre a experiência gerencial e industrial e a inovação de produtos; e Duchesneau e Gartner (1990) identificaram associações positivas entre a experiência conjunta de gestão e industrial do empreendedor no sucesso de negócios. 
Em empresas incubadas de base tecnológica a experiência não se mostrou uma variável significativa quando desconsiderado o efeito moderador da variável porte da organização. A hipótese seguinte busca analisar o efeito moderador do porte da organização nessa relação.

Hipótese 06: A relações entre o background do empreendedor e a inovação de produtos são mais significativas em empresas de maior porte do que naquelas de menor porte.

O porte da organização foi analisado em termos de número de empregados na empresa. Considerando a mediana do total de empregados da empresa, a amostra foi dividida em empresas de maior porte e empresas de menor porte. Os critérios de seleção dos portes somente permite visualizar as empresas que são maiores dentre a amostra e aquelas que são menores. Dessa forma, 47 empresas foram classificadas como pequeno porte por estarem abaixo da mediana, enquanto que 48 empresas foram classificadas como grande porte por estarem acima da mediana.

Quando considerado os resultados das regressões logísticas para os portes maiores e menores, dispostos nas tabelas 09 e 10, encontrou-se os resultados que permitem auferir uma diferença, quando comparado os portes das organizações, para a variável área do conhecimento. Para as demais variáveis, não houve mudanças nas significâncias que elas apresentaram no modelo completo. Dessa forma, para empresas de grande porte, somente a área do conhecimento foi suportada com $\mathrm{p}<0,01$, enquanto que, para as empresas de pequeno porte, a área do conhecimento foi suportada com $\mathrm{p}<0,05$, e a experiência na empresa foi suportada com $\mathrm{p}<$ 0,01 .

Esses resultados indicam que, em empresas de grande porte, a área do conhecimento é uma variável bastante significativa para a inovação de produtos em empresas incubadas de base tecnológica. A experiência não foi considerada uma variável significativa para o modelo. Isso indica que, em empresas maiores, a experiência do empreendedor não é tão relevante, uma vez que, a experiência da organização e seus fluxos de conhecimento permitem uma aprendizagem organizacional que leva o empreendedor a apoiar-se tanto nos conhecimentos da organização quanto nas experiências dos profissionais colaboradores da organização.

Para empresas pequenas, esse cenário muda, uma vez que a experiência passa a mostrar-se como uma variável significativa para explicar a inovação de produtos em empresas incubadas 
de base tecnológica. Isso indica que, empresas de pequeno porte são mais centralizadas na pessoa do empreendedor, fazendo com que a experiência desse empreendedor seja fundamental para que a organização mantenha um processo de inovação em produtos que seja eficaz.

Os resultados vão ao encontro do que a literatura aponta e ajuda a compreender algumas controvérsias identificadas no sentido da relação entre a experiência e alguns indicadores de desempenho, a exemplo de faturamento, receita em vendas, dentre outros (Stuart \& Abetti, 1990; Van de Vem et al., 1984; Vesper, 1980; Dyke et al., 1992; Duchesneau \& Gartner, 1990).

Algumas dessas divergências se explicam aí pelo porte da organização. Não obstante a diferença entre as amostras dos estudos citados e a amostra utilizada nessa pesquisa, o porte mostrou-se como uma variável moderadora no modelo proposto, haja vista que, modera, principalmente, a variável experiência da organização, que é bastante significativa para empresas com porte menor.

\subsubsection{Síntese dos Resultados}

A hipótese 01 foi rejeitada, indicando a ausência de associação entre o grau de instrução do empreendedor e a inovação de produtos em empresas incubadas de base tecnológica; A hipótese 02 foi aceita, indicando uma associação positiva entre a área de conhecimento mais próxima das ciências exatas e a inovação de produtos; A hipótese 03 foi rejeitada, indicando ausência de associação entre a atuação do empreendedor em áreas mais próximas da pesquisa e desenvolvimento e a inovação de produtos; A hipótese 04 foi rejeitada, indicando que não há associação entre o tempo de experiência do empreendedor na empresa e a inovação de produtos; A hipótese 05 foi rejeitada, indicando que não há associação entre a experiência profissional total do empreendedor e a inovação de produtos; e por fim, a hipótese 06 foi aceita, indicando um efeito moderador da variável porte da organização no modelo analisado. Para essa hipótese, a variável experiência mostra-se significativa quando considerado empresas de pequeno porte, e não significativa para empresas de grande porte. Além disso, a variável Área do Conhecimento apresentou maior significância em empresas de grande porte do que em empresas de pequeno porte. 
Quadro 06 - Resumo dos resultados do teste de hipóteses

\begin{tabular}{|l|l|}
\hline Hipótese & Resultado \\
\hline Hipótese 01 & Rejeitada \\
\hline Hipótese 02 & Aceita com $\mathrm{p}<0,01$ \\
\hline Hipótese 03 & Rejeitada \\
\hline Hipótese 04 & Rejeitada \\
\hline Hipótese 05 & Rejeitada \\
\hline Hipótese 06 & Aceita \\
\hline
\end{tabular}

Fonte: Elaborado pelo autor com base nos resultados. 


\section{CONCLUSÕES E CONSIDERAÇÕES FINAIS}

O estudo foi desenvolvido em Empresas Incubadas de Base Tecnológica no Estado de São Paulo e teve como objetivo geral analisar relações entre o background dos empreendedores e a inovação de produtos em Empresas Incubadas de Base Tecnológica no Estado de São Paulo. Esse objetivo se desdobrou em quatro outros específicos, sendo eles (1) Identificar o background dos empreendedores de empresas vinculadas às incubadoras de empresas de base tecnológica no Estado de São Paulo; (2) Identificar a inovação de produtos das empresas incubadas de base tecnológica do estado de São Paulo; (3) Identificar relações entre o background do empreendedor e a inovação de produtos em empresas de base tecnológica no estado de São Paulo; (4) Identificar a interferência do porte da organização nessas relações.

A revisão da literatura permitiu a reunião de estudos que contemplaram a análise do background do empreendedor (formação e experiência) e sua relação com indicadores de desempenho, tais como, faturamento, crescimento em vendas, dentre outros. A análise do background compõe a delimitação da pesquisa, que buscou afunilar, dentro das características pessoais do empreendedor, para suportar o presente estudo. Assim, a formação do empreendedor foi considerada na pesquisa como um constructo que envolveu as variáveis "Nível de formação" e "Área de Formação", enquanto que, a experiência do empreendedor envolveu as variáveis “Área de Atuação"; "Experiência do Empreendedor na Empresa"; e "Experiência Total do Empreendedor".

Na direção dos objetivos levantados, os resultados foram apurados e analisados. Quanto ao primeiro objetivo, o background do empreendedor foi mensurado na pesquisa do ponto de vista das cinco variáveis apontadas anteriormente. Os empreendedores apresentaram uma média de Nível de Formação bastante especializada, havendo apenas 11,6\% dos empreendedores com formação abaixo de nível superior. Os demais possuem níveis de formação abrangendo acima de nível superior, sendo que 30,5\% dos empreendedores apresentam o nível superior como nível máximo de formação, enquanto que 23,2\% possuem MBA ou Especialização Lato Sensu, 12,6\% possuem mestrado, 8,4\% possuem doutorado, e $13,7 \%$ possuem Pós-doutorado. Quanto ao nível de formação, percebe-se que os empreendedores apresentam um nível elevado de formação, com conhecimentos técnicos especializados, alguns com formações específicas quando considerados cursos stricto sensu 
(mestrado, doutorado e pós-doutorado), denotando uma especialização em determinada área de conhecimento e com profundidade.

Quando considerado a área de conhecimento na qual os empreendedores se formaram, os resultados apontaram que 57,9\% possuem formações mais próximas das ciências exatas, enquanto que $42,1 \%$ apresentaram formações mais distantes. Essa variável permite identificar as especificidades dos conhecimentos dos empreendedores de Empresas Incubadas de Base Tecnológica do Estado de São Paulo, indicando que esses empreendedores voltam-se com mais frequência para formações mais técnicas, com cursos mais exatos que permitam a lida técnica com as atividades que desenvolvem, sendo elas de base tecnológica.

Até aqui, apontou-se a característica pessoal do empreendedor do ponto de vista da formação. Quando analisado a experiência dos empreendedores nas empresas em que trabalham, os resultados indicaram uma média de 5,94 anos, enquanto que, quando considerado a experiência total do empreendedor, os resultados indicam uma média de 18,82 anos.

Essa análise do total de anos de experiência do empreendedor somente permite uma análise quantitativa das experiências por eles vivenciadas. Outra variável considerada na pesquisa também é a variável área de atuação do empreendedor, a qual permite uma visualização mais qualitativa dessa experiência, indicando ao menos a área em que a experiência ocorreu dentro da empresa. Quando analisado dessa maneira, percebeu-se que 90,5\% dos empreendedores atuam em áreas próximas à Pesquisa e Desenvolvimento (P\&D) e Produção, enquanto que 9,5\% deles atuam em áreas mais distantes.

Nesse sentido, respondendo ao primeiro objetivo, percebe-se o background do empreendedor como composto por indicadores de formação elevados, com grande parte deles detendo conhecimentos especializados, sendo esses conhecimentos, em sua maioria, direcionados para as áreas próximas das ciências exatas. Em paralelo, os indicadores de experiência também apontam para uma média elevada, tanto dentro da empresa, o que indica a experiência em gestão na empresa, quanto em experiência total, o que indica a experiência do empreendedor na indústria.

O segundo objetivo de pesquisa levantado buscou identificar a inovação de produtos nas empresas incubadas de base tecnológica do estado de São Paulo. A mensuração ocorreu 
analisando a existência ou não de inovação em produtos nessas empresas. Os resultados apontaram que 52,6\% das empresas Incubadas de Base Tecnológica do Estado de São Paulo apresentaram algum tipo de inovação em produto, enquanto que 47,4\% delas não apresentaram inovações. Assim, a inovação ocorre nessas empresas, porém, ainda com uma porcentagem alta de empresas que não inovam em produtos, ainda mais considerando suas características essenciais que são abrigadas dentro da definição de Empresas de Base Tecnológica, sendo uma delas a necessidade de inovações.

Esses dois objetivos anteriores permitem responder o terceiro objetivo específico da pesquisa. Para tanto, a técnica de regressão logística foi aplicada para testar as relações entre o background do empreendedor e a inovação de produtos. Os resultados indicaram a existência de relações significativas entre a área do conhecimento e a inovação de produtos. Assim, como achado dessa pesquisa, identificou-se que quanto mais próximas a formação do empreendedor é das ciências exatas, mais a empresa inova em produtos. A associação foi fortemente significativa, a um nível $\mathrm{p}<0,01$. Isso indica que as informações adquiridas pelos empreendedores estão associadas diretamente com a descoberta de oportunidades empreendedoras, consideradas aqui como a inovação de produtos.

A formação mais próxima das ciências exatas permite ao empreendedor uma assimetria da informação que é fundamental na condução de projetos de inovação. Além dessas informações adquiridas pelos empreendedores os colocarem à frente dos demais quando da descoberta de oportunidades empreendedoras, ela permite ainda formações bastantes técnicas que favorecem a condução técnicas de projetos de inovação em produto.

O nível de formação do empreendedor não se mostrou uma variável significativa para o modelo. Dessa forma, formações em níveis elevados não apresentou associação com a inovação de produtos. Isso se explica por que a assimetria da informação depende em maior parte da qualidade das informações que são adquiridas, e não da quantidade de informações, o que indica que especializações demasiadas em áreas que não concedem informações diferenciadas do ponto de vista da inovação em produtos, não tornam as empresas desses empreendedores mais inovadoras.

A experiência do empreendedor não se mostrou associadas com a inovação de produtos em empresas incubadas. As três variáveis consideradas não demonstraram associações, nem a 
experiência do empreendedor na empresa (experiência em gestão), nem a experiência do empreendedor na indústria (mensurada mediante total da experiência em anos). Esse resultado pode direcionar o foco dos processos de seleção de empresas incubadas de base tecnológica. Grande parte dos editais de seleção de empresas incubadas por incubadoras de empresas de base tecnológica levam em consideração a ideia do negócio e a capacidade da equipe, ou time que a irá gerenciar. Como característica dessas empresas, os empreendedores são as peças principais da equipe de gestão, e muitas vezes, esse critério é avaliado em cima das características pessoais, técnicas e de gestão dos empreendedores. Do ponto de vista das características pessoais, o aspecto mais importante a ser considerado na seleção do empreendedor, caso a incubadora tenha a inovação como um direcionador importante, é a área de conhecimento do empreendedor, sendo que, quanto mais próxima for das ciências exatas maiores as possibilidades daquela empresa candidata a incubada ser inovadora em produtos.

Em resposta ao quarto objetivo específico da pesquisa, esse estudo analisou também o efeito moderação da variável porte da organização. Quando considerado o porte da organização e aplicado a técnica de regressão logística para amostras separadas entre empresas menores e empresas maiores, os resultados apontam para um efeito moderador do porte na associação das variáveis "área do conhecimento" e "experiência na empresa".

Com relação à área de conhecimento do empreendedor, para empresas maiores, essa variável é muito significativa para o modelo, com valor $\mathrm{p}<0,01$, o que indica que essas empresas têm como principal direcionadora da inovação em produtos, dentre as características pessoais que compõe o background do empreendedor, a área de conhecimento, ou seja, quanto mais próxima das ciências exatas é a formação do empreendedor, mais inovações em produtos ocorrem na organização, haja vista a alta associação existente.

Para empresas menores, a área de conhecimento continua significativa, porém, a variável experiência da empresa apresenta uma significância maior. Nesse contexto, a área de conhecimento é significativa para um valor $\mathrm{p}<0,05$, enquanto que a variável experiência da empresa é significativa ao valor $\mathrm{p}<0,01$. O que permite uma consideração importante sobre as empresas incubadas de base tecnológica quando considerado o porte.

Em empresas menores, em fase inicial, a inovação de produtos se sustenta fortemente na experiência do empreendedor em gestão, ou seja, experiência do empreendedor na condução 
daquela empresa e daquele negócio. Nesse caso, a formação do empreendedor, sendo ela mais próxima das ciências exatas, aliado à experiência desse empreendedor na empresa e na lida com as atividades fins que ela desempenha, é o que apresenta associação com a inovação de produtos em empresas incubadas de base tecnológica menores.

Além do mais, esse efeito moderador do porte indica ainda que, em empresas menores, o conhecimento da empresa é fortemente concentrado no empreendedor, mais do que na equipe. Quando considerado empresas maiores, essa lógica se inverte, havendo uma distribuição do conhecimento da organização dentre os funcionários, descentralizando o conhecimento do sócio empreendedor. Isso explica a alta significância da variável experiência do empreendedor para empresas menores, sendo a mesma variável, não significativa para empresas maiores.

Assim, respondendo diretamente o quarto objetivo de pesquisa, a variável porte modera as relações entre as variáveis e o lançamento de produtos em empresas incubadas de base tecnológica no estado de São Paulo.

Os resultados apontados neste estudo permitem algumas implicações teóricas e práticas. Do ponto de vista teórico, o estudo amplia de alguma forma o estado da arte, sem desejar ser pretencioso em suas contribuições. A contribuição principal do estudo está direcionada para lançar luz à literatura sobre a relação background do empreendedor e inovação de produtos, fornecendo com isso um suporte teórico para os esforços de capacitação dos sócioempreendedores que tenham como objetivo tornar a empresa inovadora.

Do ponto de vista das contribuições práticas do estudo, podem-se mencionar duas principais. A primeira delas refere-se à utilização dos resultados como orientação aos empreendedores, como meio de direcionarem seus esforços de formação e experiência, ampliando o seu background de maneira eficiente, com esforços direcionados para aquelas variáveis que demonstraram maior associação com a inovação de produtos nas empresas incubadas de base tecnológicas do estado de São Paulo. Isso permitirá uma postura mais inovativa por parte das empresas, e permitirá, além do mais, o crescimento em termos de faturamento, ampliação do mix de produtos, participação no mercado, todos resultantes e direcionados pela inovação. Essas são as contribuições práticas da pesquisa para o empreendedor. 
A segunda contribuição do estudo é direcionada para a otimização dos esforços e aplicação dos recursos das Incubadoras de Empresas de Base Tecnológica. Essa eficientização de esforços e recursos por parte das incubadoras se explica adequada seleção das empresas com potencial de sucesso futuro. Assim, os resultados do estudo orientarão as incubadoras na seleção das empresas, considerando, para tanto, aspectos do empreendedor que possam influenciar na inovatividade da empresa candidata à incubação. Essa é uma importante questão abordada na literatura: a seleção de empresas incubadas. Conforme apontado no desenvolvimento teórico, os aspectos mais utilizados para a seleção de empresas incubadas por incubadoras é a análise do potencial de mercado da ideia apresentada e o perfil da equipe que gerenciará a empresa, ou seja, em grande parte, os sócios. Esse processo poderá se apoiar nos resultados desse estudo.

Aparte as contribuições do estudo, os resultados precisam ser analisados com alguns cuidados, haja vista que o estudo apresenta algumas limitações que dá margem à realização de estudos futuros que venham a saná-las. A primeira delas é materializada na distância e distribuição dessas incubadoras de empresas dentro do estado de São Paulo. Apesar do desenvolvimento da pesquisa ser realizado via ferramentas digitais e com o uso da internet, essa distância implicou em custos maiores para o desenvolvimento da pesquisa, o que, havendo a necessidade de deslocamento até algumas dessas incubadoras para que a pesquisa pudesse ser viabilizada e as respostas aos questionários fossem realmente efetivadas.

Além dessas limitações práticas, existem também as limitações originadas da própria delimitação da pesquisa. Isto é, como a pesquisa é delimitada para o estado de São Paulo, provavelmente, os resultados encontrados não corresponderão à realidade de outras incubadoras localizadas em outras regiões que não dentro do estado de São Paulo. Portanto, a generalização dos resultados não é possível, especialmente quando considerado as diferenças regionais resultantes das dimensões do território brasileiro, cujas disparidades econômicas implicam em prováveis diferenças significativas também entre as Incubadoras de Empresas de Base Tecnológicas e, consequentemente, entre as Empresas Incubadas de Base Tecnológica (IEBTs).

Uma vez que o problema de pesquisa, além de ser delimitado em termos da definição do estado de São Paulo como alvo da pesquisa, é delimitado também para as características pessoais que compõe o background do empreendedor, surge aqui outra limitação, de natureza 
conceitual. A inovação de produtos nas organizações, segundo evidências da literatura, depende de uma série de outros fatores, a exemplo da cultura da organização, do ambiente onde a empresa está inserida, dos incentivos que essa empresa encontra para inovar, linhas de financiamentos destinadas à inovação, dentre outros fatores, o que concede ao fenômeno da inovação, seja ela de produto, de processo, organizacional ou de marketing, uma complexidade bastante elevada.

Dado essa complexidade, seria bastante pretencioso querer entender a inovação de produtos analisando apenas as características pessoais que compõe o background dos empreendedores. Assim, o objetivo desse trabalho vai ao encontro do entendimento de apenas um fator dentre os vários que compõe e explicam a inovação de produtos, que é o background do empreendedor. Diante disso, outros estudos são bem vindos no sentido de compreender os demais fatores, para assim, obter-se uma visão mais integrada do fenômeno, à altura da complexidade que ele exige. Como um estudo mais integrado referente ao fenômeno da inovação de produtos em empresas incubadas de base tecnológica no estado de São Paulo exige um tempo que transcende aos limites disponíveis para o desenvolvimento da pesquisa, optou-se pela delimitação apenas ao background do empreendedor, assumindo essa limitação conceitual.

Outra delimitação resultante do estudo é que o questionário somente captou a área de atuação do empreendedor na empresa, desconsiderando as áreas de atuação do empreendedor ao longo da sua experiência total. Isso implica que o estudo considera o background do empreendedor, no que toca à experiência em áreas de atuação, no período em que o empreendedor atua na empresa, sendo, portanto, necessários novos estudos que captem a área de atuação do empreendedor ao longo da sua experiência total.

Além disso, outra importante limitação assumida nesse estudo, é que a inovação de produtos foi considerada apenas pelo indicador "lançamento de novos produtos", desconsiderando o lançamento de serviços, que também compõe o conceito de inovação de produtos de acordo com OCDE (1997). Portanto, esse estudo indica a associação entre o background do empreendedor e a inovação de produtos, e não inovação de serviços.

O procedimento de campo também apresenta algumas limitações além daquelas apontadas no início dessa seção. A principal limitação desse método é o acesso às empresas incubadas. 
Naturalmente, esse acesso precisa ser consenso e permitido pelas empresas incubadas de base tecnológica, o que pode, eventualmente, resultar em questionários não respondidos por razão do não consentimento quanto à participação por parte dos empreendedores de algumas dessas empresas. Tentou-se minimizar essa limitação mediante a argumentação e convencimento dos respondentes quanto à importância das suas participações nas respostas aos questionários da pesquisa.

Além disso, outra limitação proveniente do procedimento de campo é que o questionário é enviado ao respondente, o qual, à distância, o responderá. Isso não permite um controle efetivo de quem realmente responderá ao questionário. O questionário é direcionado ao gestor da organização, tendo essa premissa espaço nas indicações iniciais do questionário, e, portanto, nesse ponto, espera-se um bom senso por parte dos respondentes para que ele seja respondido pelo publico alvo para o qual é destinado.

Diante disso, e ainda considerando limitações do procedimento de campo, a aplicação do questionário, por experiências prévias de pesquisa, poderá resultar em data missing que precisam ser identificados, trabalhados, e, caso seja necessário para uma melhor aplicação da técnica, o questionário será descartado, descartando assim aqueles casos cujo data missing tenha inviabilizado a aplicação da técnica de análise estatística. 


\section{REFERÊNCIAS}

Acs, Z. J. \& Audretsch, D. B. (1987). Innovation, market structure, and firm size. Review of Economics and Statistics, 69(4), 567-575.

Aerts, K., Matthyssens, P., Vandenbempt, K. (2007). Critical role and screening practices of European business incubators. Technovation, 27, 254-267.

Akerlof, G. (1976). The economics of caste and of the rat race and other woeful tales. The Quarterly Journal of Economics, 90(4), pp. 599-617.

Aldrich, H. E. \& Zimmer, C. (1986). Entrepreneurship through social networks. In D. L. Sexton e R. W. Smilor, eds., The Art and Science of Entrepreneurship. Cambridge, MA: Ballinger Publishing, pp. 3-23.

Alvarez, S. A. \& Busenitz, L. W. (2001). The entrepreneurship of resource-based theory. Journal of Management, 27, pp. 755-775.

Autio, E. \& Klofsten, M. (1998). A comparative study of two European Business Incubators. Journal of Small Business Management, 36(1), 30-43.

Baron, R. M.; Kenny, D. A. (1986). The moderator-mediator variable distinction in social psychological research: conceptual, strategic, and statistical considerations. Journal of Personality and Social Psychology, v. 51, n. 6, p. 1173-1182.

Begley, T. M. \& Boyd, D. P. (1987). Psychological characteristics associated with performance in entrepreneurial firms and smaller business. Journal of Business Venturing, 2, 79-93.

Bergek, A. \& Norrman, C. (2008). Incubator best practice: A framework. Technovation, 28, 20-28.

Bowonder, B.; Dambal, A.; Kumar, S.; Shirodkar, A. (2010). Innovation strategies for creating competitive advantage. Research Technology Management. 53(3):19-32.

Brockhaus, R. H. \& Horwitz, P. S. (1986). The psychology of the entrepreneur. In D. L. Sexton e R. W. Smilor, eds., The Art and Science of Entrepreneurship. Cambridge, MA: Ballinger Publishing.

Brockhaus, R. H. \& Nord, W. R. (1979). An exploration of factors affecting the entrepreneurial decision: Personal characteristics vs. environmental conditions. Proceedings of the Annual Meeting of the Academy of Management.

Brockhaus, R. H. (1980). Risk taking propensity of entrepreneurs. Academy of Management Journal, 23(3), 509-520.

Busenitz, L. W. \& Barney, J. B. (1997). Differences between entrepreneurs and managers in large organizations: biases and heuristics in strategic decision-making. Journal of Business Venturing, 12, 9-30. 
Casson, M. (1982). The entrepreneur. Totowa, NJ: Barnes \& Noble Books.

Chan, K. F. \& Lau, T. (2005). Assessing technology incubator programs in the science park: the good, the bad and the ugly. Technovation, 25 (10), 1215-1228.

Colombo, M. G. \& Delmastro, M. (2002). How effective are technology incubators? Evidences from Italy. Research Policy, 31, pp. 1103-1122.

Cooper, A. C. (1985). The role of incubator organizations in the founding of growth-oriented firms. Journal of Business Venturing, 1, 75-86.

Cooper, A. C. \& Dunkelberg, W. C. (1987). Entrepreneurial research: Old questions, new answers and methodological issues. American Journal of Small Business, Winter: 1122.

Cooper, R. G. \& Edgett, S. J. (2008). Maximizing productivity in product innovation. Research Technology Management, pp. 47-58.

Dornelas, J. (2015). Empreendedorismo na prática: mitos e verdades do empreendedor de sucesso. $3^{\circ}$ Ed. Rio de Janeiro: LTC.

Drucker, P. F. 1985. Innovation and entrepreneurship: practice and principles. New York: Harper \& Row.

Duchesneau, D. A. \& Gartner, W. B. (1990). A profile of new venture success and failure in an emerging industry. Journal of Business Venturing, 5, 297-312.

Dyke, L. S., Fischer, E. M. \& Reuber, A. R. (1992). An inter-industry examination of the impact of owner experience on firm performance. Journal of Small Business Management, 30 (4), 72-87.

Fávero, L. P.; Belfiore, P.; Silva, F. L.; Chan, B. L. (2009). Análise de dados: modelagem multivariada para tomada de decisões. Rio de Janeiro: Elsevier.

Ferraresi, A. A. (2010). Gestão do conhecimento, orientação para o mercado, inovatividade e resultados organizacionais: um estudo em empresas instaladas no Brasil. Tese (Doutorado) - Universidade de São Paulo, São Paulo.

Freeman, C. (1982). The economics of industrial innovation. London: Frances Pinter.

Freeman, C. \& Soete, L. (2008). A economia da inovação industrial. Campinas: Editora da Unicamp.

Garcia, R.; Calantone, R. (2002). A critical look at technological innovation typology and innovativeness terminology: A literature review. The Journal of Product Innovation Management. 19, pp. 110-132.

Gartner, W. B. 1985. A conceptual framework for describing the phenomenon of New Venture Creation. The Academy of Management Review, 10 (4), pp. 696-706. 
Gartner, W. B. 1989. "Who Is an Entrepreneur?” Is the Wrong Question. American Journal of Small Business. 12: 11-32.

Gartner, W. B.; Bird, B. J. \& Starr, J. A. (1992). Acting as if: Differentiating entrepreneurial from organizational behavior. Entrepreneurship Theory and Practice, 16(3), 13-31.

Gasse, Y. (1982). Commentary elaboration: elaborations on the psychology of the entrepreneur. In Kent, C. A., Sexton, D. L. e Vesper, K. H. (Eds), Encyclopedia of Entrepreneurship. Englewood Cliffs, NJ: Prentice-Hall, 58-71.

Ginsberg, A. \& Buchholtz, A. (1989). Are entrepreneurs a breed apart? A look at the evidence. Journal of General Management, 15(2), 32-40.

Grimaldi, R. \& Grandi, A. (2005). Business incubators and new venture creation: an assessment of incubating models. Technovation, 25, pp. $111-121$.

Hackett, S. M. \& Dilts, D. M. (2004). A systematic review of business incubation research. Journal of Technology Transfer, 29 (1), pp. 55-82.

Hornaday, J. \& Aboud, J. (1971). Characteristics of successful entrepreneurs. Personnel Psychology, 24, pp. 141-153.

Hornaday, J. \& Bunker, C. (1970). The nature of the entrepreneur. Personnel Psychology, 23, 47-54.

Hull, D. L., Bosley, J. J. \& Udell, G. G. (1980) Reviewing the heffalump: Identifying potential entrepreneurs by personality characteristics. Journal of Small Business Management, 18, 11-18.

Jo, H. \& Lee, J. (1996). The relationship between an entrepreneur's background and performance in a new venture. Technovation, 16(4), 161-171.

Kangasharju, A. \& Pekkala, S. (2001). The role of education in self-employment success in Finland. Growth and Change, 33, pp. 216-237.

Komives, J. L. (1972). A preliminary study of the personal values of high technology entrepreneurs. In: A. C. Cooper \& J. L. Komives (Eds), Technical entrepreneurship: A symposium. Milwaukee: Center for Venture Management, 231-242.

Kumpe, T.; Bolwijn, P. T. (1994). Toward the Innovative Firm - Challenge for R\&D Management. Research Technology Management, vol. 37, $\mathrm{n}^{\circ} 1$.

Lee, D. Y. \& Tsang, E. W. K. (2001). The effects of entrepreneurial personality, background and network activities on venture growth. Journal of Management Studies, 38(4), 583602.

Lenzi, F. C., Kiesel, M. D., \& Zucco, F. D [Orgs]. (2010). Ação Empreendedora: Como desenvolver e administrar o seu negócio com excelência. São Paulo: Editora Gente. 
Lenzi, F. C., \& Santiago, N. M. (2010). Ação empreendedora. In Lenzi, F. C., Kiesel, M. D., \& Zucco, F. D. Ação empreendedora: como desenvolver e administrar o seu negócio com excelência. São Paulo: Editora Gente.

Liles, P. (1974). Who are the entrepreneurs? MSU Business Topics, 22, 5-14.

Lindholm-Dahlstrand, A. \& Klofsten, M. (2002). Growth and Innovation Support in Swedish Science Parks and Incubators. New Technology-Based Firms at the New Millennium. Elsevier, Oxford, pp. 31-46.

Lyons, T. S. \& Li, S. (2003). The state of the Wisconsin incubation industry in 2002: an analysis of the results of the survey of membership. Report prepared for The Wisconsin Business Incubator Association, August 2003.

Lumpkin, G. T. \& Dess, G. G. (1996). Clarifying the entrepreneurial orientation construct and linking it to performance. Academy of Management Review, 21 (1), 135-172.

Lumpkin, G. T. \& Dess, G. G. (2001). Linking two dimensions of entrepreneurial orientation to firm performance: The moderating role of environment and industry life cycle. Journal of Business Venturing, 16, pp. 429-451.

Lumpkin, J. R. \& Ireland, R. D. (1988). Screening practices of new business incubators: the evaluation or critical success factors. American Journal of Small Business, v. 12 (4), pp. 59-81, 1988.

Malek, k.; Maine, E.; McCarthy, I. P. (2014). A typology of clean technology commercialization accelerators. Journal of Engineering and Technology Management, v. 32, pp. 26-39.

Maroco, J. Análise estatística com utilização do SPSS. 3 ed. Lisboa: Edições Sílabo, 2007.

Merrifield, D, B. (1987). New Business Incubator. Journal of Business Venturing, 2, 277-284.

McClelland, D \& Winter, D. G. (1969). Motivating economic achievement. New York: Free Press.

McClelland, D. (1961). The achieving society. Princeton, NJ: Van Nostrand.

McClelland, D. C. (1987). Characteristics of successful entrepreneurs. The Journal of Creative Behavior, 21(3), pp. 219-233.

Mian, S. A. (1994). US university-sponsored technology incubators: an overview of management, policies and performance. Technovation, 14 (8), 515-526.

Mian, S. A. (1996). Assessing value added contributions of university technology business incubators to tenant firms. Research Policy, 25, 325-335.

Neely, A. \& Hii J. 1998. Innovation and business performance: A literature Review. The Judge Institute of Management Studies. University of Cambridge. 
OECD (1997). Proposed guidelines for collecting and interpreting technological innovation data-OSLO Manual. Paris: OECD.

Palmer, M. (1971). The application of Psychological testing to entrepreneurial potential. California Management Review, 13(3), 32-39.

Pereira, J. A. G. (2014). Estudos dos fatores de promoção, estímulo e apoio à criatividade e o desempenho inovador das indústrias da região Sul do Brasil. Tese (Doutorado) Universidade de São Paulo.

Peters, L.; Rice, M.; Sundararajan, M. (2004). The role of incubators in the entrepreneurial process. Journal of Technology Transfer, 29 (1), 83-91.

Phan, P. H.; Siegel, D. S. \& Wright, M. (2005). Science parks and incubators: observations, synthesis and future research. Journal of business Venturing, v. 20, pp. $165-182$.

Porter, M. E. (1990). The Competitive Advantage of Nations. Harvard Business Review, pp. 73-93.

Porter, M. E. (1990). The Competitive Advantage of Nations. New York: The Free Press.

Radosevich, R. (1995). A model for entrepreneurial spin-offs from public technology sources. International Journal of Technology Management, 10 (7/8), 879-893.

Rauch, A. \& Frese, M. (2007). Let's put the person back into entrepreneurship research: A meta-analysis on the relationship between business owners' personality traits, business creation, and success. European Journal of Work and Organizational Psychology, 16(4), 353-385.

Robinson, P. B. \& Sexton, E. A. (1994). The effect of education on self-employment success. Journal of Business Venturing, 9, 141-156.

Robinson, P. B.; Stimpson, D. V.; Huefner, J. C. \& Hunt, H. K. (1991). An attitude approach to prediction of entrepreneurship. Entrepreneurship Theory and Practice, 15, 13-31.

Rogers, E. M. (1962). Diffusion of Innovations. New York: Free Press.

Rothwell, R.; Gardiner, P. (1985). Invention, innovation, re-innovation and the role of the user. Technovation, Vol. 3.

Sanches, P. L. B. (2011). Estratégias de Inovação sob a perspectiva da Resource-Based View: Análise e evidências em empresas de base tecnológica. Dissertação (Mestrado). Universidade Federal da Paraíba. João Pessoa.

Sbragia, R. et al. (1998). The impact of R\&D on firm innovative performance: a comparative analysis between Brazil and United States. $8^{\text {th }}$ International Conference on Management of Technology (IAMOT). Orlando/FL, USA, Feb.

Schumpeter, J. A. 1942. The theory of economic development. Cambridge, MA: Harvard University Press. 
Secretaria de Desenvolvimento Econômico, Ciência, Tecnologia e Inovação do Estado de São Paulo. (2013). Mapeamento das Incubadoras de Base Tecnológica do Estado de São Paulo. Relatório Final.

Sexton, D. L. \& Bowman, N. (1984). The effects of pre-existing psychological characteristics on new venture initiations. Paper presented at the annual meeting of the Academy of Management, Boston, MA.

Shane, S. \& Venkataraman, S. 2000. The promise of entrepreneurship as a field of research. The Academy of Management Review, 25 (1), pp. 217-226.

Shane, S. (2000). Prior knowledge and the discovery of entrepreneurial opportunities. Organizational Science, 11(4), pp. 448-469.

Shapero, A. (1984). The entrepreneurial event. In. C. A. Kent, ed., The Environment for Entrepreneurship. Lexington, MA: D. C. Heath, pp. 21-40.

Spence, M. (1973). Job market signaling. The Quarterly Journal of Economics, 87(3), pp. 355-374.

Stiglitz, J. \& Weiss, A. (1981). Credit rationing in markets with imperfect information. The American Economic Review, 71(3), pp. 393-410.

Stuart, R. W. \& Abetti, P. A. (1990). Impact of entrepreneurial and managerial experience on early performance. Journal of Business Venturing, 5, 151-162.

Sweeney, D. J.; Williams, T. A. \& Anderson, D. R. (2013). Estatística Aplicada à Administração e Economia. $3^{\text {a }}$ Ed. São Paulo: Cengage Learning.

Tajeddine, K. et al. (2006). Examining the effect of market orientation on innovativeness. Journal of Marketing Management, 22, pp. 529-551.

Tan, W. C. M. \& Tay, R. S. T. (1995). Factors contributing to the growth of SMEs: The Singapore case. Journal of Enterprising Culture, 3(2), pp. 197-210.

Thompson, P. (1986). Characteristics of the small business entrepreneur in Canada. Journal of Small Business and Entrepreneurship, 4 (1), 5-11.

Tidd, J.; Bessant, J. (2015). Gestão da Inovação. 5ª Ed. Porto Alegre: Bookman.

Tipping, J. W.; Zeffren, E.; Fusfeld, A. R. (1995). Assessing the value of your technology. Research Technology Management, 38 (5).

Van de Ven, A. H.; Hudson, R. e Schroeder, D. M. (1984). Designing new business start-ups: entrepreneurial, organizational, and ecological considerations. Journal of Management, 10, 87-107. 
Venkataraman, S. (1997). The distinctive domain of entrepreneurship research: An editor's perspective. In: J. Katz \& R. Brockhaus (Eds.), Advances in entrepreneurship, firm emergence, and growth, vol. 3: 119-138. Greenwich, CT: JAI Press.

Vesper, K. (1980). New Venture Strategies. Englewood Cliffs, NJ: Prentice Hall.

Zahra, S. A. (2008). The virtuous cycle of discovery and creation of entrepreneurial opportunities. Strategic Entrepreneurship Journal, vol. 2: 243-257. 


\section{APÊNDICE}

\section{QUESTIONÁRIO DE PESQUISA}

\section{PROJETO: MAPEAMENTO DAS IBTs DO ESTADO DE SÃO PAULO - EMPRESA INCUBADA.}

Caro empresário,

Este questionário faz parte do Projeto de Mapeamento de Incubadoras do Estado de São Paulo, sob a coordenação técnica do professor da Faculdade de Economia, Administração e Ciências Contábeis da Universidade de São Paulo, Prof. Dr. Moacir de Miranda Oliveira Jr.

Seu objetivo é coletar informações gerais que permitam identificar o desenvolvimento de sua empresa e os trabalhos da incubadora, com vistas a mostrar as melhores práticas no Estado de São Paulo, assim como apontar futuras melhorias e caminhos para o fortalecimento deste tipo de empreendimento e atividade.

Suas informações serão consideradas confidenciais, sendo os resultados gerados por meio de tratamentos estatísticos agregados, sem a identificação das empresas e seus respondentes.

O preenchimento é ágil e rápido, não levando mais de 20 minutos.

Procure fazê-lo sem interrupções. É muito importante que os dados sejam respondidos com a maior seriedade possível!

Agradecemos sua colaboração!

\section{QUALIFICAÇÃO:}

1) Atualmente, sua empresa se encontra ligada formalmente a alguma incubadora?*

() $\mathrm{Sim}$

( ) Não (o questionário será encerrado)

2) Informe a qual incubadora sua empresa está vinculada:*

\section{( ) CECOMPI}

( ) CEDIN - Centro de Desenvolvimento das Indústrias Nascentes

( ) CIATEC 
( ) CIE Rio Preto - Incubadora de Empresas de São José do Rio Preto

( ) CIEM - Centro Incubador de Empresas Miguel Silva

( ) CIETEC - Unidade de Negócios Mogi das Cruzes

( ) CIETEC - Unidade de Negócios São Paulo

( ) CINET

( ) EsalqTec

( ) FEISTEC - Incubadora de Empresas de Base Tecnológica da Faculdade de Engenharia

( ) IEBM - Incubadora de Empresas Barão de Mauá

( ) IEL - Incubadora de Empresas Leme

( ) INCAMP - Incubadora de Empresas de Base Tecnológica da UNICAMP

( ) Incubadora de Americana

( ) Incubadora de Base Tecnológica de Bauru

( ) Incubadora de Empresas Araraquara

( ) Incubadora de Empresas de Assis

( ) Incubadora de Empresas de Guarulhos

( ) Incubadora de Empresas de Jaboticabal

( ) Incubadora de Empresas de Jundiaí

( ) Incubadora de Empresas de Lins

( ) Incubadora de Empresas de Osasco

( ) Incubadora de Empresas de Santos

( ) Incubadora de Empresas de Sertãozinho

( ) Incubadora de Empresas de Votuporanga

( ) Incubadora de Empresas Mackenzie

( ) Incubadora de Jacareí

( ) Incubadora Empresarial de Bebedouro

( ) Incubadora Empresarial Tecnológica de Barretos

( ) Incubadora Softex Campinas

( ) Incubadora Tecnológica de Botucatu

( ) Incubadora Tecnológica UNIVAP

( ) Incubadora Tecnológica UNIVAP REVAP

( ) INCUBAERO

( ) IncubaTec - Incubadora de Bases Tecnológicas da Escola Técnica Estadual de Fernandópolis

( ) INCUNESP - Incubadora de Base Tecnológica da Unesp (Rio Claro)

( ) INOVA Guaratinguetá

( ) INTEPP - Incubadora Tecnológica de Presidente Prudente

( ) Núcleo de Desenvolvimento Empresarial - Incubadora de Empresas de Piracicaba

( ) Núcleo de Desenvolvimento Empresarial Alfeu Rosário - Incubadora de Empresas de Garça

( ) PROSPECTA - Incubadora de Empresas e Projetos Tecnológicos de Botucatu

( ) SOFTNET - Centro Incubador de Empresas de Software

( ) SUPERA - Unidade Campos Elíseos

( ) SUPERA - Unidade Campus

( ) SUPERA - Unidade Hemocentro

( ) Outra. Especifique::

3) Informe qual posição você ocupa na empresa:*

( ) Colaborador

( ) Sócio-empreendedor 


\section{CARACTERIZAÇÃO DO SÓCIO-EMPREENDEDOR:}

4) Informe em qual ou quais áreas da empresa você atua na maior parte do tempo (é possível marcar mais de uma resposta):*

[ ] Contribuição com o capital, mas sem participação direta nas atividades da empresa

[ ] Administrativo

[ ] Assistência técnica

[ ] Compras

[ ] Contabilidade

[ ] Financeiro

[ ] Gestão de pessoas

[ ] Gestão operacional

[ ] Implantação

[ ] Marketing

[ ] Operações logísticas

[ ] Pesquisa, desenvolvimento e inovação

[ ] Planejamento

[ ] Pós-venda comercial

[ ] Produção

[ ] Vendas e estudos de mercado

[ ] Outra. Especifique::

5) Qual é o seu grau de instrução?*

( ) Ensino fundamental

( ) Ensino médio

( ) Ensino profissionalizante

( ) Ensino superior

( ) MBA/especialização lato sensu

( ) Mestrado

( ) Doutorado

( ) Pós-doutorado

6) Informe em qual ou quais eixos tecnológicos você se formou no nível técnico:*

[ ] Ambiente e Saúde

[ ] Controle e Processos Industriais

[ ] Desenvolvimento Educacional e Social

[ ] Gestão e Negócios

[ ] Informação e Comunicação

[ ] Infraestrutura

[ ] Militar

[ ] Produção Alimentícia

[ ] Produção Cultural e Design

[ ] Produção Industrial 
[ ] Recursos Naturais

[ ] Segurança

[ ] Turismo, Hospitalidade e Lazer

7) Informe em qual ou quais áreas de conhecimento você se formou no nível superior:*

[ ] Ciências agrárias

[ ] Ciências biológicas

[ ] Ciências da saúde

[ ] Ciências exatas e da terra

[ ] Ciências humanas

[ ] Ciências sociais aplicadas

[ ] Engenharias

[ ] Linguística, letras e artes

[ ] Multidisciplinar

8) Informe em qual ano você ingressou nesta empresa:*
( ) 2013
( ) 2012
( ) 2011
( ) 2010
( ) 2009
( ) 2008
( ) 2007
( ) 2006
( ) 2005
( ) 2004
( ) 2003
( ) 2002
( ) 2001
( ) 2000
( ) 1999
( ) 1998
( ) 1997
( ) 1996
( ) 1995
( ) 1994
( ) 1993
( ) 1992
( ) 1991
( ) 1990
( ) 1989
( ) 1988
( ) 1987
( ) 1986
( ) 1985
( ) 1984 

( ) 1983
( ) 1982
( ) 1981
( ) 1980

9) Informe sua experiência profissional total em anos (considerando todas as áreas em que já trabalhou):*
( ) 1
( ) 2
( ) 3
( ) 4
( ) 5
( ) 6
( ) 7
( ) 8
( ) 9
( ) 10
( ) 11
( ) 12
( ) 13
( ) 14
( ) 15
( ) 16
( ) 17
( ) 18
( ) 19
( ) 20
( ) 21
( ) 22
( ) 23
( ) 24
( ) 25
( ) 26
( ) 27
( ) 28
( ) 29
( ) 30
( ) 31
( ) 32
( ) 33
( ) 34
( ) 35
( ) 36
( ) 37
( ) 38
( ) 39
( ) 40
( ) 41 

( ) 42
( ) 43
( ) 44
( ) 45
( ) 46
( ) 47
( ) 48
( ) 49
( ) 50

\section{CARACTERIZAÇÃO DA EMPRESA:}

10) Ano de fundação da empresa:*
( ) 2013
( ) 2012
( ) 2011
( ) 2010
( ) 2009
( ) 2008
( ) 2007
( ) 2006
( ) 2005
( ) 2004
( ) 2003
( ) 2002
( ) 2001
( ) 2000
( ) 1999
( ) 1998
( ) 1997
( ) 1996
( ) 1995
( ) 1994
( ) 1993
( ) 1992
( ) 1991
( ) 1990
( ) 1989
( ) 1988
( ) 1987
( ) 1986
( ) 1985
( ) 1984
( ) 1983
( ) 1982
( ) 1981 
( ) 1980

11) Ano em que a empresa entrou na incubadora:*
( ) 2013
( ) 2012
( ) 2011
( ) 2010
( ) 2009
( ) 2008
( ) 2007
( ) 2006
( ) 2005
( ) 2004
( ) 2003
( ) 2002
( ) 2001
( ) 2000
( ) 1999
( ) 1998
( ) 1997
( ) 1996
( ) 1995
( ) 1994
( ) 1993
( ) 1992
( ) 1991
( ) 1990
( ) 1989
( ) 1988
( ) 1987
( ) 1986
( ) 1985
( ) 1984
( ) 1983
( ) 1982
( ) 1981
( ) 1980

12) Informe a quantidade total de pessoas que trabalham na empresa (incluindo você, sócios, estagiários, temporários, pessoal não CLT, bolsistas e colaboradores em geral):*

13) A empresa possui alguma outra unidade (exemplo: escritório de representação comercial, planta industrial, dentre outros)?* 
( ) Sim, com o mesmo CNPJ

( ) Sim, mas com outro CNPJ

( ) Não

14) Informe a função e localização da outra unidade (nome do município e UF):*

15) Informe a composição societária da empresa:*

( ) Apenas pessoas físicas

( ) Apenas pessoas jurídicas

( ) Pessoas físicas e sócio-investidor (ex: investidor anjo, fundo de investimento, capital de risco etc)

( ) Pessoas físicas e empresa participante do capital (que não seja apenas fornecedora de capital)

( ) Outro. Especifique::

16) Qual o principal mercado geográfico da empresa?*

( ) Local (região no entorno de onde está sediado)

( ) Estadual

( ) Regional

( ) Nacional

( ) Mercosul

( ) Global

17) Indique o principal segmento de atuação de sua empresa (é possível marcar mais de um segmento):*

[ ] Agronegócio

[ ] Automação

[ ] Biotecnologia

[ ] Construção Civil

[ ] Educação

[ ] E-Learning

[ ] Eletroeletrônicos

[ ] Energia

[ ] Equipamentos

[ ] Fármacos

[ ] Indústria extrativa

[ ] Medicina e saúde humana

[ ] Meio ambiente

[ ] Mobilidade/Telecomunicações

[ ] Nanotecnologia

[ ] Química 

[ ] Recursos hídricos
[ ] Resíduos e reciclagem
[ ] Serviços de consultoria
[ ] Serviços sociais
[] Software
[ ] Tecnologia da informação
[] Veterinária
[ ] Outro. Especifique::

18) Qual é o tipo de administração/propriedade de sua empresa?*

( ) Empresa gerida pelos próprios empreendedores/sócios

( ) Administrada por profissional contratado

19) A empresa encontra-se atualmente em qual estágio?*
( ) Pré-incubação
( ) Incubação
( ) Empresa graduada

20) Em qual nível de maturidade a empresa se encontra:*

( ) Aprimoramento da ideia

( ) Desenvolvimento de protótipo

( ) Primeiro produto/serviço já em fase de produção/prestação

( ) Conquista dos primeiros clientes

( ) Difusão e expansão de mercado

21) Informe qual foi o faturamento bruto de sua empresa no ano de $\underline{2012}$ :*

( ) Não teve faturamento

( ) Até R\$ 100 mil

( ) De R\$ 100 mil a R\$ 500 mil

( ) De R \$ 500 mil a R\$ 1 milhão

( ) De R\$ 1 milhão a $\mathrm{R} \$ 3$ milhões

( ) De R \$ 3 milhões a $\mathrm{R} \$ 10$ milhões

( ) Acima de R\$10 milhões

22) A empresa já conquistou o ponto de autonomia financeira (breakeven point, onde a receita se iguala ou supera as despesas no período)?**

( ) $\mathrm{Sim}$

( ) Não 
23) Informe qual ou quais são os principais outputs da empresa (é possível marcar mais de um):*
[ ] Produtos
[ ] Serviços
[ ] Consultoria
[ ] Treinamento
[ ] Outro. Especifique::

24) Informe a quantidade de sócios para cada nível de instrução abaixo (informar "0", se for o caso):*

\begin{tabular}{|l|l|}
\hline & \multicolumn{1}{c|}{ Quantidade de sócios } \\
\hline Ensino fundamental & \\
\hline Ensino médio & \\
\hline $\begin{array}{l}\text { Ensino } \\
\text { profissionalizante }\end{array}$ & \\
\hline Ensino superior & \\
\hline $\begin{array}{l}\text { MBA/especialização lato } \\
\text { sensu }\end{array}$ & \\
\hline Mestrado & \\
\hline Doutorado & \\
\hline Pós-doutorado & \\
\hline
\end{tabular}

\section{PESQUISA, DESENVOLVIMENTO E INOVAÇÃO:}

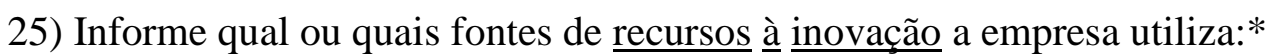




\section{[ ] BNDES \\ [ ] CNPq \\ [ ] FAPESP \\ [ ] FINEP \\ [ ] SEBRAE \\ [ ] SENAI \\ [ ] Outro. Especifique::}

26) Informe a quantidade de métodos de proteção que a empresa empregou para proteger inovações de produto e/ou processo em cada ano (informar a quantidade de solicitações feitas junto ao INPI ou indicar "0", se for o caso):*

\begin{tabular}{|c|c|c|c|}
\hline & 2012 & 2011 & 2010 \\
\hline Patente de invenção & & & \\
\hline $\begin{array}{l}\text { Patente de modelo de } \\
\text { utilidade }\end{array}$ & & & \\
\hline $\begin{array}{l}\text { Registro de desenho } \\
\text { industrial }\end{array}$ & & & \\
\hline Marcas & & & \\
\hline Direitos de autor & & & \\
\hline
\end{tabular}

27) Informe o número de produtos e/ou serviços lançados ao mercado nos últimos anos (indicar "0", se for o caso):*

\begin{tabular}{|l|l|l|l|}
\hline & 2012 & 2011 & 2010 \\
\hline Produtos & - & - & - \\
\hline Serviços & - & & - \\
\hline
\end{tabular}

28) Informe o número de acordos vigentes em cada ano com o objetivo de transferência de conhecimento realizados entre empresas, institutos de ciência e tecnologia (ICTs) e universidades (indicar " 0 ", se for o caso):* 


\begin{tabular}{|c|c|c|c|}
\hline & 2012 & 2011 & 2010 \\
\hline Acordos com empresas & & & \\
\hline Acordos com ICTs & & & \\
\hline $\begin{array}{l}\text { Acordos com } \\
\text { universidades }\end{array}$ & & & \\
\hline
\end{tabular}

29) Informe a participação dos investimentos em $P \& D$ sobre o faturamento bruto ao longo dos últimos anos:*

( ) Informar em porcentagem (\%)

( ) Informar em valores absolutos $(\mathrm{R} \$)$

30) Investimentos em P\&D sobre o faturamento bruto em porcentagem (indicar "0\%", se for o caso):*

\begin{tabular}{|l|l|l|l|}
\hline & 2012 & 2011 & 2010 \\
\hline $\begin{array}{l}\text { Investimentos em P\&D / } \\
\text { faturamento bruto (em \%) }\end{array}$ & - & - & \\
\hline
\end{tabular}

31) Investimentos em $P \& D$ e faturamento bruto em valores absolutos (indicar "R $\$ 0$ ", se for o caso):*

\begin{tabular}{|l|l|l|l|}
\hline & $\mathbf{2 0 1 2}$ & $\mathbf{2 0 1 1}$ & $\mathbf{2 0 1 0}$ \\
\hline $\begin{array}{l}\text { Investimento em P\&D } \\
(\text { em R } \$):\end{array}$ & - & - & \\
\hline $\begin{array}{l}\text { Faturamento bruto (em } \\
\text { R\$): }\end{array}$ & - & - & - \\
\hline
\end{tabular}




\section{IDENTIFICAÇÃO:}

39) Informe o nome de sua empresa (lembrando que todas as informações são consideradas confidenciais):*

40) Informe os seus dados (esta questão não é obrigatória):

Seu nome:

E-mail:

Telefone (com DDD):

\section{ENCERRAMENTO:}

\section{QUESTIONÁRIO CONCLUÍDO!}

Caro empresário, obrigado por responder ao questionário de empresas incubadas.

Sua participação é muito importante! 